\title{
SOIL MOISTURE ESTIMATION BY SYNERGETIC USE OF AQUARIUS ACTIVE AND PASSIVE L-BAND MICROWAVE OBSERVATIONS
}

Qiang Wang 


\section{Graduation committee}

Chairman and Secretary

Prof.dr.ir. A. Veldkamp

University of Twente

Supervisor

Prof.dr.ir. Z. Su

University of Twente

Co-supervisor

Dr.ir. R.van der Velde

University of Twente

Members

Prof. dr. W. Verhoef

University of Twente

Prof. dr. M. van der Meijde

University of Twente

Prof. dr. P. Ferrazzoli

University of Rome Tor Vergata

Prof. dr. J. Wen

Chengdu University of Information Technology

Prof. dr. Y. Kerr

Director of CESBIO, PI on the SMOS project

Prof. dr. R. Hanssen

Delft University of Technology

ITC dissertation number 334

ITC, P.O. Box 217, 7500 AA Enschede, The Netherlands

ISBN: 978-90-365-4648-5

DOI: $10.3990 / 1.9789036546485$

Cover designed by Job Duim and Qiang Wang

Printed by ITC Printing Department

(c) Qiang Wang. Enschede, The Netherlands

All right reserved. No part of the material protected by this copyright notice may be reproduced or utilized in any form or by any means, electronic or mechanical, including photocopying, recording or by any information storage and retrieval system, without the prior permission of the author.

\section{UNIVERSITY OF TWENTE.}

1U FACULTY OF GEO-INFORMATION SCIENCE AND EARTH OBSERVATION 


\title{
SOIL MOISTURE ESTIMATION BY SYNERGETIC USE OF AQUARIUS ACTIVE AND PASSIVE L-BAND MICROWAVE OBSERVATIONS
}

\author{
DISSERTATION
}

\author{
to obtain \\ the degree of doctor at the University of Twente, \\ on the authority of the rector magnificus, \\ prof.dr.T.T.M.Palstra, \\ on account of the decision of the graduation committee, \\ to be publicly defended \\ on Thursday 18 October 2018 at 12:45 hrs
}

\author{
by \\ Qiang Wang \\ born on 13 July 1986 \\ in Shanxi Province, China
}


This thesis is approved by:

Prof. Dr. Ir. Z. Su (supervisor)

Dr. Ir. R. van der Velde (co-supervisor) 
Dedicated to my mother

谨以此书献给我最亲爱的母亲 



\section{Table of Contents}

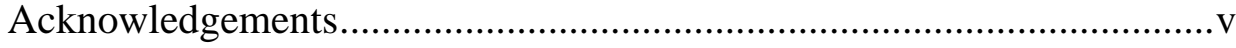

List of symbols .............................................................................. vii

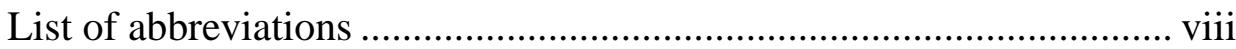

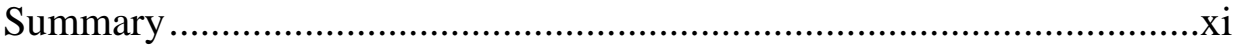

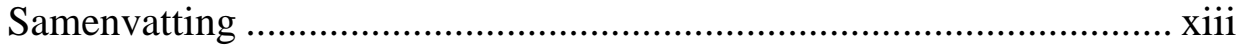

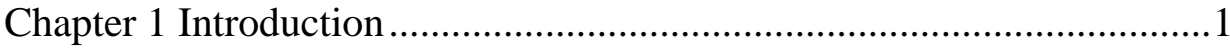

1.1 Soil moisture, a key variable in water cycle .................................. 1

1.2 Remote sensing of soil moisture .................................................. 1

1.3 Thesis objective and proposed approach ......................................5

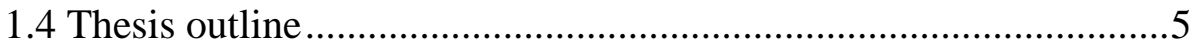

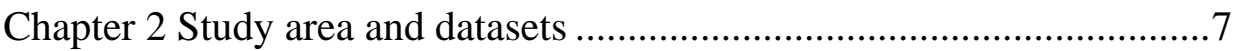

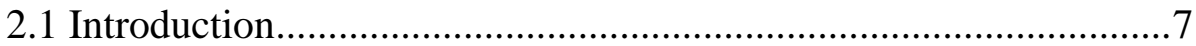

2.2 Tibetan Plateau observatory ......................................................... 8

2.2.1 Maqu site and network description ........................................

2.2.2 Naqu network description .................................................... 10

2.2.3 Ngari network description ....................................................12

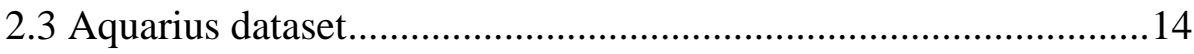

2.3.1 Aquarius level 2 brightness and backscattering coefficient

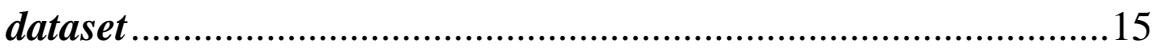

2.3.2 Aquarius level 3 soil moisture dataset ..................................16

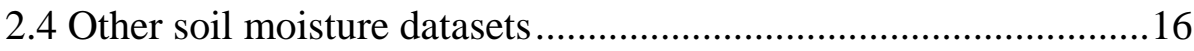

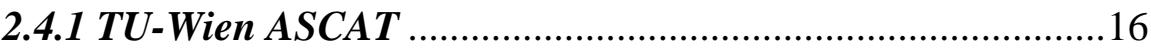

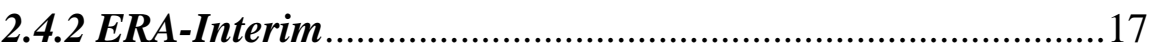

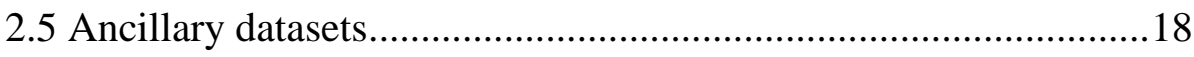


2.5.1 Moderate resolution imaging Spectroradiometer (MODIS) Normalized Difference Vegetation Index (NDVI) ........................18

2.5.2 MODIS Leaf Area Index (LAI)

2.5.3 Climate Hazards Group Infrared Precipitation with Station data (CHIRPS)

2.5.4 Surface Energy Balance System (SEBS) evapotranspiration

Chapter 3 Sensitivity of Aquarius observations over soil moisture in Maqu network .21

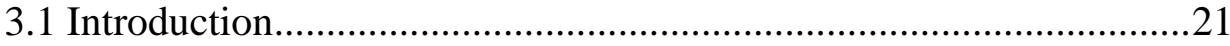

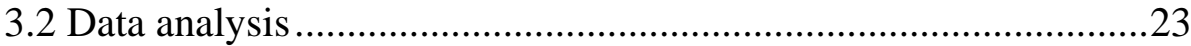

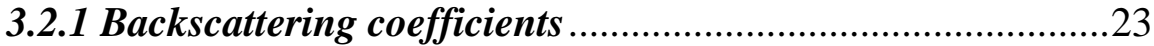

3.2.2 Brightness temperatures .....................................................24

3.2.3 Response to soil moisture ....................................................26

3.3 Behavior of polarimetric indices ..................................................

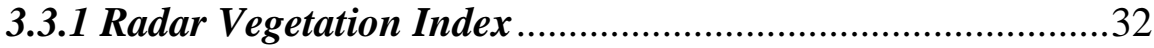

3.3.2 Microwave Polarization Difference Index ...........................33

3.4 Summary and Conclusions ............................................................40

Chapter 4 Use of a discrete electromagnetic model for simulating Aquarius L-band active/passive observations and soil moisture retrieval

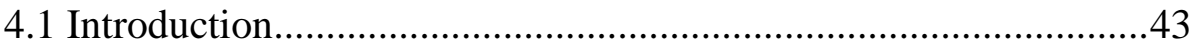

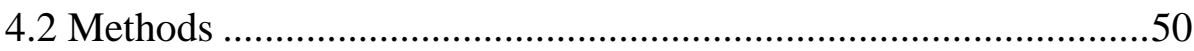

4.2.1 Tor Vergata-Discrete electromagnetic model .......................50

4.2.2 Application to Maqu ........................................................52

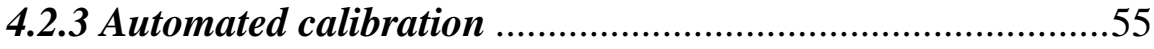

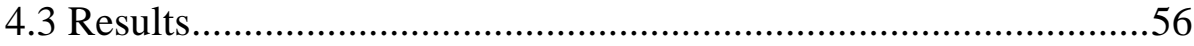

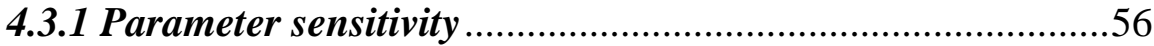

4.3.2 Calibration and validation ...................................................60 


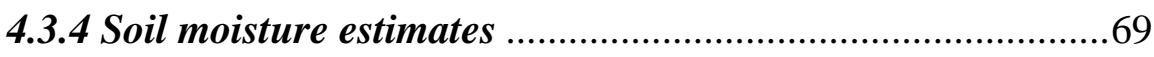

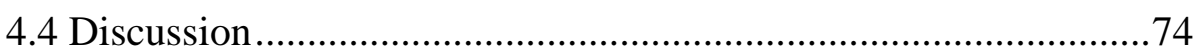

4.4.1 Assumptions for surface roughness .................................... 74

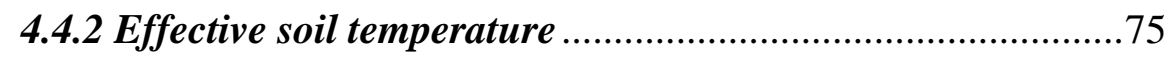

4.4.3 Effect of depolarization on calibration results ....................77

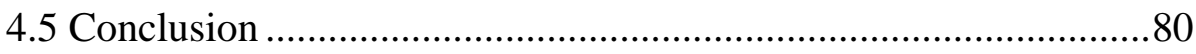

Chapter 5 Soil moisture estimation from L-band active and passive microwave observations acquired by Aquarius over the Tibetan Plateau

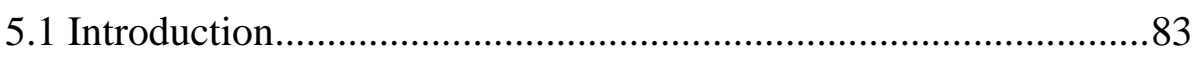

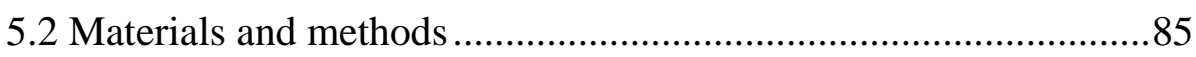

5.2.1 Look up table (LUT) establishment ...................................85

5.2.2 Object function definition and soil moisture retrieval scheme

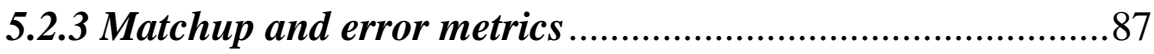

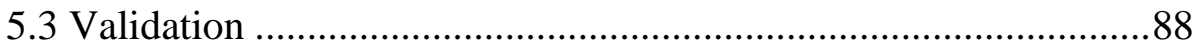

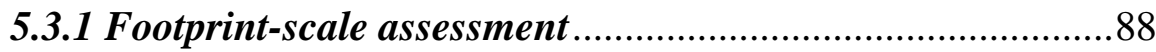

5.3.2 Plateau-scale assessment .....................................................92

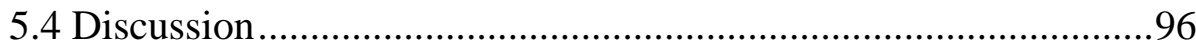

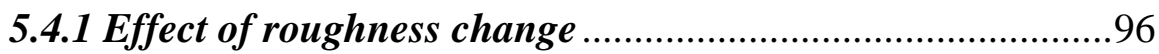

5.4.2 Spatially variable roughness ................................................98

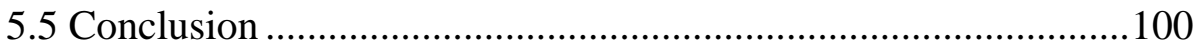

Chapter 6 Conclusions and recommendations .....................................103

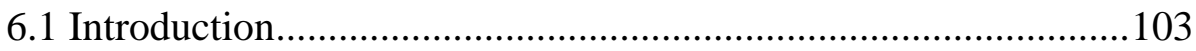

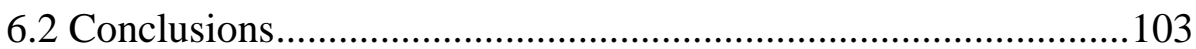

6.2.1 Sensitivity of Aquarius observations over soil moisture in

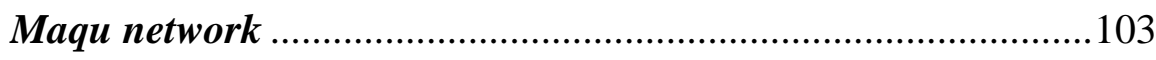


6.2.2 Use of a discrete electromagnetic model for simulating Aquarius L-band active/passive observations and soil moisture retrieval.

104

6.2.3 Soil moisture estimation over the Tibetan Plateau ..............105

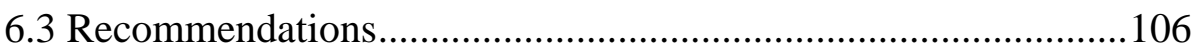

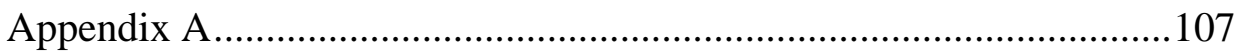

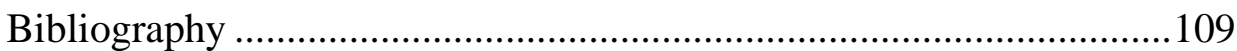




\section{Acknowledgements}

Doing a $\mathrm{PhD}$ is such a long tough journey as running a marathon, luckily, I am approaching the destination. However, it can't be such a peaceful and happy running without the help and support from many people. I would like to thank everyone who helped me, encouraged me and stimulated me in the journey, but there are a few special people I would like to express sincere thanks to them.

I really appreciate the help from my promoter, Prof. Zhongbo Su for his tireless guidance and scientific support. Without many discussions during regular meetings and short talks outside office, I can't make my PhD journey complete. Moreover, thanks for your encouragement to make me more open and willing to discuss and exchange ideas in a large community. Your broad knowledge and profound insights guided me in a wonderful direction to make my journey quick and safe.

I am also grateful to my co-promoter, Dr. Rogier van der Velde. You were so patient in our meetings and gave me such a lot supply in my journey. You acted like a pacer in the journey and stimulated me to run faster when I am capable and energetic to make my running journey quicker and gave me the right guidance for the scientific direction. I still remember that you were so critical when I was suffering in 2016 for my second paper and sometimes lost my focus and motivation, but you told me being critical is the baseline for the scientific researcher. I will bear it in mind and discipline myself according to your words. Moreover, thanks for taking care of me during field works in Tibetan Plateau and also Twente area and gave me plenty of explanation while I just stepped in the new scientific direction in the first year.

I am indebted to Prof. Paolo Ferrazolli, who played an important role in my research period. A nice work of your discrete electromagnetic model enabled me to carry on my research smoothly, and I really enjoyed to discuss with you via email or meeting. Your patience and modesty impressed me and I have learned a lot from you.

I would like to thank Prof. Jun Wen and his colleagues in the Cold and Arid Regions Environmental and Engineering Research Institute, Chinese Academy 
of Sciences for their hospitality and great support for the field work over Maqu network. I also thank Dr. Tangtang Zhang, Dr. Xin Wang, Jinlei Chen and Zuoliang Wang for their help during my stay in Lanzhou for my field campaign. Furthermore, I am grateful to Prof. Yaoming Ma from the Institute of Tibetan Plateau Research, Chinese Academy of Sciences for his great support for my field work in Naqu and Ngari, I really got an unforgettable experience there. I appreciate the help from my supervisor Prof. Dr. Guangli Guo in China University of Mining \& Technology (CUMT) during my joint$\mathrm{PhD}$ study, without his guidance, I wouldn't get on the research filed for my career. Moreover, thanks for giving me a chance to go abroad to start my new $\mathrm{PhD}$ journey. I also thank Dr. Jianfeng Zha for his support and I really enjoyed our friendship built in CUMT, you really acted like a brother and tried to help me to overcome the problems in research and daily life. I owe my thanks to the Chinese Scholarship Council (CSC) for the financial support of my study in the Netherlands.

I am so glad to work in the Water Resources department and meet so many awesome people to make my personal life colorful. I would like to thank Anke and Tina for their supports to make my PhD life smoothly. I would like to thank my gym partners Jiangrong Wang, Lianyu Yu and Min Xu to accompany me for fitness. Moreover, great thanks to Yijian Zeng, Xuelong Chen, Shaoning Lv, Junping Du, Peiqi Yang, Xiaolong Yu, Xu Yuan, Hong Zhao, Wen Bai, Chengliang Liu, Ruosha Zeng, Pei Zhang, Mengna Li, it is really cool to meet you and have parties together. Moreover, there a several formal colleagues in Delft University I would like to give thanks to, dr. Jiangjun Ran and Ling Chang, thanks for your help during my stay in Delft.

Thanks are extended to my family, I am proud to have an open-mind mom, Gouxiang Meng, it is your love and support to make me go further and more ambitious. Thanks for my sisters, Liqin Wang and Junqin Wang and my brothers, Bin Wang and Qi Wang for your love and support. I would like to express my great thanks to Jie $\mathrm{Fu}$, you are really a member of my family and it is such a destiny that we met each other in university and built our strong friendship onwards, and we will extend it forever. Qin Feng is also to be thanked for her support together with Jie Fu.

Qiang Wang

Enschede, July, 15, 2018 


\section{List of symbols}

\begin{tabular}{|c|c|c|}
\hline Symbol & Name & Units \\
\hline$\lambda$ & wavelength & $\mathrm{cm}$ \\
\hline$a$ & Slope of linear regression & $(-)$ \\
\hline$b$ & Intercept of linear regression & $\mathrm{cm}$ \\
\hline$s$ & Standard deviation of surface height & $\mathrm{dB}$ or m$^{2} \mathrm{~m}^{-2}$ \\
\hline$\sigma^{0}$ & Backscattering coefficient & degree \\
\hline$\theta$ & Incidence angle & $(-)$ \\
\hline $\mathrm{R}^{2}$ & Coefficient of determination & $(-)$ \\
\hline$R_{0}$ & Fresnel reflectivity & $\mathrm{cm}^{-1}$ \\
\hline$k$ & Wavenumber & $\mathrm{m}^{3} \mathrm{~m}^{-3}$ \\
\hline$s m$ & Soil moisture & $(-)$ \\
\hline$\tau$ & Vegetation optical depth & $(-)$ \\
\hline$\omega$ & Single scattering albedo & $(-)$ \\
\hline$\gamma$ & Transmissivity & $\mathrm{K}$ \\
\hline$T_{b}$ & Brightness temperature & $(-)$ \\
\hline$\phi$ & Object function & $(-)$ \\
\hline$h_{r}$ & Roughness parameter & $(-)$ \\
\hline$\mu$ & Ratio & $(-)$ \\
\hline$\delta$ & Standard deviation & $\mathrm{cm}^{-2}$ \\
\hline$e$ & Eoughissivity & \\
\hline$h_{r}$ & Vegetation water content & $(-)$ \\
\hline$W$ & & \\
\hline
\end{tabular}




\section{List of abbreviations}

ACF

ADPS

AIEM

AMSR-E

ASAR

ASCAT

ASTER

ATBD

CAS

CDF

CHIRPS

CONAE

DAAC

DCA

ECMWF

EKF

ERS

ESA

GOM

GRMDM

HANTS

IEM

JAXA

LAI

LPRM

LSM

LUT

MAD

MD

MODIS

MPDI

NASA

NDVI

NSIDC

viii
Autocorrelation Function

Aquarius Data Processing Segment

Advanced IEM

Advanced Microwave Scanning Radiometer

Advanced Synthetic Aperture Radar

Advanced Scatterometer

Advanced Spaceborne Thermal Emission and Reflection Radiometer

Algorithm Theoretical Baseline Document

Chinese Academy of Sciences

Cumulative Distribution Function

Climate Hazards Group InfraRed Precipitation with Station data

Comisión Nacional de Actividades Espaciales

Distributed Active Archive Center

Dual Channel Algorithm

European Centre for Medium-range Weather Forecasts

Extended Kalman Filter

European Remote Sensing Satellite

European Space Agency

Geometrical Optical Model

Generalized Refraction Mixing Dielectric Model

Harmonic ANalysis of Time Series

Integral Equation Method

Japan Aerospace Exploration Agency

Leaf Area Index

Land Parameter Retrieval Model

Land Surface Model

Look Up Table

Mean Absolute Difference

Mean Difference

Moderate Resolution Imaging Spectrometer

Microwave Polarization Difference Index

National Aeronautics and Space Administration

Normalized Difference Vegetation Index

National Snow \& Ice Data Center 
PALS

PDF

POM

PSU

RFI

RMSD

RMSE

RVI

SAR

SCA

SEBS

SMDM

SMAP

SMMR

SMOS

SPM

SSM/I

TRMM

TMI

TV-DEM

ubRMSD

VUA

WGS 84
Passive Active Land S-band airborne sensor

Probability Density Function Physical Optics Model Practical Salinity Unit Radio Frequency Interference Root Mean Squared Difference Root Mean Squared Error Radar Vegetation Index Synthetic Aperture Radar Single Channel Algorithm Surface Energy Balance System Semi-empirical Mixing Dielectric Model

Soil Moisture Active Passive Scanning Multichannel Microwave Radiometer Soil Moisture and Ocean Salinity Small Perturbation Model Special Sensor Microwave Imager Tropical Rainfall Measuring Misson

TRMM Microwave Imager Tor Vergata Discrete Electromagnetic Model Unbiased Root Mean Squared Difference Vrije Universiteit Amsterdam World Geodetic System 1984 


\section{Summary}

Soil moisture is a key variable in the water cycle and it plays an important role in the exchanges of energy, water and gasses between land surface and atmosphere. The availability of soil moisture information leads to a better understanding of biology, hydrology, meteorology and climatology. The most suitable frequency band to retrieve soil moisture data is considered to be the $\mathrm{L}$ band, since it can partially penetrate vegetation and is marginally affected by clouds. Numerous studies show that both active and passive microwave observations are sensitive to soil moisture and can be used to retrieve soil moisture information. However, vegetation influence and roughness effect form the main obstacles for soil moisture retrieval in, respectively, the passive and active configuration. As passive and active microwave observations differ in sensitivity to the relevant factors, combined use of both these observations is beneficial when studying soil moisture.

This dissertation contributes to a better estimation of soil moisture through synergetic use of active and passive observations from Aquarius, which is the first satellite to have both an L-band radiometer and a scatterometer onboard. The Tibetan Plateau has been selected as study area since it covers a large area with different climates, including humid, semi-arid and arid regions from east to west. Moreover, large amounts of in-situ data have been recorded across this area since 2008, providing ancillary data for the validation of soil moisture estimations.

Aquarius observations are firstly analyzed for one of the Tibetan Plateau observatory sites, Maqu, in chapter 3. This confirms that both the Aquarius radiometer and scatterometer observations show a response to soil moisture variation across Maqu, especially when the soil moisture is less than $0.30 \mathrm{~m}^{3} \mathrm{~m}^{-3}$. Moreover, the Microwave Polarization Difference Index (MPDI) is investigated and shows that the derived vegetation optical depth $(\tau)$ is in line with the vegetation dynamics. However, even though the Radar Vegetation Index (RVI) might capture the seasonal dynamic change of vegetation, the accuracy is insufficient from a meaningful signal-to-noise point of view.

In chapter 4 , a discrete electromagnetic model developed by the Tor Vergata University of Rome (hereafter, Tor Vergata-discrete electromagnetic model, TV-DEM) is used to simulate both active and passive L-band responses and then compared with Aquarius observations from a view angle of $28.7^{\circ}$ over Maqu, using a single set of input parameters. Litter biomass, litter moisture, plant moisture and standard deviation of height variations $(s)$ in the TV-DEM are calibrated by minimizing the difference between the observed and simulated emissivity and backscattering coefficient from the warm seasons of 2012 and 2013. The calibrated parameters are used to reproduce the 


\section{Summary}

brightness temperature and backscattering coefficient in the warm seasons of 2014 and 2015, to validate the model's performance. Furthermore, the soil moisture retrieval based on the TV-DEM is carried out and compared with the current single channel algorithm (SCA) retrieved soil moisture. Results present an unbiased root means square difference (ubRMSD) of 0.021 and $0.026 \mathrm{~m}^{3} \mathrm{~m}^{-3}$, as well as a coefficient of determination of 0.76 and 0.79 (-), for TV-DEM based soil moisture retrieval and SCA retrieval, respectively, with respect to the in-situ measurements.

Chapter 5 follows up on the results of chapter 4 and introduces an algorithm for retrieving soil moisture at plateau scale, combining the use of Aquarius active and passive L-band observations. Look-Up-Tables (LUTs) are generated through forward modeling of the TV-DEM by varying LAI and soil moisture while keeping litter biomass, litter moisture, plant moisture and surface roughness the same as the calibrated parameters. By searching for the minimum squared difference between the emissivity and backscattering coefficient observed by Aquarius and the simulations included in the LUT, the corresponding soil moisture is derived. The soil moisture retrievals are assessed at footprint scale with respect to the in-situ measurements collected at three regional scale networks across the Tibetan Plateau. An intercomparison is also conducted among the TV-DEM retrieval, passive-only Aquarius, Metop-A Advanced SCATterometer (ASCAT) soil moisture L2 product, and the soil moisture of global atmospheric reanalysis (ERA-Interim) generated by the European Center for Medium-Range Weather Forecasts (ECMWF) on a point-scale.

Furthermore, the spatial distribution of these four soil moisture retrievals is verified, alongside complementary rainfall (Climate Hazards Group Infrared Precipitation with Station data (CHIRPS)) and evapotranspiration (Surface Energy Balance System (SEBS)) products.

In conclusion, this dissertation confirms that soil moisture retrieval through the synergetic use of passive and active observations in the TV-DEM framework is comparable with those by the passive only Aquarius operational product, the C-band ASCAT product and the re-analysis ECMWF soil moisture product. Moreover, TVDEM soil moisture retrieval scheme can be applied at plateau scale and the TV-DEM retrieval can capture the spatial distribution of soil moisture at plateau scale, opening up new opportunities in general for hydrology, meteorology and climatology. 


\section{Samenvatting}

Bodemvocht is een belangrijke variabele in de waterkringloop en speelt een cruciale rol bij de uitwisseling van energie, water en gassen tussen het landoppervlak en de atmosfeer. De beschikbaarheid van bodemvochtinformatie kan helpen bij het beter begrijpen van processen die worden onderzocht in de biologie, hydrologie, meteorologie en klimatologie. L-band wordt beschouwd als de meest geschikte frequentieband voor het bepalen van bodemvochtgegevens uit satellietwaarnemingen, omdat deze gedeeltelijk door vegetatie heen kan kijken en marginaal beïnvloed wordt door wolken. Talrijke studies tonen aan dat zowel actieve als passieve microgolfwaarnemingen gevoelig zijn voor bodemvocht en daarom ook gebruikt kunnen worden om het bodemvochtgehalte te kwantificeren. Echter, vegetatie- en oppervlakteruwheidseffecten vormen de belangrijke obstakels bij het bepalen van bodemvocht uit zowel passieve als actieve gegevens. Aangezien passieve en actieve microgolfobservaties verschillende gevoeligheden hebben voor de relevante omgevingsfactoren (bodemvocht, vegetatie en ruwheid), kan het gecombineerde gebruik van beide soorten waarnemingen gunstig zijn voor de betrouwbaarheid van bodemvocht bepaald uit satellietdata.

Dit proefschrift draagt bij aan een betere schatting van bodemvocht door synergetisch gebruik van actieve en passieve waarnemingen verkregen met de NASA-CONAE Aquarius satelliet, de eerste met zowel een L-band radiometer als een scatterometer aan boord. Het Tibetaanse plateau is geselecteerd als studiegebied omdat het een groot gebied bestrijkt met verschillende klimaten, met in het oosten humide gebieden dat verandert tot aride in het uiterste westen. Bovendien zijn op diverse plekken op het Tibetaans Plateau sinds 2008 grote hoeveelheden in-situ metingen verzameld, die kunnen dienen als referentie voor de validatie van de bodemvochtschattingen.

Als eerste zijn in hoofdstuk 3 de Aquarius waarnemingen geanalyseerd voor één van de sites op het Tibetaanse plateau, die Maqu wordt genoemd. De resultaten van dit onderzoek laten zien dat zowel de Aquarius radiometer- als scatterometerwaarnemingen beide veranderen als gevolg van veranderingen in bodemvochtgehalte, met name als het vochtgehalte minder dan $0,30 \mathrm{~m} 3 \mathrm{~m}-3$ is. De Microwave Polarization Difference Index (MPDI) is bovendien onderzocht en de hieruit afgeleide vegetatie optische diepte $(\tau)$ komt overeen met de verwachte vegetatiedynamiek. De Radar Vegetation Index (RVI) bepaald uit Aquarius' scatterometerwaarnemingen laat een vergelijkbaar seizoensgebonden 


\section{Samenvatting}

tendens zien, maar de signaal-ruis verhouding is onvoldoende om betrouwbaar relaties te kunnen bepalen.

In hoofdstuk 4 wordt het discrete elektromagnetische model ontwikkeld door de Tor Vergata Universiteit van Rome (hierna Tor Vergata-discreet elektromagnetisch model, TV-DEM) gebruikt om zowel actieve als passieve Lband signalen te simuleren. De modelsimulaties zijn vervolgens vergeleken met de Aquariuswaarnemingen gemaakt over het Maqu studiegebied vanuit een $28.7^{\circ}$ kijkhoek. De biomassa en het vochtgehalte van het strooisel op de grond, het plantvochtgehalte en de standaarddeviatie van de hoogtevariaties van het oppervlakte zijn parameters van het TV-DEM die zijn gekalibreerd door de verschillen tussen de Aquarius waargenomen en gesimuleerde actieve als passieve microwave signalen te minimaliseren voor de warme seizoenen van 2012 en 2013. De gekalibreerde parameterwaarden zijn gevalideerd voor de warme seizoenen van 2014 en 2015. De bodemvochtgehaltes geschat door het gekalibreerde TV-DEM te inverteren en door toepassing van het veel gebruikte single channel algoritme (SCA) zijn vergeleken met gemeten bodemvochtdata resulterend in unbiased root mean squared differences (ubRMSDs) van 0.021 en $0.026 \mathrm{~m}^{3} \mathrm{~m}^{-3}$, en determinatiecoëfficiënten $\left(\mathrm{R}^{2}\right)$ van 0.76 en $0.79(-)$, respectievelijk.

Hoofdstuk 5 bouwt voort op de resultaten van hoofdstuk 4 op en introduceert een algoritme voor het afleiden van het bodemvochtgehalte op het Tibetaanse plateau uit de combinatie van Aquarius actieve en passieve waarnemingen. Look-Up-Tables (LUT's) zijn gegeneerd met TV-DEM simulaties met verschillende Leaf Area Index (LAI)-waarden en bodemvochtgehaltes terwijl de overige parameters constant zijn. Het algoritme leidt het bodemvochtgehalte af door binnen de LUT op zoek te gaan naar het minimale gekwadrateerde verschil tussen de Aquarius waarnemingen en de TV-DEM simulaties. De bodemvochtschattingen zijn gevalideerd voor individuele Aquarius waarnemingen door middel van in-situ metingen verzameld bij drie regionale netwerken verspreid over het Tibetaanse plateau. Daarnaast is op puntschaal een vergelijking gemaakt met verschillende bestaande producten, namelijk het officiële Aquarius L2 bodemvochtproduct gebaseerd op alleen de passieve waarnemingen, het Metop-A Advanced SCATterometer (ASCAT) L2 bodemvochtproduct, en het 'global atmospheric reanalysis' bodemvochtproduct (ERA-Interim) van de European Center for Medium-Range Weather Forecast (ECMWF). De ruimtelijke bodemvochtverdelingen in kaart gebracht door de vier bodemvochtproducten is geanalyseerd door vergelijking met

xiv 
Samenvatting complementerende neerslag (Climate Hazards Group Infrared Precipitation with Station data, CHIRPS) en evapotranspiratie (Surface Energy Balance System, SEBS) data.

Tot slot, dit proefschrift bevestigt dat het afleiden van bodemvocht uit een combinatie van passieve en actieve waarnemingen met behulp van het TV-DEM simulaties vergelijkbare resultaten oplevert als de hierboven genoemde bestaande bodemvochtproducten. Bovendien kan het algoritme gebaseerd op het TV-DEM toegepast worden voor het in kaart brengen van bodemvocht op plateau schaal wat nieuwe onderzoeksmogelijkheden biedt voor de hydrologie, meteorologie en klimatologie op het Tibetaans plateau. 
Samenvatting 


\section{Chapter 1 Introduction}

\subsection{Soil moisture, a key variable in water cycle}

Soil moisture is a crucial variable in the water cycle; it controls evapotranspiration as well as sensible and latent heat fluxes, thus having an impact on surface runoff, which could then lead to floods and droughts. Moreover, it directly affects plant growth and ultimately influences agriculture and biogeography. Consequently, accurate soil moisture information is important for better understanding the land surface processes as well as exchanges of energy, water and gases between land surface and atmosphere.

Traditional approaches such as gravimetric sampling and automatic probes are able to accurately obtain soil moisture information, however, the spatial resolution is limited to a point scale and it is labor intensive as well. Probes (resistive, capacitive, time domain reflectometry, etc.) can be used to measure soil moisture automatically with a larger coverage, however, these methods are limited to sites where careful maintenance can be achieved (Bircher et al., 2013). As soil moisture varies significantly in space and time, remote sensing techniques, which can monitor soil moisture on a large scale at reasonable time intervals, either using aircraft or satellites, should be taken into consideration.

\subsection{Remote sensing of soil moisture}

Soil moisture estimation by remote sensing can be performed in different ways. Numerous studies (Kaleita et al, 2005; Lesaignoux et al., 2013; Fabre et al., 2015) have been conducted to analyze spectral reflectance and establish empirical relationships between the spectral reflectance and soil moisture content. However, optical signals are affected by atmospheric effect as well as by cloud and vegetation coverage, which limits the application of spectral reflectance based approaches. As land surface temperature is sensitive to soil moisture in conditions with bare soil or sparse vegetation cover, scholars (Pratt and Ellyett, 1979; Verstraeten et al., 2006; Matsushima et al., 2012) have made an effort to estimate soil moisture by calculating the thermal inertia. However, this approach is limited to bare soil or only partly vegetated soil, 


\section{Introduction}

since the signal is affected by atmospheric effect, cloud cover and vegetation cover. However, microwave measurements, with their low frequency signal, are barely influenced by the weather (the atmosphere or the clouds); the signal is able to partially penetrate vegetation (Ulaby et al.,1986) and is not affected by the time of day/night (Srivastava et al., 2015). Therefore, microwave remote sensing is regarded as the preferable approach for large scale soil moisture estimation.

The basis for soil moisture estimation by microwave has been formed by the large contrast between the dielectric constant of dry soil (between 3 and 5) and water (80). This was first discussed by Ulaby (1974), drawing the attention of the hydrology, meteorology and other communities and providing a way to study soil moisture. Since then, numerous investigations (Jackson, 1993; Wagner et al., 1999; Owe et al.,2001) have been conducted by scholars involving soil moisture estimation through microwave remote sensing, either using passive (radiometer) or active (scatterometer/radar) observations.

Schmugge et al. (1974) analyzed the brightness temperature captured by airborne microwave radiometers over a non-vegetated terrain and found that a linear relationship existed between brightness temperature and soil moisture at a wavelength of $21 \mathrm{~cm}$. A model with roughness considered for describing microwave emission from soil was developed by Choudhury et al. (1979). Mo et al. (1982) proposed a radiative transfer model for simulating brightness temperature over a vegetated surface with vegetation optical depth $(\tau)$ and single scattering albedo $(\omega)$ included, which is known as the $\tau$ - $\omega$ mode and provides the basis for soil moisture estimation with passive configuration. Jackson (1993) proposed a single channel algorithm (SCA) to estimate soil moisture using horizontally polarized brightness temperature; this algorithm is widely used with different satellite observations (e.g. SMOS, Aquarius). Owe et al. (2001) developed a land parameter retrieval model (LPRM) to retrieve soil moisture through a radiative transfer equation by using Scanning Multichannel Microwave Radiometer (SMMR) brightness temperature, which has later also been used for the Special Sensor Microwave Imager (SSM/I), Tropical Rainfall Measuring Mission's (TRMM) Microwave Imager (TMI) (TRMM-TMI) as well as the Advanced Microwave Scanning Radiometer for EOS (AMSR-E).

As observations from spaceborne radiometers have a low spatial resolution, many researchers (Ulaby et al., 1982; Wagner et al., 1999; Wagner et al., 2013; 


\section{Chapter 1}

Brocca et al., 2017) rely on active observations (scatterometer/radar) in their effort to estimate soil moisture. Ulaby et al (1974) refer to the radar response to soil moisture in experiments using a truck-mounted radar scatterometer. Later, numerous investigations were carried out to analyze the relationship between soil moisture and radar observations by aircraft as well as satellite. Meanwhile, other researchers (Ulaby et al., 1982; Fung,1992; Wu and Chen, 2004) applied physical laws to attempt to establish theoretical scattering models, such as geometrical optical model (GOM), and the physical optics model (POM), and a small perturbation model (SPM) (Ulaby et al., 1982). However, GOM, POM and SPM are valid in great, intermediate and small roughness, respectively, with no single model being applicable to all types of surface roughness. Therefore, Fung (1992) proposed an integral equation method (IEM), a surface scattering model, which uses a wider applicable range of surface roughness conditions as it is based on an approximate solution of a pair of integral equations for the tangential surfaces. However, the absolute phase terms of Green's function (Arfken et al., 2012) were neglected for simplicity in the mathematic computation. Later, Wu and Chen (2004) developed an advanced IEM (AIEM) including more terms of Green's function as well as a transition model to obtain a continuous Fresnel reflection, which allows a precise calculation of scattering for a surface with a wider range of dielectric properties and surface roughness conditions. However, both the IEM and the AIEM are only valid for bare soil and sparsely vegetated areas since vegetation produces complex volume scattering behaviors that reduce the sensitivity of radar signals to soil moisture. To this end, Attema and Ulaby (1978) described vegetation as a water cloud, for which the droplets are held in vegetative matter, while Bracaglia et al. (1995) proposed a discrete electromagnetic model to calculate the backscattering coefficient of agricultural fields.

As both active and passive observations are sensitive to soil moisture, numerous scholars have put their efforts into comparing soil moisture estimations based on these two types of observations (Liu et al., 2011; Fascetti et al., 2016). Liu et al (2011) concluded that the Vrije Universiteit Amsterdam (VUA) and NASA (VUA-NASA) passive microwave product performed better over sparsely vegetated regions, whereas the change detection based Metop Advanced Scatterometer (ASCAT) product showed better agreement with in-situ measurements for regions of moderate vegetation density. Fascetti et al. (2016) concluded that a determination coefficient of 0.66 (-) is found between the Soil Moisture and Ocean Salinity (SMOS) and ASCAT soil moisture products. 


\section{Introduction}

Other scholars (Njoku et al., 2002; Das et al., 2011; Akbar and Moghaddam, 2015) focused on the combined usage of active and passive observations, either employing statistical or physical based methods. In the statistical direction, Njoku et al. (2002) found that brightness temperature and backscattering coefficient show similar sensitivities to soil moisture spatial distributions by using a Passive and Active Land S-band airborne sensor (PALS). Based on the results, a change detection method for estimating soil moisture through the combined usage of radar and radiometer observations was proposed. Furthermore, Piles et al. (2009) indicated that by using a change detection method including both active and passive observations, the soil moisture estimation is improved by $2 \%$ compared to when only passive soil moisture observations are used. Following the investigation of Piles et al. (2009), Das et al. (2011) developed a disaggregation algorithm to merge soil moisture active passive (SMAP) radiometer and radar data for high resolution soil moisture retrieval by assuming that a linear relationship exists between radiometer and radar data with the same resolution, which is considered to be the baseline for SMAP high resolution soil moisture retrieval.

Apart from the efforts described above, several researchers attempted implementing physical models by combining the usage of active and passive observations for soil moisture estimation on the basis that the emissivity (observed from passive microwaves) of a rough surface can be related to the backscattering coefficient (observed from active microwaves) of the same surface by energy conservation (Peake, 1959). Chauhan et al. (1994) used a discrete electromagnetic model to simulate both the active and passive microwave response for corn, including morphology information. O'Neill et al. (1995) retrieved soil moisture from the $\tau-\omega$ model with the transmissivity and single scattering albedo estimated by applying the discrete electromagnetic model by Chauhan et al. (1994). Della Vecchia et al. (2006) investigated the geometrical factors of the discrete electromagnetic model. Dente et al. (2014) investigated the C-band Metop Advanced Scatterometer (ASCAT) and the Advanced Microwave Scanning Radiometer (AMSR-E) observations in the Maqu, China, area with a discrete electromagnetic model developed by Bracaglia et al. (1995) and concluded that a single model can simulate the satellite active and passive observations properly. 


\subsection{Thesis objective and proposed approach}

\section{Chapter 1}

Following the context described above, the main objective of the research in this thesis is to develop an algorithm to improve the accuracy of current soil moisture estimation through the combined usage of active and passive observations from the same Aquarius satellite. As a starting point, the Maqu, China, network was selected as the study area, because soil moisture measurements have been collected in this area since July, 2008. With the ground truth and satellite dataset available, the following three objectives of this research can be formulated.

The first objective of this research is: Do Aquarius active and passive observations reveal sensitivity to soil moisture? To this end, Aquarius satellite observations of brightness temperature as well as the backscattering coefficient were investigated and compared with the soil moisture of in-situ measurements of the Maqu network to prove the feasibility of combined usage of the Aquarius active and passive datasets for later soil moisture estimation.

Following on from this investigation, the second objective of this research arises, which is: Can a single discrete electromagnetic model be used to reproduce both Aquarius active and passive microwave signals? To address this objective, the Tor Vergata Discrete Electromagnetic Model (TVDEM), which can calculate emissivity as well as backscattering coefficients, is selected to reproduce the Aquarius brightness temperature and backscattering coefficient. Moreover, the estimation of soil moisture by inverting the model is discussed and validated using in-situ measurements from the Maqu area.

The third objective of this research is contained in the question: Can we develop an algorithm to retrieve soil moisture based on a single discrete electromagnetic model by using Aquarius active and passive observations? To achieve this objective, an algorithm for retrieving soil moisture is developed based on TV-DEM simulations. This algorithm is verified using measurements from two other networks.

\subsection{Thesis outline}

The dissertation consists of 6 chapters, starting with this introductory Chapter 1. The study area and the satellite data as well as the ancillary remote sensing data are described in detail in Chapter 2. A description is included of the soil 


\section{Introduction}

moisture-soil temperature network, which forms the foundation for this research. The Aquarius satellite brightness temperature and backscattering coefficient are analyzed in Chapter $\mathbf{3}$ and the sensitivity of Aquarius observations to soil moisture is investigated here as well. In Chapter 4, a discrete electromagnetic model, which was developed at the Tor Vergata University of Rome (TV-DEM) and simulates emissivity and backscattering coefficient is selected to reproduce Aquarius observations. The approach to retrieve soil moisture based on this model is discussed and validated, using the in-situ measurements of the Maqu area as ground truth. An algorithm for the estimation of soil moisture through combined usage of Aquarius active and passive observations is developed in Chapter 5. A plateau scale soil moisture map is also generated with this method, and the retrieval of this approach is validated with Tibet Observatory measurements as well as compared to other available soil moisture products. Chapter 6 summarizes the findings of this research and presents recommendations for further study. 


\section{Chapter 2 Study area and datasets}

\subsection{Introduction}

Tibetan Plateau is characterized by its high elevation and it contains the largest reserve of fresh water outside the polar regions and is recognized as the third pole. As such, it plays an important role in Asian monsoon. Three networks are set up in this area to measure the soil moisture and soil temperature continuously to provide the basic information for calibration and validation of satellite and model products, named Maqu, Naqu and Ngari from east to west in humid, semi-arid and arid environment (Su et al., 2011). Fig.2.1 displays the location of the three monitoring networks overlain over a land cover map of Tibetan Plateau cropped from ESA GlobCover Version 2.32009 (http://due.esrin.esa.int/page_globcover.php, accessed on April 1, 2017) with $300 \mathrm{~m}$ resolution.

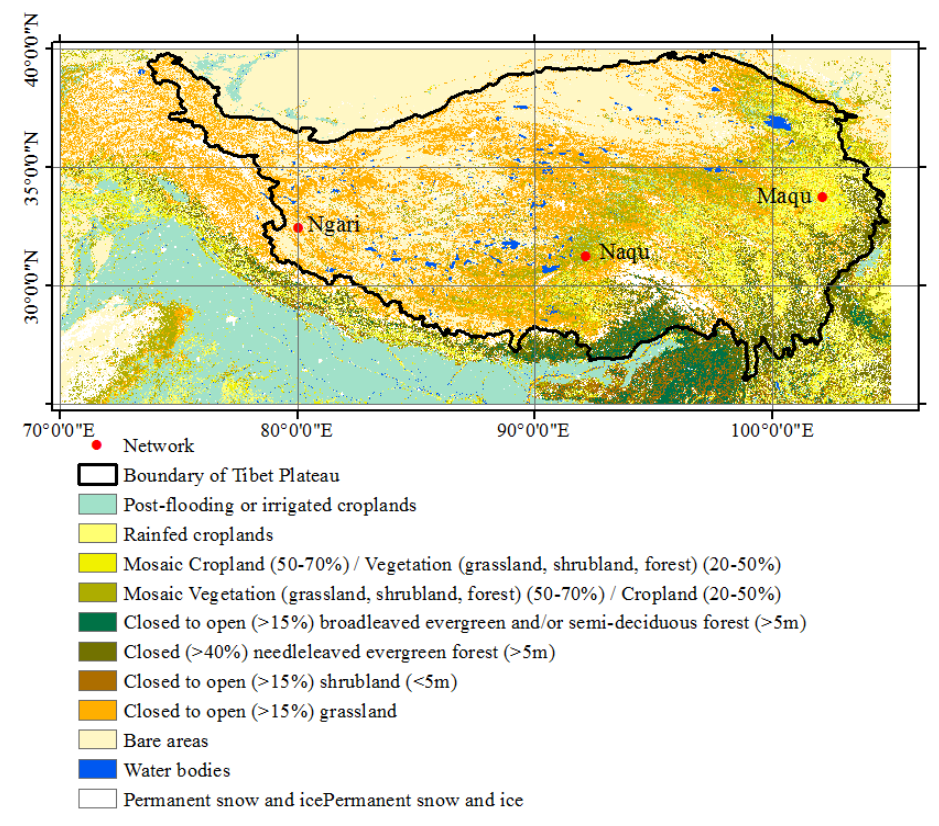

Fig. 2.1. Land cover of Tibetan Plateau cropped from ESA GlobCover Version $2.32009300 \mathrm{~m}$ resolution Land Cover Map with the three networks (Maqu, Naqu and Ngari) are indicated with red circles 


\section{Study area and datasets}

\subsection{Tibetan Plateau observatory}

\subsubsection{Maqu site and network description}

Maqu region is located in the eastern part of Tibetan Plateau in the Yellow River Source Region. The elevation of this area is between 3,200 $\mathrm{m}$ and 4,200 $\mathrm{m}$ above sea level. The weather category falls under the class of wet and cold climate according to the updated the Köppen-Geiger climate classification by Peel et al. (2007). Land cover of this region is dominated by alpine meadows with heights vary from $5 \mathrm{~cm}$ to $15 \mathrm{~cm}$ throughout the growing season due to intensive grazing by livestock (e.g. yaks and sheep). The prevailing soil types are sandy loam, silt loam and organic soil with on average $39.7 \%$ sand, $8.08 \%$ clay and a maximum of $18.3 \%$ organic matter. Additional information on the study area and monitoring network can be found in Su et al. (2011), Dente et al. (2012) and Zheng et al. (2015). Fig. 2.2 shows a mosaic of Landsat 5 Thematic Mapper images acquired on 28 July, 2009, 6 August, 2009 and 5 September, 2009 displayed as a false color composite. The figure illustrates the spatial distribution of the alpine meadows (light green), open water/wetland (dark/blue) and bare mountainous areas (magenta/brown).

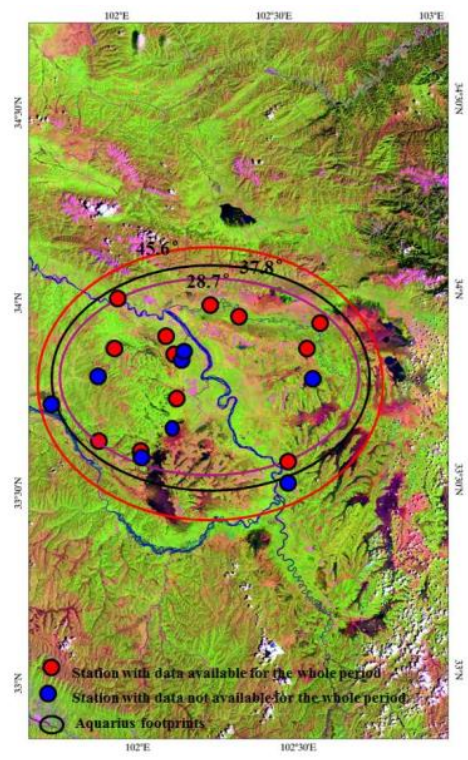

Fig. 2.2 Landsat 5 TM false composite (R: band5, G: band4, B: band3) of the Maqu study area, highlighting the location of the soil moisture/temperature stations and the footprints of three Aquarius beam $\left(28.7^{\circ}, 37.8^{\circ}\right.$, $\left.45.6^{\circ}\right)$. 
Chapter 2

Since 2008, the Maqu region holds a regional scale soil moisture/temperature monitoring network that includes 20 measurement locations and is situated in between $33^{\circ} 30^{\prime}-34^{\circ} 15^{\prime} \mathrm{N}$ latitude and $101^{\circ} 38^{\prime}$ to $102^{\circ} 45^{\prime} \mathrm{E}$ longitude (WGS84). The locations of the stations are indicated in Fig.2.2 by red and blue dots. The red dots represent stations for which the soil moisture dataset is complete for the entire period from August 2011 to May 2013, while blue dots indicate stations for which the dataset is not complete. The in-situ network is designed in such manner that the stations are placed across a complete range of land covers and elevations varying from $3428 \mathrm{~m}$ to $3752 \mathrm{~m}$ above sea level (see Su et al. 2011).

Each station is composed of a Decagon (EM50) data logger that is set up to record a measurement every 15 minutes and EC-TM ECH2O capacitance probes that are connected to the EM50 logger and measure the dielectric constant or dielectric constant as well as temperature with a thermistor embedded within the probe. The volumetric soil moisture content is obtained through application of a calibration equation that describes the relationship between the probe reading and moisture content. Dente et al. (2012) reported on the development of a soil specific calibration for the Maqu network that leads to an accuracy of $0.02 \mathrm{~m}^{3} \mathrm{~m}^{-3}$. This has been applied to the measurements utilized for this study.

Averages of the 5-cm soil moisture and temperature measurements from the 12 stations that are available for the complete study period from August 2011 to May 2013 are utilized here as matchups for the Aquarius data. Fig. 2.3 shows time series of the mean and standard deviation calculated from the 12 independent soil moisture and temperature measurements. The soil moisture plot illustrates that both the mean and standard deviation are lowest and fairly constant during the winter season. This can be attributed to the fact that in this time of the year soil in the Maqu region is primarily frozen (see also Fig.2.3b) and the EC-TM ECH2O probes measure the liquid water. Hence, low soil moisture contents are recorded across the Maqu region resulting in low mean values and low standard deviation.

From the moment the temperatures rise above freezing point the mean soil moisture as well as standard deviation increase and remain throughout warm season at levels varying from 0.30 to $0.50 \mathrm{~m}^{3} \mathrm{~m}^{-3}$ and from 0.10 to $0.20 \mathrm{~m}^{3} \mathrm{~m}^{-3}$, respectively. The small fluctuations in the standard deviation during seasons indicate that the spatial variability is temporally stable and, thus, that the mean 


\section{Study area and datasets}

captures the temporal soil moisture dynamics of the study area and can be assumed to be representative for the coarse Aquarius footprints (Vachaud et al. 1985, Ryu and Famiglietti 2005, Cosh et al. 2008). Likewise, the mean soil temperature can be considered representative for the study area and radiometer/scatterometer footprint because the standard deviation is very low in general, $0.4-2.0 \mathrm{~K}$, and displays little variation.
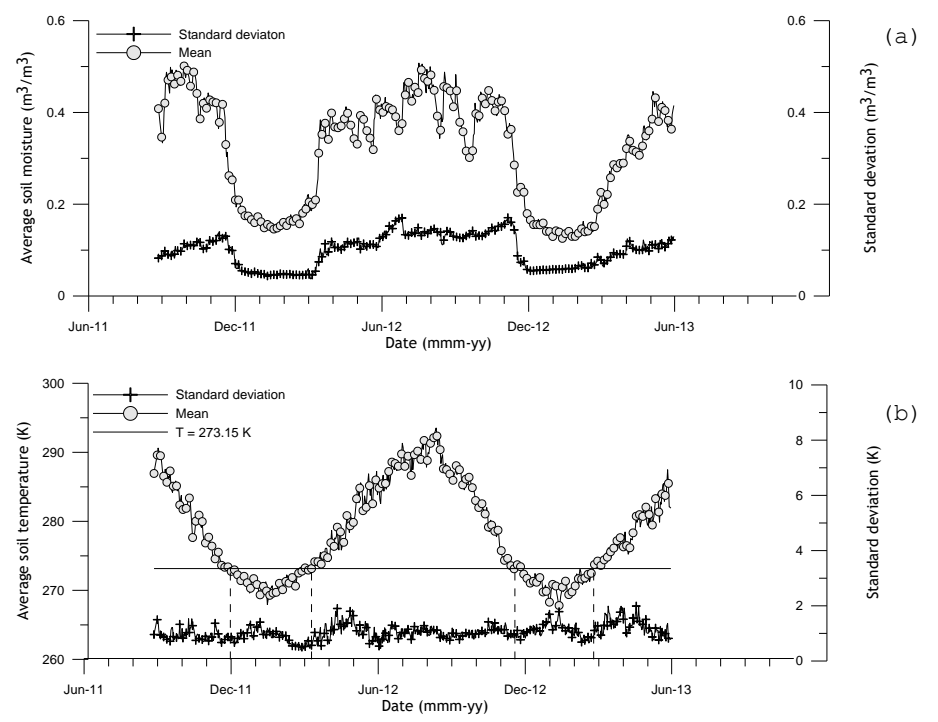

Fig.2.3. Top 5-cm soil moisture (a) and soil temperature (b) derived from in- situ measurements collected at 12 stations of the Maqu network in the period from August 2011 to May 2013.

\subsubsection{Naqu network description}

Naqu network is located in the central part of Tibetan Plateau in the Naqu basin. The elevation of this area is more than $4500 \mathrm{~m}$ above sea level. According to the updated Köppen-Geiger climate classification by Peel et al. (2007), Naqu falls under the class of semi-arid and cold climate. Grassland and wetland are the most widely seen land cover over this region. Soil located in the area is characterized as sandy loam (70\% sand and $10 \%$ silt) with a high saturated hydraulic conductivity above the impermeable permafrost layer. Additional information on the study area and monitoring network can be found in Su et al. (2011). Fig.2.4 shows the land cover of Naqu network overlaid over ESA GlobCover Version 2.3 land cover map for the Tibetan Plateau region 
Chapter 2

(http://due.esrin.esa.int/page_globcover.php, accessed on 1 April, 2017) with the stations are indicated with green circles.

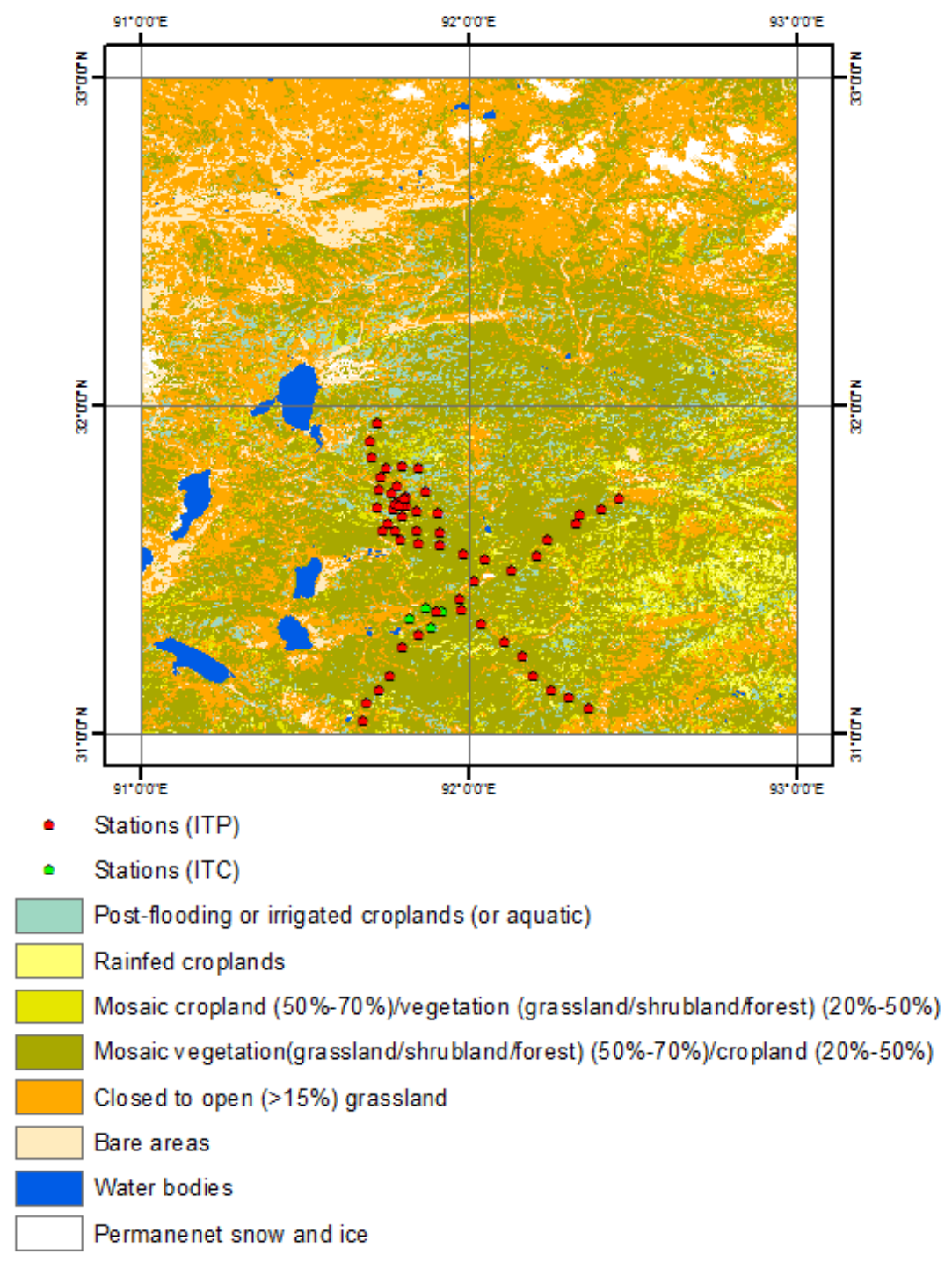

Fig.2.4. Land cover of Naqu area cropped from ESA GlobCover Version 2.32009 300m resolution Land Cover Map. Stations installed by ITC and ITP are indicated with green and red circles

Naqu network includes five stations installed in July 2006 with an area of $10 \mathrm{x}$ $10 \mathrm{~km}$ and being used for validating of soil moisture retrieval algorithms (van der Velde et al. 2012a, 2012b). Four of the stations are located in a grassland 


\section{Study area and datasets}

environment, while the land cover of the other station falls in the wetland group. Soil permittivity is recorded by the EM5b data logger connected with EC-10 ECH2O probe inserted at depths of 2.5 to $60 \mathrm{~cm}$, and a Root Mean Squared Difference (RMSD) of $0.029 \mathrm{~m}^{3} \mathrm{~m}^{-3}$ is achieved by comparing the gravimetrically determined against the $2.5-\mathrm{cm}$ probe volumetric soil moisture in a well-defined linear relationship for calibrating the probe readings. Additionally, Yang et al. (2013) from Institute of Tibetan Plateau Research (ITP), Chinese Academy of Sciences (CAS) installed fifty-six stations (represented by red circles in Fig 2.4) in a 100 x $100 \mathrm{~km}$ area nearby to enrich the soil moisture/temperature network in different scales $\left(0.1^{\circ}, 0.3^{\circ}, 1^{\circ}\right)$ for monitoring the freeze-thaw cycle of the third pole. With Yang's stations, probes are located in the depth of $5-40 \mathrm{~cm}$ and record the soil moisture/temperature at a 30 minute interval. Sensor calibration is conducted by the experimental analysis through comparing the soil moisture measured by the probe and gravimetric method, detailed information for this network can be found in Yang et al. (2013)

\subsubsection{Ngari network description}

Ngari network is located in the southwest part of Tibetan Plateau, including twenty soil moisture/temperature stations, which are installed in June 2010. Four of the twenty stations are in the neighborhood of Ngari Station for Desert Environment Observation and Research of the Chinese Academy of Sciences (NASDE/CAS), while other sixteen stations are near the Shiquanhe city covering a large soil moisture range depending on its distance to the Shiquanhe River, a tributary of the Indus. The elevation of this area is around 4200-4300 m above sea level with the elevation variation is less than $100 \mathrm{~m}$. According to the updated Köppen-Geiger climate classification by Peel et al. (2007), Ngari falls under the class of arid and cold climate. Bare areas and grasslands are the most widely seen land cover over this region. Soil located in the area is characterized as sandy loam (85\% sand and $12 \%$ silt) with high saturated hydraulic conductivity. The locations of the stations are indicated in Fig. 2.5 by red and red dots as well as the land cover in the Ngari/Ali area. 
Chapter 2

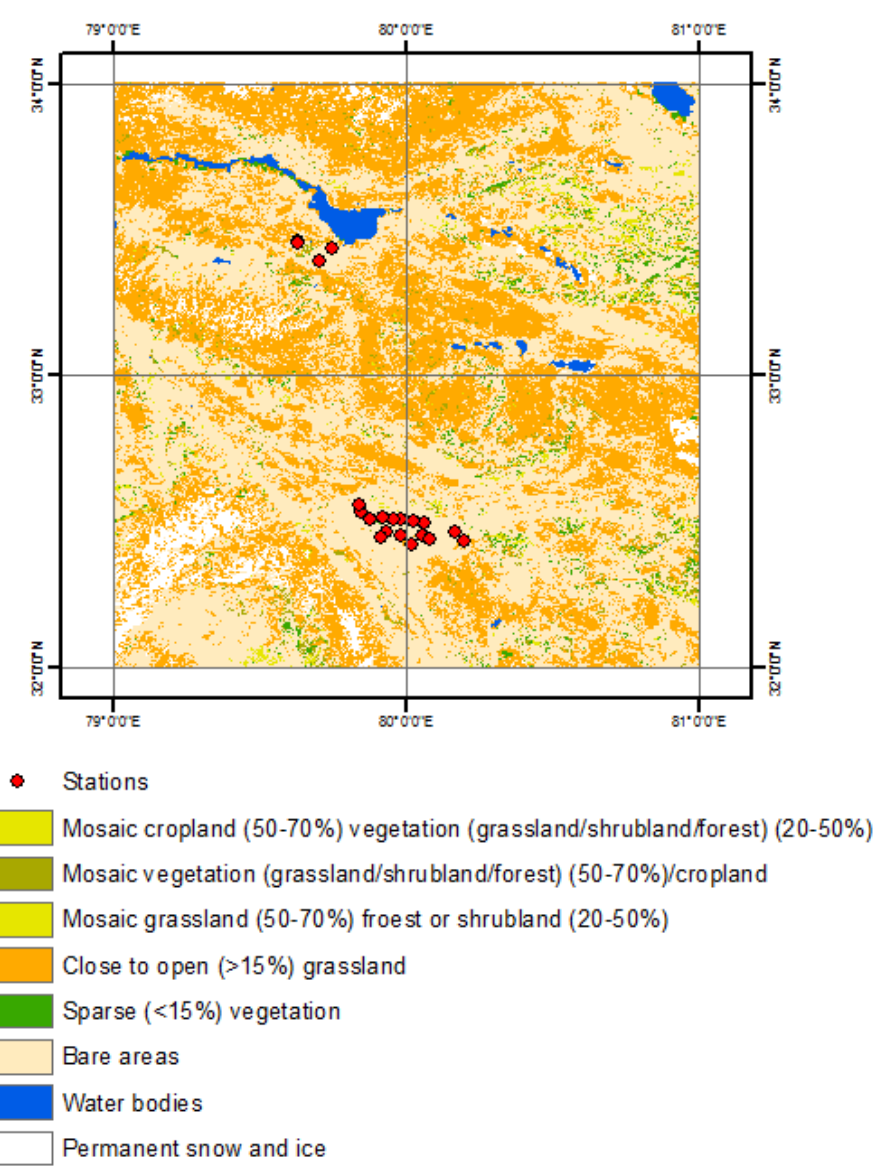

Fig.2.5. Land cover of Ngari/Ali area cropped from ESA GlobCover Version 2.32009 300m resolution Land Cover Map. Stations are indicated with red circles

Each station is composed of a Decagon (EM50) data logger that is set up to record a measurement every 15 minutes and 5TM ECH2O capacitance probes that are connected to the EM50 logger and measure the dielectric constant or dielectric constant and soil temperature with a thermistor embedded within the probe. The probes are placed at the depths ranges from $5 \mathrm{~cm}$ to $80 \mathrm{~cm}$ below the surface, detailed information can be found in Su et al. (2011). The calibration was conducted and validated immediately after the installation with experimental work and a RMSD of $0.031 \mathrm{~m}^{3} \mathrm{~m}^{-3}$ was found for the $5-\mathrm{cm}$ probe volumetric soil moisture. 


\section{Study area and datasets}

\subsection{Aquarius dataset}

Aquarius/ Satélite de Aplicaciones Científicas (SAC-D) was a joint National Aeronautics and Space Administration (NASA)-Comisión Nacional de Actividades Espaciales (CONAE) mission launched on 10 June 2011, which targeted the monthly measurement of the ocean's Sea Surface Salinity (SSS) with the accuracy of 0.2 Practical Salinity Unit (PSU). Unfortunately, failures in the power-supply and altitude control system brought the Aquarius mission to an end on 8 June 2015. The satellite operated in a sun-synchronous orbit from a height of $657 \mathrm{~km}$ that crosses the equator at $6 \mathrm{pm}$ (ascending) and 6 am (descending) local time, covering the globe every seven days. The Aquarius system consisted of three dual polarized L-band $(1.413 \mathrm{GHz})$ microwave radiometers and a fully polarimetric L-band $(1.26 \mathrm{GHz})$ scatterometer. Each radiometer had its own feedhorn, shared with the scatterometer, mounted at view angles of $28.7^{\circ}$ (beam 1), $37.8^{\circ}$ (beam 2) and $45.6^{\circ}$ (beam 3 ) leading to footprints of 62 (along track) x68 (cross track) km, 68 x $62 \mathrm{~km}$, and 75 x 100 $\mathrm{km}$, respectively, for the radiometers and of 76 x $94 \mathrm{~km}, 84 \times 120 \mathrm{~km}$ and $96 \mathrm{x}$ $156 \mathrm{~km}$, respectively, for the scatterometer. Table 2.1 summarizes several technical details about the Aquarius mission.

Table 2.1 Aquarius satellite characteristics and parameters of the radiometer/scatterometer.

\begin{tabular}{|l|l|l|}
\hline \multirow{4}{*}{ Orbit } & Altitude & $657 \mathrm{~km}$ \\
\cline { 2 - 3 } & Sun-synchronous & $6 \mathrm{pm}$ ascending and 6 am descending \\
\cline { 2 - 3 } & Inclination & $98^{\circ}$ \\
\cline { 2 - 3 } & Revisit time & 7 -day global coverage \\
\cline { 2 - 3 } & Swath & $390 \mathrm{~km}$ \\
\hline \multirow{4}{*}{ Radiometer } & Reflector diameter & $2.5 \mathrm{~m}$ \\
\cline { 2 - 3 } & Incidence angle & $28.7^{\circ}, 37.8^{\circ}, 45.6^{\circ}$ \\
\hline \multirow{5}{*}{ Scatterometer } & Frequency & $1.413 \mathrm{GHz}$ \\
\cline { 2 - 3 } & Polarization & $\mathrm{V}$ and H \\
\cline { 2 - 3 } & Calibration stability for 7 days & $0.13 \mathrm{~K}$ \\
\cline { 2 - 3 } & Resolution & $62 \times 68 \mathrm{~km}, 68 \times 62 \mathrm{~km}, 75 \times 100 \mathrm{~km}$ \\
\hline & Frequency & $1.26 \mathrm{GHz}$ \\
\cline { 2 - 3 } & Polarization & $\mathrm{VV}, \mathrm{HH}, \mathrm{VH}, \mathrm{HV}$ \\
\cline { 2 - 3 } & Pulse repetition frequency & $100 \mathrm{~Hz}$ \\
\cline { 2 - 3 } & Calibration stability for 7 days & $0.1 \mathrm{~dB}$ \\
\cline { 2 - 3 } & Resolution & $76 \times 94 \mathrm{~km}, 84 \times 120 \mathrm{~km}, 96 \times 156 \mathrm{~km}$ \\
\hline
\end{tabular}


Chapter 2

NASA Distributed Active Archive Center (DAAC) at National Snow \& Ice Data Center (NSIDC) archives and distributes the data products from Aquarius SAC-D platform. The level 2 swath single orbit based dataset with 98 minute temporal resolution and level-3 gridded based data (soil moisture with 7 day, 1 month, 3 month and 1 year resolution) are available through https://nsidc.org/data/aquarius/data-sets.html. In this research, the level 2 swath single orbit data and level 3 gridded soil moisture data with 7 day revisit time observed with incidence angle $28.7^{\circ}$ are used in chapter 4 and 5 for analysis since they have a better resolution compared with other two incidence angles.

\subsubsection{Aquarius level 2 brightness and backscattering coefficient dataset}

For the analysis presented in this research, we use the NASA Aquarius Level-2 Sea Surface Salinity \& Wind Speed Data version 2.0 which is available from ftp://podaac-ftp.jpl.nasa.gov/allData/aquarius/retired/L2/V2/ (last verified: 09 January 2014) in chapter 3 and version 4.0 through ftp://podaacftp.jpl.nasa.gov/allData/aquarius/L2/V4/ (last verified on 07 June 2015) in the chapter 4 and 5. The product is deduced from data collected in $1.44 \mathrm{~s}$ measurement sequences consisting of twelve blocks of $120 \mathrm{~ms}$ subsamples. Five data samples from each block are sent to ground segment along with internal calibration measurements as input for the offline Radio Frequency Interference (RFI) detection. Thus, 60 data samples are available within each $1.44 \mathrm{~s}$ sequence.

RFI is flagged within the level-2 data using onboard and offline detection procedures as described in Aquarius Radiometer Post-Launch Calibration for Product Version-2 (Piepmeier et al., 2013) and Le Vine et al. (2014). The RFI detection is based on the glitch algorithm proposed by Misra and Ruf (2008), which identifies individual antenna temperature samples (or short accumulations) that deviate abnormally from the nearby samples. The parameters in RFI filter algorithm in version 4.0 have been updated to reflect differences in the algorithm for land and ocean compared with version 2 dataset. To be noticed, RFI flagged observations for level 2 product is removed for later analysis in this research 


\section{Study area and datasets}

\subsubsection{Aquarius level 3 soil moisture dataset}

NASA Goddard Space Flight Center's Aquarius Data Processing Segment (ADPS) produced the global soil moisture derived from Aquarius observation. The soil moisture is derived from the horizontally polarized brightness temperature through application of SCA (Jackson, 1993; Bindlish et al., 2015) and distributed by NASA NSIDC DAAC. Initial assessment is carried out for this dataset and results show a good performance by the algorithm with Root Mean Square Error (RMSE) of $0.031 \mathrm{~m}^{3} \mathrm{~m}^{-3}$ is achieved with respect to the insitu measurement in two watersheds (Bindlish et al., 2015). Various temporal resolutions (daily, weekly, monthly, seasonal, annual) of the soil moisture product are available during the period from 25 August 2011 to 7 June 2015.

In this study, the L3 gridded $1^{\circ}$ grid Aquarius/SAC-D soil moisture (Version 4, http://nsidc.org/data/docs/daac/aquarius/aq3-sm/, accessed on 1 February, 2017) is used, it is hereafter referred to as official Aquarius. This data is generated by resampling the Aquarius Level-2 swath single orbit soil moisture Data (version 4.0) product in to a $1^{\circ} \times 1^{\circ}$ grid by using local polynomial fitting algorithm (Fan and Gijbels, 1996; Lilly and Lagerloef, 2008). Observations flagged for Radio Frequency Interference (RFI) or collected in the freezing period (when the surface temperature obtained from NCEP GFS GDAS product is lower than $273 \mathrm{~K}$, Aquarius level-2 data product, 2015) are excluded from this research.

\subsection{Other soil moisture datasets}

\subsubsection{TU-Wien ASCAT}

ASCAT on-board Metop-A is a real aperture radar aboard the Meteorological Operational Platform and records the $\sigma^{0}$ in VV polarization in $\mathrm{C}$ band (5.255 $\mathrm{GHz}$ ) since October 2006. The three scatterometer radar beams look sideways at $45^{\circ}$ (fore), $90^{\circ}$ (mid), and $135^{\circ}$ (aft) with respect to the satellite flight direction, resulting incidence angles ranging from $18^{\circ}$ to $59^{\circ}$. It was designed to monitor wind speed and direction over the ocean, but can be also used to monitor the soil moisture. The ASCAT soil moisture product is generated by a change detection algorithm originally proposed by Wagner et al (1999) and subsequently assessed by various investigators (Brocca et al., 2010; Matgen et al., 2012; Wagner et al., 2013). The validation results show that the correlation 
Chapter 2

coefficient for the soil moisture was higher than 0.8 when compared to the insitu measurement as well as a RMSE is around $0.04 \mathrm{~m}^{3} \mathrm{~m}^{-3}$ except forest coverage. Details about the change detection algorithm can be found in the Algorithm Theoretical Baseline Document (ATBD) Surface Soil Moisture ASCAT NRT Orbit

(http://hsaf.meteoam.it/documents/ATDD/ssm_ascat_nrt_o_atbd.pdf).

In this research, the Metop-A ASCAT soil moisture L2 product developed by Vienna University of Technology (TU-Wien) at $12.5 \mathrm{~km}$ Swath Grid (https://eoportal.eumetsat.int, accessed on 15 February, 2017) is used. This product provides an estimate of the water saturation of the $5 \mathrm{~cm}$ topsoil layer, with its value ranges between 0 and 100 [\%]. For later comparison, this is converted into volumetric soil moisture $\left(\mathrm{m}^{3} \mathrm{~m}^{-3}\right)$ by using the global soil porosity map provided on the ESA-CCI website (http://www.esa-soilmoisturecci.org/, accessed on 15 February, 2017).

\subsubsection{ERA-Interim}

The European Centre for Medium-Range Weather Forecasts (ECMWF) provides a global atmospheric reanalysis data from 1979 to present, ERAInterim (Dee et al., 2011). It is generated by a data assimilation system to estimate the state of global atmosphere and surface by using a forecast model and prior information with 12-hourly analysis cycles. The data assimilation system starts with computing a 4-dimentioanl variational analysis (4D-Var) of basic upper-air atmospheric fields, followed by separate analysis of near-surface parameters, soil moisture, soil temperature, snow and ocean waves. This analysis is used to initialize a short- range model forecast to provide prior state estimation for next analysis cycle.

ERA-Interim dataset can be downloaded through (http://apps.ecmwf.int/datasets/data/interim-full-daily/, accessed on 10

February, 2017) with the spatial resolution ranges between $0.125^{\circ}$ and $3^{\circ}$ (the $1^{\circ}$ dataset is used in this research). The ERA-Interim products are updated once per month regularly and a delay of two months can happen for quality assurance and for correcting technical problems with the production. Soil moisture is recorded in four layers of 0-0.07 m, 0.07-0.28 m, 0.28-1.00 m and 1.00-2.89 m together with the corresponding soil temperature ERA-Interim dataset. The performance of ERA-Interim soil moisture is assessed by numbers of scholars 


\section{Study area and datasets}

(Albergel et al., 2012a; Albergel et al., 2012b; Su et al., 2013). Results show that ERA-Interim first layer soil moisture follows the seasonal trend with in-situ soil moisture variation with the average coefficient of determination of 0.63 (-) and an overestimation of $0.079 \mathrm{~m}^{3} \mathrm{~m}^{-3}$ is observed with respect to in-situ measurement. In this article, the soil moisture recorded at 12:00 in the first layer is used for comparison since it is closest to Aquarius acquisition time over Tibetan Plateau.

\subsection{Ancillary datasets}

\subsubsection{Moderate resolution imaging Spectroradiometer (MODIS) Normalized Difference Vegetation Index (NDVI)}

MODIS instrument was first launched aboard Terra spacecraft in 1999 and the second MODIS instrument was launched aboard the Aqua platform in 2002 with the swath is $2330 \mathrm{~km}$. Both Terra- and Aqua-MODIS instruments acquire data in 36 discrete spectral bands with the wavelengths between $0.4 \mu \mathrm{m}$ and $14.4 \mu \mathrm{m}$ at three spatial resolutions, $250 \mathrm{~m}, 500 \mathrm{~m}$ and $1000 \mathrm{~m}$. With the available MODIS observations, MODIS science team produces and distributes the MODIS products, namely land, ocean and atmosphere products.

Normalized Difference Vegetation Index (NDVI) is one of MODIS land products, which is computed from bi-directional (red and near-infrared spectral band) surface reflectance after atmosphere correction. NDVI is widely used to monitor the vegetation growth conditions, drought as well as land cover classification. The MODIS NDVI products are of spatial resolutions with $250 \mathrm{~m}$, $500 \mathrm{~m}, 1 \mathrm{~km}$ and $0.05^{\circ}$ with a 16 day interval. In this research, MOD13Q1 which is of 16 day temporal resolution with 250 meter spatial resolution is used (https://e4ft101.cr.usgs.gov/MOLT/MOD13Q1.005/, last accessed: 15 October 2016). The Harmonic ANalysis of Time Series (HANTS, Verhoef et al., 1996) algorithm is applied to suppress the effects of clouds within the NDVI time series. An additional linear interpolation is performed to match the 16-day cloud mitigated NDVI to the 7-day Aquarius observations. 


\subsubsection{MODIS Leaf Area Index (LAI)}

Chapter 2

The LAI (MCD15A2, Weiss et al., 2007) product derived from data acquired by both Terra and Aqua satellites is used to characterize the dynamic vegetation effects on microwave signals. The dataset has spatial and temporal resolutions of $1 \mathrm{~km}$ and 8 days, respectively, and can be downloaded from http://e4ft101.cr.usgs.gov/MOTA/MCD15A2.005/(last accessed on 30 March, 2017). Similar to NDVI, HANTS algorithm and linear interpolation are used to match the 8-day cloud mitigated LAI to the 7-day Aquarius observations.

\subsubsection{Climate Hazards Group Infrared Precipitation with Station data (CHIRPS)}

CHIRPS is a quasi-global precipitation dataset since 1981 to near present with a spatial coverage from $50^{\circ} \mathrm{S}$ to $50^{\circ} \mathrm{N}$ at a $0.05^{\circ}$ resolution and provides information at daily, decadal, and monthly temporal resolutions (Funk et al., 2015). It incorporates global precipitation climatologies, satellite-based precipitation estimates and in-situ precipitation observations.

CHIRPS was validated by several researchers with in-situ measurements (Katsanos et al., 2016; Paredes-Trejo et al., 2017; Zambrano-Bigiarini et al., 2017 ) that the CHIRPS agrees with the in-situ measurements. For instance, Katsanos et al. (2016) indicated that a correlation of around 0.85 (-) was found between monthly CHIRPS and station observed precipitation in Cyprus. Paredess-Trejo et al. (2017) concluded the CHIRPS data correlate well with observations for all stations in Northeast Brazil with the Pearson correlation coefficient is 0.94 (-). The latest version 2.0 dataset was released in February, 2015 and is used in this research http://chg.geog.ucsb.edu/data/chirps/ (accessed on 1 March, 2017).

\subsubsection{Surface Energy Balance System (SEBS) evapotranspiration}

$\mathrm{Su}$ (2002) developed the SEBS for retrieval regional and global atmospheric turbulent fluxes and evapotranspiration with satellite earth observation data. The SEBS requires inputs from: (1) land surface physical parameters, such as albedo, emissivity, temperature, etc.; (2) radiation measurements; (3) meteorological parameters. The original SEBS was assessed by Su et al. (2002) and results showed that SEBS was capable to estimate turbulent heat fluxes and evaporative fraction at various scales with acceptable accuracy (20\% relative 


\section{Study area and datasets}

error of mean sensible heat flux). Ma et al. (2014) evaluated the SEBS evapotranspiration (ET) with the Advanced Spaceborne Thermal Emission and Reflection Radiometer (ASTER) dataset over Tibetan Plateau and concluded the RMSE of ET is $0.7 \mathrm{~mm} / \mathrm{d}$ with respect to the in-situ flux tower data.

Chen et al. (2013) further enhanced the turbulent parameterization method used in SEBS specifically for the bare soil and major land covers over the Tibetan Plateau. Using the updated SEBS version, Chen et al. (2014) produced a monthly ET dataset for mainland China area and a RMSE of $21.9 \mathrm{~W} \mathrm{~m}^{-2}$ is found for the ET with respect to the stations' measurements. This higher resolution evapotranspiration product is used for this research to verify the spatial trend included in the soil moisture datasets. 


\section{Chapter 3 Sensitivity of Aquarius observations over soil moisture in Maqu network*}

\subsection{Introduction}

L-band microwave remote sensing is regarded as a viable method for realizing the global soil moisture monitoring ambition as an imperative for an improved understanding of the heat and mass exchanges at the land-atmosphere interface that regulate weather and climate (Dorigo et al.,2014). The potential for soil moisture applications has been demonstrated for both active and passive measurements techniques (e.g., Jackson 1993; Njoku and Entekhabi, 1996; Pellarin et al., 2003; Ulaby et al., 1996; Wigneron, et al., 2007). This led in 2009 to the launch of the first satellite dedicated to soil moisture by the European Space Agency (ESA) named the Soil Moisture and Ocean Salinity (SMOS, Kerr et al., 2001) mission. Also, the National Aeronautics and Space Administration (NASA) launched a L-band satellite dedicated to global soil moisture monitoring, named the Soil Moisture Active Passive mission (SMAP, Entekhabi et al., 2010). In contrast to SMOS, the soil moisture is the sole objective of SMAP and carries active as well as passive microwave instrumentation. The rationale behind the active/passive combination is that, apart from their physical complementarity, the active microwave observations can be availed for the downscaling of the coarse passive microwave products.

NASA launched the first satellite with both active and passive L-band microwave instrumentation called Aquarius/SAC-D mission in 2011. The Aquarius instrument consists of three dual polarized L-band $(1.413 \mathrm{GHz})$ radiometers each with its own feedhorn and a fully polarimetric L-band (1.26 $\mathrm{GHz})$ scatterometer that makes use of the radiometer feedhorns. The three

\footnotetext{
* This chapter is based on

Wang, Q., van der Velde, R., Su, Z., \& Wen, J. (2016). Aquarius L-band scatterometer and radiometer observations over a Tibetan Plateau site. International Journal of Applied Earth Observation and Geoinformation, 45, 165-177. DOI: 10.1016/j.jag.2015.06.010
} 


\section{Sensitivity of Aquarius observations over soil moisture in Maqu network}

feedhorns are aligned in the push broom configuration and point at three different off-nadir angles of $28.7^{\circ}, 37.8^{\circ}$ and $45.6^{\circ}$.

Despite Aquarius/SAC-D mission is not designed for land applications, the availability of both active and passive microwave observations from a single space platform has attracted the attention of researchers (e.g. Bruscantini et al., 2014; Colliander and Xu, 2013; Luo et al., 2013; McColl et al., 2014) from the soil moisture community, primarily in anticipation of SMAP. Luo et al. (2013) and Bruscantini et al. (2014), for instance, reported on the development of an Observing System Simulation Experiments (OSSEs) for Red-Arkansas River basin to synthetically assess the impact of uncertainties on the soil moisture retrieved from Aquarius radiometer and scatterometer observations. Colliander and $\mathrm{Xu}$ (2013) introduced the normalized residual scattering index (NRSI) based on radar backscatter $\left(\sigma^{0}\right)$ and brightness temperature $\left(T_{b}\right)$, and demonstrated its global applicability using Aquarius data. Further, McColl et al. (2014) assessed the uncertainty embedded within soil moisture and vegetation indices derived Aquarius scatterometer observations.

This chapter emphasizes on the analysis of the L-band Aquarius scatterometer/radiometer observations in the Maqu area situated on the eastern part of the Tibetan Plateau at the high-elevation Yellow River Source Region. The Maqu area holds since 2008 a regional scale soil moisture/temperature monitoring network that is part of Tibetan Plateau Observatory (Tibet-Obs, Su et al., 2011). For the analysis presented in this chapter, we use the NASA Aquarius Level-2 Sea Surface Salinity \& Wind Speed Data version 2.0 which is available from ftp://podaac-ftp.jpl.nasa.gov/allData/aquarius/retired/L2/V2/ (last verified: 09 January 2014). To be noticed, RFI flagged observations for level 2 product is removed for later analysis in this research.

In particular, we study the impact of freeze-thaw, soil moisture and vegetation on the L-band scatterometer/radiometer observations collected across an almost two-year period from August 2011 to May 2013 using in-situ measurements. The primary purpose is to investigate how the regional hydrometeorological processes influence the L-band active/passive microwave observations and the possible synergetic use of the two data sources via the available polarimetric information. To this aim, Radar Vegetation Index (RVI) time series derived from the Aquarius $\sigma^{0}$ observations is analyzed. Further, the $\tau-\omega$ concept (Mo et al., 1982) is utilized to reproduce the Microwave Polarization Difference Index (MPDI) derived from the time series of 


\section{Chapter 3}

Aquarius $T_{b}$ 's and quantify the vegetation optical depth $(\tau)$. Subsequently, the relationships are investigated among the $\tau$, RVI and Moderate Resolution Imaging Spectrometer (MODIS) Normalized Difference Vegetation Index (NDVI) as proxy for the vegetation biomass.

\subsection{Data analysis}

\subsubsection{Backscattering coefficients}

Fig.3.1 shows the Aquarius VV, $\mathrm{HH}$, and $\mathrm{VH}$ polarized $\sigma^{0}$ measured at the three incidence angles over Maqu region in the period August 2011 to May 2013. The plots illustrate that the temporal $\sigma^{0}$ variability is strongly determined by the transition from a frozen to a thawed land surface. In late November, the soil temperature drops below freezing point (see Fig.2.3b), and water in the soil matrix starts to freeze. This reduces the dielectric constant and causes the $\sigma^{0}$ decrease noted in the VV, $\mathrm{HH}$ as well as $\mathrm{VH}$ polarization. The minimum $\sigma^{0}$ values are typically reached in early January and can be considered as the month during which most soil water is frozen. In months afterwards, soil temperatures rise again increasing the liquid water content in the soil and produce a higher $\sigma^{0}$ response. Van der Velde and $\mathrm{Su}$ (2009) reported on a similar behavior of the $\sigma^{0}$ observed by the C-band Advanced Synthetic Aperture Radar (ASAR) over the central part of the Tibetan Plateau. Once the frozen season has ended, more liquid water is present in the soil and the $\sigma^{0}$ variations remain fairly small but also some agreement is noted with the soil moisture dynamics (see Fig.2.3 a) as will be discussed in section 3.2.2.

The magnitude of the VV polarized $\sigma^{0}$ is close to the $\mathrm{HH}$ polarized one for all three incidence angles. The $\sigma^{0}$ observed at incidence angle of $37.8^{\circ}$ matches closely the $\sigma^{0}$ observed at an incidence of $45.6^{\circ}$; both are substantially smaller than the $\sigma^{0}$ measured at $28.7^{\circ}$. This angular behavior is as expected based on theory (e.g. Ulaby et al. 1982) and has been confirmed in various investigations (e.g. Abdel-Messeh and Quegan, 2001; Lievens et al., 2011; Van der Velde and $\mathrm{Su}, 2009$; Van der Velde et al., 2014). The VH polarized $\sigma^{0}$ displays a similar seasonal behavior as the co-polarized ones ( $\mathrm{VV}$ and $\mathrm{HH}$ ), but smaller differences are noted among the three incidence angles. 


\section{Sensitivity of Aquarius observations over soil moisture in Maqu network}
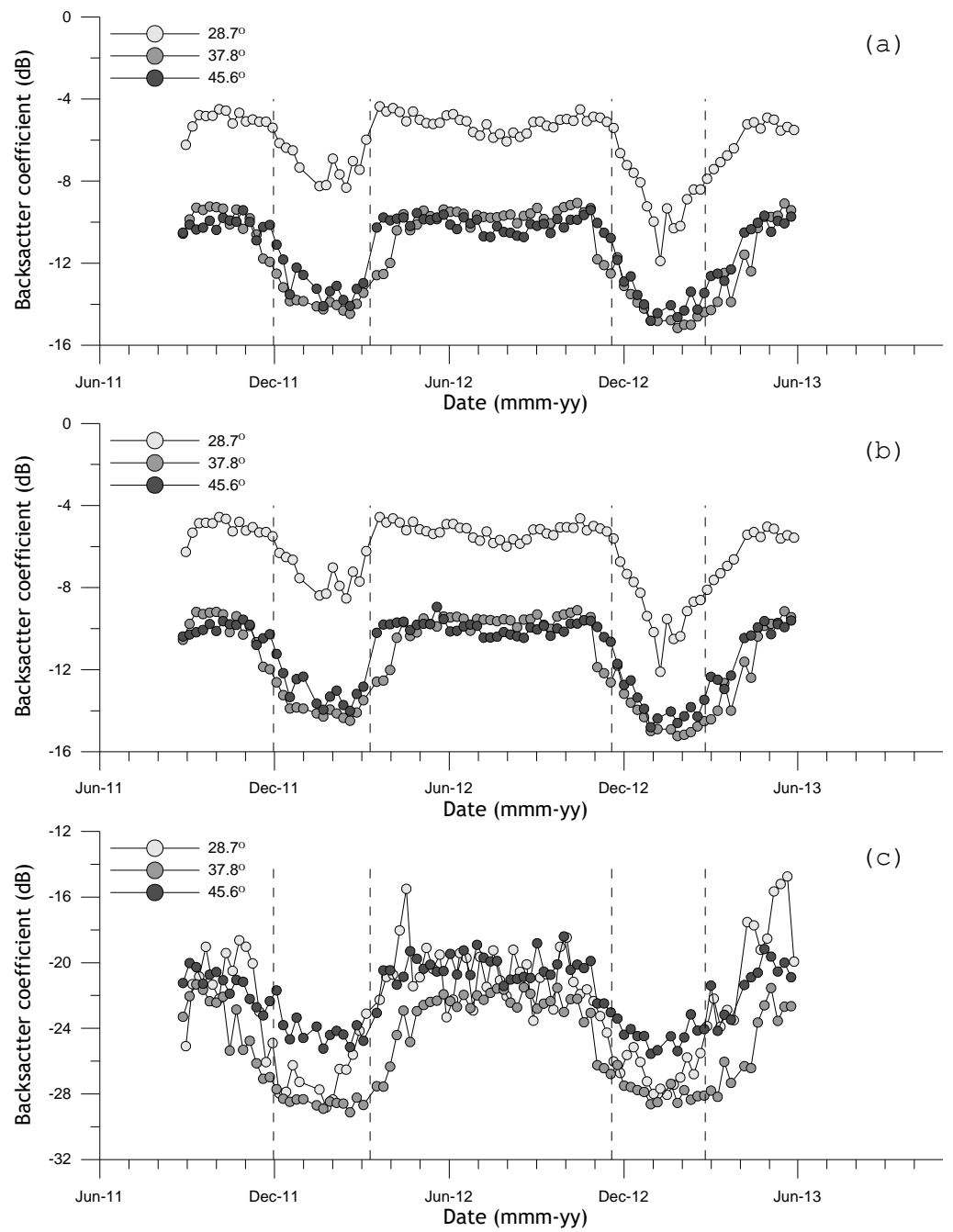

Fig.3.1. Multi-angular $\left(28.7^{\circ}, 37.8^{\circ}\right.$ and $\left.45.6^{\circ}\right)$ L-band backscatter observed by Aquarius in the VV (a) HH (b) and VH (c) polarization over the Maqu soil moisture monitoring network (lat:33.8 ${ }^{\circ}$, lon:102.2 ${ }^{\circ}$, WGS84).

The vertical dashed lines indicate when the mean daily temperature measured at a 5 -cm depth is $0{ }^{\circ} \mathrm{C}$.

\subsubsection{Brightness temperatures}

Fig.3.2 shows the series of the Aquarius $\mathrm{V}$ and $\mathrm{H}$ polarized radiometer observation for the three incidence angles over the Maqu region from August 2011 to May 2013, whereby the $T_{b}$ is commonly defined as the product of the emissivity and the temperature of the emitting layer. In the passive case, the decrease in the dielectric constant associated with the freezing of soil water 
Chapter 3

reduces the reflectivity and increases the emissivity because of its complementarity according to Kirchhoff's law. This explains the $T_{b}$ increase noted during wintertime as the emissivity increase outweighs the drop in the temperature of the emitting layer. Similar to the depression in the Aquarius $\sigma^{0}$ is the $T_{b}$ peak reached in early January whereby the exact timing depends on the incidence angle. A comparable $T_{b}$ response to the freezing and thawing of bare land is reported in Wegmüller (1990) for two diurnal cycles monitored with a ground based radiometer.

Upon completion of the thawing of the land surface, the $T_{b}$ drops to about 200 and $180 \mathrm{~K}$ for $\mathrm{V}$ and $\mathrm{H}$ polarization respectively, after which a gradual increase is noted towards the warm monsoon. The enhanced land surface emission is caused on a seasonal time scale by an increase in the land surface temperature possibly in combination with a larger emissivity induced by vegetation biomass following from its growth. Vegetation is generally known to attenuate the soil emission and contribute itself to the total emission, thereby, enlarging the overall land surface emissivity in the microwave region in particular under wet conditions (e.g. Mo et al. 1982, Joseph et al. 2010).

As the warm season dissipates and, yet, the soil moisture content does not change substantially (see Fig.3.2), the $T_{b}$ decreases as a result of a drop in the land surface temperature and vegetation biomass. It should be noted that the $T_{b}$ observed from an incidence of $45.6^{\circ}$ is in particular for the $\mathrm{V}$ polarization larger than the $28.7^{\circ}$ and $37.8^{\circ} T_{b}$. This is explained on the one hand by the theoretical angular dependence and on the other hand by the fact that the impact of vegetation is larger at high incidence angles as will be demonstrated in section 3.3. 


\section{Sensitivity of Aquarius observations over soil moisture in Maqu network}
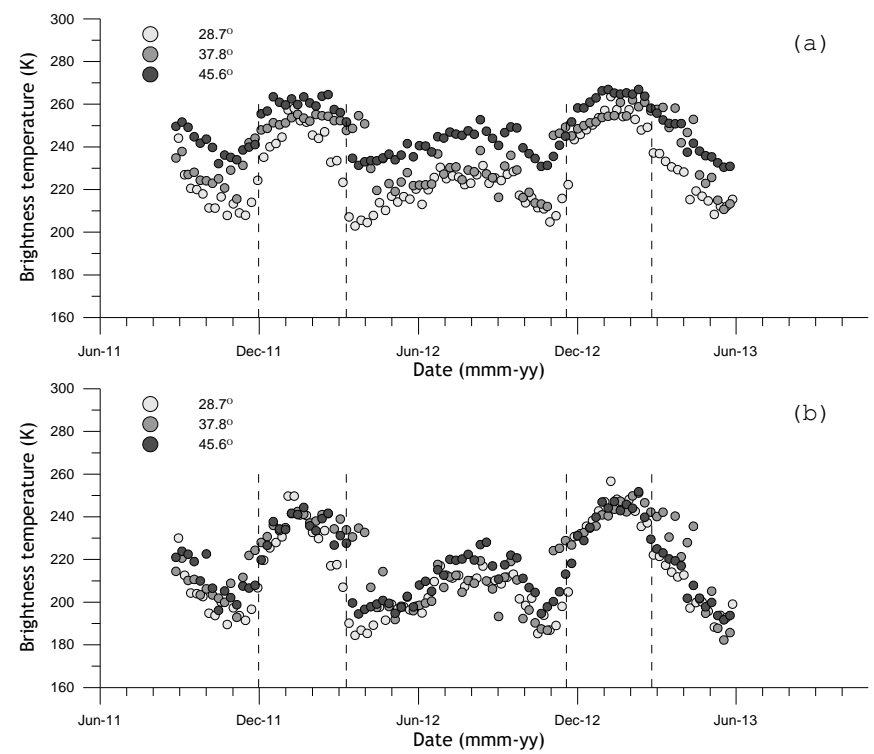

Fig.3.2. Multi-angular $\left(28.7^{\circ}, 37.8^{\circ}\right.$ and $\left.45.6^{\circ}\right)$ L-band brightness temperatures observed by Aquarius in the V (a) and $\mathrm{H}$ (b) polarization over the Maqu soil moisture monitoring network (lat:33.8 ${ }^{\circ}$, lon:102.2 ${ }^{\circ}$, WGS84). The vertical dashed lines indicate when the mean daily temperature measured at a 5 -cm depth is $0{ }^{\circ} \mathrm{C}$.

\subsubsection{Response to soil moisture}

The soil moisture sensitivity of both active and passive microwave observations has been demonstrated in numerous studies (Dubois et al., 1995; Njoku and Entekhabi, 1996; Naemi et al., 2009; McColl et al., 2014). Here, we investigate the sensitivity of the coarse Aquarius scatterometer/radiometer observations to the soil moisture measurements from the Maqu region. For the active case, Fig.3.3 shows plots of the $\mathrm{VV}$ and $\mathrm{HH}$ polarized Aquarius $\sigma^{0}$ versus soil moisture and Fig.3.4 presents the passive case with plots of the $\mathrm{V}$ and $\mathrm{H}$ polarized emissivity against the measured soil moisture, whereby the emissivity is computed as the Aquarius $T_{b}$ divided by the measured soil temperature. Both soil moisture and temperature data used for Figs.3.3 and 3.4 are mean values of the $5-\mathrm{cm}$ measurements from the 12 stations for which the record is complete for the selected Aquarius observation period from August 2011 to May 2013. 
Chapter 3
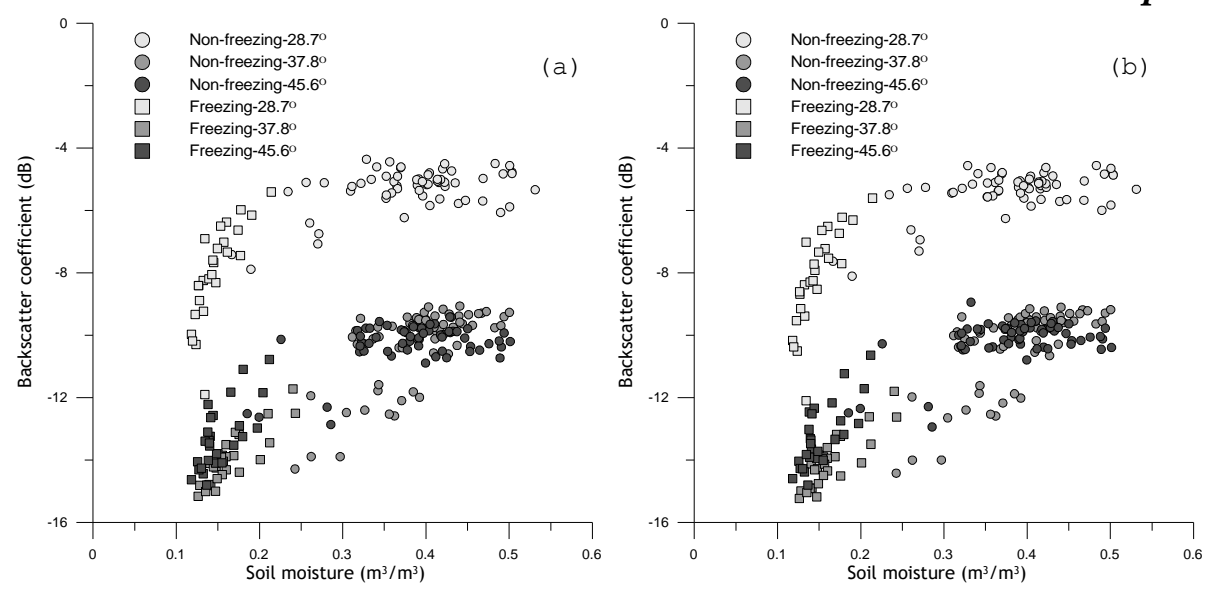

Fig.3.3. Multi-angular $\left(28.7^{\circ}, 37.8^{\circ}\right.$ and $\left.45.6^{\circ}\right)$ L-band $\sigma^{\circ}$ observed by Aquarius in the VV (a) and HH (b) polarization versus the measured soil moisture. Data collected under conditions with 5-cm soil temperature below (square symbols) and above $0^{\circ} \mathrm{C}$ (circular symbols) are separated.

In general, positive relationships are observed between the Aquarius $\sigma^{0}$ and the mean soil moisture derived from measurements, which is expected based on previous investigations (e.g. Joseph et al. 2010; Kaojarern et al. 2004; Mancini et al. 1999). In fact, we find two linear relationships for the VV as well as $\mathrm{HH}$ polarized Aquarius $\sigma^{0}$. The first is noted for conditions when the $5-\mathrm{cm}$ soil temperature is below $0^{\circ} \mathrm{C}$. Increments in both $\mathrm{VV}$ and $\mathrm{HH}$ polarized $\sigma^{0}$ are recorded varying from about 2.0 up to $4.0 \mathrm{~dB}$ over the $0.1-0.2 \mathrm{~m}^{3} \mathrm{~m}^{-3}$ soil moisture range depending on the view angle.

Of course, one can argue meaning of soil moisture at temperatures below $0^{\circ} \mathrm{C}$. However, we would like to remind that liquid and frozen water can co-exist in the soil matrix up to several degrees below freezing point depending on the soil type, temperature and water content (Watanabe and Flury 2008). In fact, Wegmüller (1990) has reported on the impact of liquid water in soils below $0{ }^{\circ} \mathrm{C}$ on active as well as passive microwave signatures. Here, a correlation is found between the $\sigma^{0}$ and the in-situ soil moisture because the selected in-situ sensors essentially measure a dielectric constant (section 2.2.1) that also influences the microwave observations.

The other relationship is found for data collected when the recorded 5-cm soil temperature is above $0{ }^{\circ} \mathrm{C}$, which is much weaker than the previous one. In all six sensing configurations the $\sigma^{0}$ increases less than $1.0 \mathrm{~dB}$ over a soil moisture range from 0.30 to $0.50 \mathrm{~m}^{3} \mathrm{~m}^{-3}$. The weaker sensitivity of $\sigma^{0}$ observation 


\section{Sensitivity of Aquarius observations over soil moisture in Maqu network}

towards soil moisture is well known under wet conditions. For instance, Altese et al. (1996) eloquently demonstrated using C-band measurements performed under controlled laboratory conditions. They found that above a dielectric constant of $10(-)$ the $\sigma^{0}$ hardly increases regardless of the surface roughness condition and confirmed this result using the surface scattering simulations with the theoretical Integral Equation Method model (IEM, Fung et al. 1992). Similar conclusions were drawn from the study by Joseph et al. (2008) that focused on soil moisture estimation from ground based L-band $\sigma^{0}$ observations collected during the corn growth cycle. Table 3.1 lists the regression coefficients and coefficients of determination $\left(\mathrm{R}^{2}\right)$ following from fitting a linear equation of the form $\sigma^{0}=\boldsymbol{a} \mathrm{s} m+\boldsymbol{b}$ through $\sigma^{0}$ - soil moisture matchup data collected under below $0{ }^{\circ} \mathrm{C}$ and above $0{ }^{\circ} \mathrm{C}$ conditions, separately.

Table 3.1. Regression coefficients ( $\boldsymbol{a}$ and $\boldsymbol{b}$ ) and coefficients of determination $\left(R^{2}\right)$ following from fitting a linear equation of the form $\sigma^{0}=\boldsymbol{a} S M+\boldsymbol{b}$ through the matchups.

\begin{tabular}{|c|c|c|c|c|c|}
\hline & Angle (degree) & Polarization & $a$ & $b$ & $R^{2}$ \\
\hline \multirow{6}{*}{ Below $0{ }^{\circ} \mathrm{C}$} & \multirow[t]{2}{*}{$28.7^{\circ}$} & V & 50.25 & -15.395 & 0.614 \\
\hline & & $\mathrm{H}$ & 50.339 & -15.591 & 0.607 \\
\hline & \multirow[t]{2}{*}{$37.8^{\circ}$} & $\mathrm{V}$ & 22.859 & -17.737 & 0.728 \\
\hline & & $\mathrm{H}$ & 22.833 & -17.815 & 0.712 \\
\hline & \multirow[t]{2}{*}{$45.6^{\circ}$} & V & 29.490 & -17.745 & 0.504 \\
\hline & & $\mathrm{H}$ & 30.994 & -17.956 & 0.569 \\
\hline \multirow{6}{*}{ Above $0{ }^{\circ} \mathrm{C}$} & \multirow{2}{*}{$28.7^{\circ}$} & V & 4.387 & -6.979 & 0.239 \\
\hline & & $\mathrm{H}$ & 5.050 & -7.332 & 0.036 \\
\hline & \multirow{2}{*}{$37.8^{\circ}$} & V & 14.706 & -16.038 & 0.450 \\
\hline & & $\mathrm{H}$ & 15.415 & -16.312 & 0.468 \\
\hline & \multirow{2}{*}{$45.6^{\circ}$} & $\mathrm{V}$ & 5.113 & -12.235 & 0.239 \\
\hline & & $\mathrm{H}$ & 5.516 & -12.288 & 0.275 \\
\hline
\end{tabular}



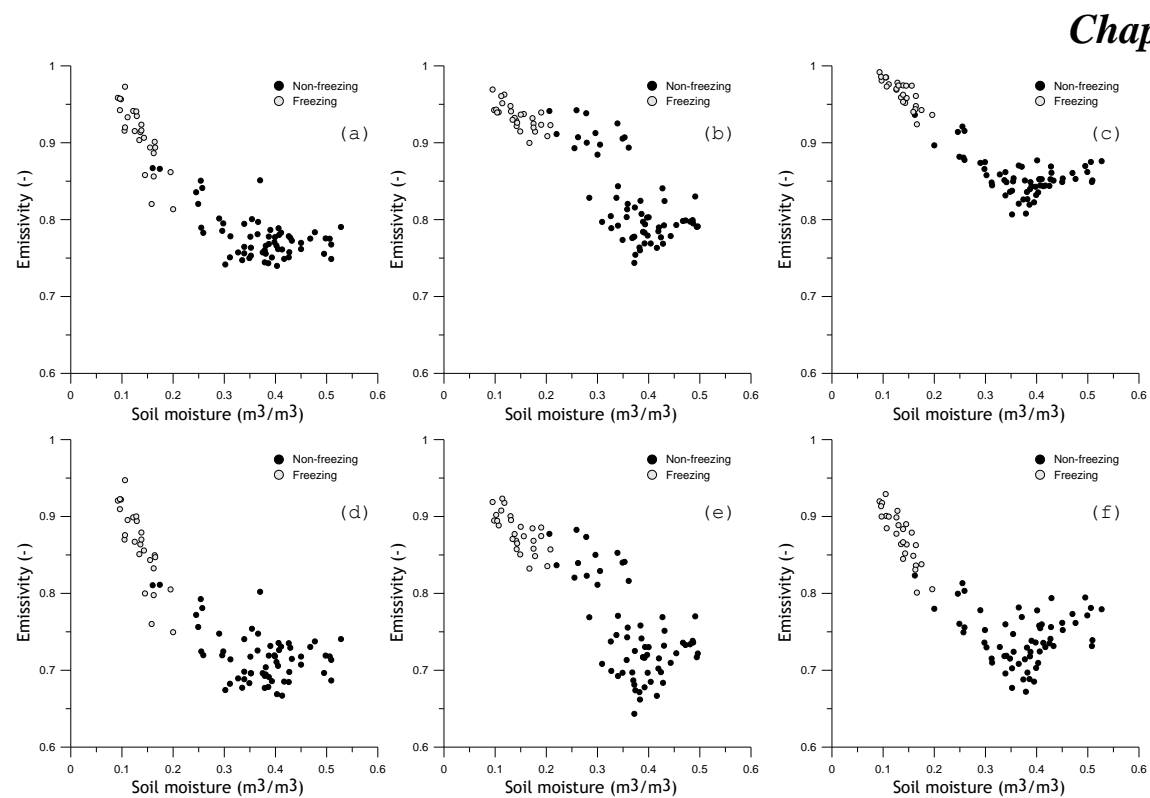

Fig.3.4. Emissivity derived from multi-angular $\left(28.7^{\circ}, 37.8^{\circ}, 45.6^{\circ}\right)$ Aquarius $\mathrm{H}$ and $\mathrm{V}$ polarized $T_{b}$ observations plotted against measured soil moisture; panels a), b) and c) present the results for the $\mathrm{V}$ polarization for angles of $28.7^{\circ}, 37.8^{\circ}$ and $45.6^{\circ}$, respectively and panels d), e) and f) show the results for the $\mathrm{H}$ polarization for the same respective angles.

The plots of Fig.3.4 demonstrate the dependence of the L-band emissivity derived from Aquarius $T_{b}$ 's on soil moisture. In line with theory (i.e. Ulaby et al. 1986) a higher L-band sensitivity to soil moisture is found for the $\mathrm{H}$ polarization that is, as expected, most appreciable at the largest incidence angle (e.g. $\left.45.6^{\circ}\right)$. In the plots, a distinction is made between data acquired under conditions when the measured $5-\mathrm{cm}$ soil temperature is respectively below and above $0^{\circ} \mathrm{C}$ illustrating that the highest emissivity is obtained under the lowest soil moisture and freezing conditions. The emissivity decreases as the recorded moisture increases while the temperature remains under the freezing point. This is explained by the fact that once temperatures drop below $0{ }^{\circ} \mathrm{C}$ not all water in the soil matrix freezes and a part remains in a liquid state. The amount of liquid water defines the dielectric properties, which both affect the Aquarius and capacitance probe measurements. Hence, a well-defined linear relationship is found between the L-band emissivity and the recorded soil moisture even during freezing. Table 3.2 presents the regression coefficients and $\mathrm{R}^{2}$ of linear equations of the form $e=\mathbf{a} s m+\mathbf{b}$ fitting through the data available for below and above $0{ }^{\circ} \mathrm{C}$ conditions. 


\section{Sensitivity of Aquarius observations over soil moisture in Maqu network}

Table 3.2 Regression coefficients $(\boldsymbol{a}$ and $\boldsymbol{b})$ and coefficients of determination $\left(R^{2}\right)$ following from fitting a

linear equation of the form $E=\boldsymbol{a} S M+\boldsymbol{b}$ through the matchups.

\begin{tabular}{|c|c|c|c|c|}
\hline \multirow{4}{*}{$\mathrm{V}$} & Angle (degree) & $\boldsymbol{a}$ & $\boldsymbol{b}$ & $R^{2}$ \\
\cline { 2 - 5 } & $28.7^{\circ}$ & -0.470 & 0.959 & 0.774 \\
\cline { 2 - 5 } & $37.8^{\circ}$ & -0.494 & 1.005 & 0.748 \\
\hline \multirow{3}{*}{$\mathrm{H}$} & $45.6^{\circ}$ & -0.380 & 1.003 & 0.775 \\
\cline { 2 - 5 } & $28.7^{\circ}$ & -0.508 & 0.914 & 0.722 \\
\cline { 2 - 5 } & $37.8^{\circ}$ & -0.564 & 0.957 & 0.725 \\
\hline
\end{tabular}

The decrease of the emissivity continues under non-freezing conditions almost seamlessly for the emissivities derived from the $T_{b}$ from angle of $28.7^{\circ}$ (beam 1) and $45.6^{\circ}$ (beam 3 ), whereas a clear discontinuity is noted at soil moisture values of $0.2-0.35 \mathrm{~m}^{3} \mathrm{~m}^{-3}$ for the $37.8^{\circ}$ (beam 2) Aquarius observations. The time of overpass forms the explanation for the difference in the obtained relationships. Beam 1 and 3 cross the study area at $19^{\mathrm{h}}$ in the afternoon, and the beam 2 measurements are performed at $7^{\mathrm{h}}$ in the morning as the land surface cools down.

In the latter case, the temperature near the land-atmosphere interface may have cooled down sufficiently to initiate dewfall as well as soil freezing. Development of ice at the soil surface lowers the dielectric constant and increases the L-band emissivity, while at a 5 -cm depth water remains liquid because the temperature is well above $0{ }^{\circ} \mathrm{C}$. Such strong soil temperature gradients near the surface have been reported for the study area by, for instance, Zheng et al. (2015). Mixed reports have been published on the effects of dew on L-band emission. For instance, Saleh et al. (2006) indicated that for a grassland L-band emission increases as a result of intercepted precipitation, whereas Hornbuckle et al. (2006) showed a decrease for the corn emission. As alpine meadow is the land cover in the study area, the noted enlarged microwave emission increase would be in line with the findings of Saleh et al. (2006). On the other hand, the emission increase occurs specifically at the intermediate moisture levels recorded at the transition from prevailing freezing to thawing conditions. Moreover, the humidity of air will be low and less appropriate for the formation of dew under those circumstances. 
Chapter 3

The relationship between the L-band emissivity and soil moisture weakens under wet conditions $\left(>0.35 \mathrm{~m}^{3} \mathrm{~m}^{-3}\right)$ whereby even an increase in the emissivity is noted towards saturated levels, particularly for large incidence angles (e.g. $37.8^{\circ}$ and $45.6^{\circ}$ ). As open water reduces the emissivity considerably, a major impact of inundation on Aquarius radiometer (and scatterometer) observations is ruled out. A more probable cause for the observed increase in the L-band emissivity is the vegetation effects, which is further quantified in section 3.3.2.

\subsection{Behavior of polarimetric indices}

Polarimetric indices derived from active as well as passive microwave observations have proven to ease the interpretation of scenes at hand and unlock land surface information embedded within polarimetric microwave signals. Choudhury et al. (1987) and Paloscia and Pampaloni (1988) are among the first to propose the microwave polarization difference index (MPDI; or polarization index, PI) derived from $T_{b}$ measured by microwave radiometers as follows,

$$
\text { MPDI }=\frac{T_{b}^{\mathrm{V}}-T_{b}^{\mathrm{h}}}{0.5\left(T_{b}^{\mathrm{V}}+T_{b}^{\mathrm{h}}\right)}
$$

where superscripts $\mathrm{v}$ and $\mathrm{h}$ stand for the vertical or horizontal polarized brightness temperature, respectively.

Kim and van Zyl (2000) introduced the radar vegetation index (RVI) deduced from polarimetric $\sigma^{0}$ measurements,

$$
\mathrm{RVI}=\frac{8 \sigma_{\mathrm{hv}}^{0}}{\sigma_{\mathrm{hh}}^{0}+\sigma_{\mathrm{vv}}^{0}+2 \sigma_{\mathrm{hv}}^{0}}
$$

where $\sigma_{\mathrm{hh}}^{0}, \sigma_{\mathrm{vv}}^{0}$ and $\sigma_{\mathrm{hv}}^{0}$ stand for the $\mathrm{HH}, \mathrm{VV}$, and $\mathrm{HV}$ polarized $\sigma^{0}$, respectively. The RVI varies from 0 to 1 , whereby values approaching unity increasingly represent the scattering behavior of a slab with randomly oriented thin cylinders.

The behavior of both RVI and MPDI derived with Aquarius observations acquired over the Maqu area is discussed below. In addition, the $\tau$ - $\omega$ concept is employed to reconstruct the MPDI with input of the measured soil moisture to estimate the vegetation effects (e.g. optical depth, $\tau$ ) on the L-band emissivity. This is subsequently related to the RVI and Normalized Difference Vegetation 


\section{Sensitivity of Aquarius observations over soil moisture in Maqu network}

Index (NDVI) taken from the Moderate Resolution Imaging Spectrometer (MODIS) MOD13Q1 product.

\subsubsection{Radar Vegetation Index}

Kim and Van Zyl $(2004,2009)$ have utilized the RVI as part of the soil moisture retrieval process from radar observations to distinguish critical biomass levels whereby RVI $<0.2$ is considered as sparse vegetation and RVI $>0.35$ is associated with significant vegetation biomass (e.g. vegetation water content, $W$ $>2.5 \mathrm{~kg} \mathrm{~m}^{-2}$ for corn). More recently, Kim et al. $(2012,2014)$ studied the RVI for its potential to quantify the $W$ of agricultural crops and McColl et al. (2014) investigated using Aquarius data the impact of inherent uncertainties following from noise and calibration errors on the RVI as a potential operational global product from SMAP. In support of this increased interest, Fig.3.5 shows time series of RVI derived from the Aquarius $\sigma^{0}$ observed from the three incidence angles along with the MODIS NDVI on the secondary axis.

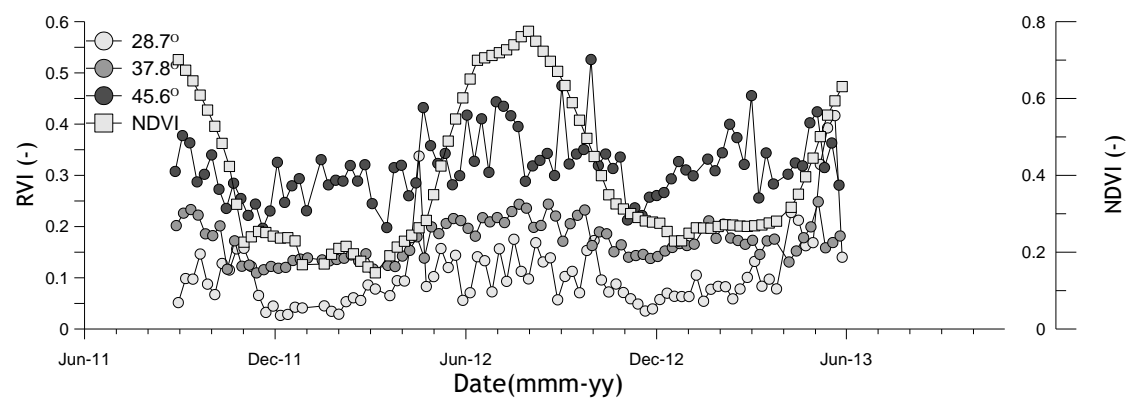

Fig. 3.5 Time series of the RVI derived from quad-polarized Aquarius $\sigma^{0}$ collected over the Maqu area at incidence angles of $28.7^{\circ}, 37.8^{\circ}$ and $45.6^{\circ}$ from August 2011 up to May 2013 with the MODIS NDVI plotted on the secondary y-axis.

The RVI time series deduced from the Aquarius observations display at all three incidence angles a seasonal cycle that is in phase with the NDVI, which demonstrates the potential use of RVI for quantifying vegetation biomass. The RVI derived from all three beams increases, on average, from the instant that the NDVI increases in early March and decreases from August. As a means of quantifying the relationship between RVI and NDVI a linear equation of the 
Chapter 3

form $R V I=\boldsymbol{a} N D V I+\boldsymbol{b}$ is fitted through the matchups, of which Table 3.3 provides the regression coefficients (e.g. $\boldsymbol{a}$ and $\boldsymbol{b}$ ) and coefficient of determination $\left(R^{2}\right)$. Additionally, Fig.3.5 illustrates that the RVI typically increases with the incidence angle indicating that, as expected, vegetation has the largest impact on the observed $\sigma^{0}$ at a $45.6^{\circ}$ angle with the RVI varying from 0.2 to more than 0.35 . The latter is representative for significant vegetation (Kim and Van Zyl 2009). On the other hand, both the $28.7^{\circ}$ and $37.8^{\circ} \mathrm{RVI}$ hardly exceeds 0.2 , which suggests that vegetation in Maqu has little impact on those radar measurements.

Table 3.3. Regression coefficients ( $\boldsymbol{a}$ and $\boldsymbol{b})$ and coefficient of determination $\left(R^{2}\right)$ following from fitting a linear equation of the form $R V I=\boldsymbol{a} N D V I+\boldsymbol{b}$ through matchups.

\begin{tabular}{|c|c|c|c|}
\hline Angle (degree) & $\boldsymbol{a}$ & $\boldsymbol{b}$ & $R^{2}$ \\
\hline $28.7^{\circ}$ & 0.121 & 0.059 & 0.101 \\
\hline $37.8^{\circ}$ & 0.149 & 0.113 & 0.603 \\
\hline $45.6^{\circ}$ & 0.145 & 0.261 & 0.184 \\
\hline
\end{tabular}

The rather noisy behavior of RVI should also be noted in particular for the $28.7^{\circ}$ and $45.6^{\circ}$ incidence angle, whereas the $37.8^{\circ}$ values exhibit a more robust behavior. This is clearly reflected in the magnitude of the $R^{2}$ listed in Table 3.3, which with 0.603 appreciable for $37.8^{\circ}$ data but with 0.101 and 0.184 rather low for the $28.7^{\circ}$ and $45.6^{\circ}$, respectively. The susceptibility of the RVI, in general, for noise and calibration errors has previously been addressed by McColl et al (2014). They conclude that due to its additive nature imperfections in the calibration of the cross polarized $\sigma^{0}$ have a large impact on the RVI. Indeed, Fig.3.1 shows that the day-to-day variability embedded within the $28.7^{\circ}$ and $45.6^{\circ} \sigma_{\mathrm{hv}}^{0}$ time series is somewhat larger than within the $37.8^{\circ} \sigma_{\mathrm{hv}}^{0}$. This could be caused by inherent different noise levels for Aquarius observations acquired from descending and ascending orbits over the study area either due to its view geometry or its overpass time.

\subsubsection{Microwave Polarization Difference Index}

The MPDI derived from high frequency microwave observations is primarily determined by the overlaying vegetation biomass (e.g. Choudhury et al. 1987, Wen and Su 2004, Wen et al. 2005). At lower frequencies, however, the MPDI decreases with decreasing soil moisture and increasing vegetation (e.g. Saleh et 


\section{Sensitivity of Aquarius observations over soil moisture in Maqu network}

al. 2006). Hence, popular retrieval algorithms (e.g. Owe et al. 2001, Paloscia et al. 2001) make use of this property to parameterize vegetation corrections and estimate the soil moisture content.

Instead of presenting the MPDI as the ratio of $\mathrm{H}$ and $\mathrm{V}$ polarize $T_{b}$ 's, the emissivity can also be used for its formulation as,

$$
\text { MPDI }=\frac{e^{\mathrm{v}}-e^{\mathrm{h}}}{0.5\left(e^{\mathrm{v}}+e^{\mathrm{h}}\right)}
$$

where $e$ is emissivity. This is attractive because the $e$ of the soil-vegetation system $\left(e_{\text {veg }}\right)$ can be computed using the $\tau$ - $\omega$ concept without information on the temperature of the emitting layer assuming a thermal equilibrium exists within the medium by,

$$
e_{\text {veg }}^{\mathrm{p}}=e_{\text {soil }}^{\mathrm{p}} \gamma+\left(1+\left(1-e_{\text {soil }}^{\mathrm{p}}\right) \gamma\right)\left(1-\omega^{\mathrm{p}}\right)(1-\gamma)
$$

where $\omega(-)$ is the single scattering albedo, superscript $\mathrm{p}$ stands for the polarization that can either be $\mathrm{H}$ or $\mathrm{V}, \gamma$ is the transmissivity defined as $\exp (-\tau \sec \theta)$ with $\tau$ as the optical depth and with $\theta$ as the incidence angle. The bare soil emissivity $\left(e_{\text {soil }}\right)$ can be computed using the model originally proposed in Choudhury et al. (1979) given in a generalized form by,

$$
e_{\text {soil }}^{\mathrm{p}}=1-R_{0}^{\mathrm{p}} \exp \left(-k^{2} s^{2} \cos ^{N} \theta\right)
$$

where $R_{0}$ is the Fresnel or smooth surface reflectivity, $k$ is wavenumber $\left(\mathrm{cm}^{-1}\right), s$ is the standard deviation of the surface height $(\mathrm{cm})$. Typically, the factor $k^{2} s^{2}$ is represented by a single effective roughness parameter, $h_{\mathrm{r}}$, of which $N$ describes the angular dependence. The system presented by Eq. 3.4 and 3.5 includes in total four parameters, of which two define the vegetation effects (e.g. $\tau$ and $\omega$ ) and the other two account for the surface roughness effects (e.g. $h_{\mathrm{r}}$ and $N$ ). The surface roughness is typically assumed invariant for natural ecosystems such as the Tibetan alpine meadows of the Maqu area (e.g. Jackson et al. 1999, Van der Velde et al. 2012, O'Neill et al. 2012), while vegetation is subject to considerable changes most notably during the warm monsoon season.

We start the development of the parameterization for our study area with quantifying the surface roughness effects using the MPDI derived from 
Chapter 3

Aquarius $T_{b}$ observations collected in the second part of May. During this time of the year, the temperatures in Maqu become sufficiently high to remove all ice from the soil matrix, yet biomass remains close to its winter levels permitting us to set $\tau$ and $\omega$ equal 0.0 thereby assuming negligible vegetation effects on the Lband microwave emission. Van der Velde and Su (2009) found that for similar land conditions that vegetation in the region has only very little impact even on the lower frequency ASAR observations that are typically known to be more affected than L-band passive microwave observations. Then, the roughness parameter, $h_{\mathrm{r}}$, is estimated by minimizing the absolute difference between the Aquarius observed and model simulated MPDI using a steepest gradient method, for which data from 29 May 2012 is used for the $28.7^{\circ}$ beam and from 18 May 2013 for both $37.8^{\circ}$ and $45.6^{\circ}$ beams. Individual MPDI calculations are performed with Eq. 3.3 and 3.5 using dielectric constants computed from the soil moisture measurements in combination with available soil texture information (e.g. Su et al. 2011) and the soil dielectric mixing model by Mironov et al. (2004).

Table 3.4 lists the obtained $h_{\mathrm{r}}$ values for an assumed angular dependence factor, $N$ of 0 . It is evident that the $h_{\mathrm{r}}$ exhibits angular dependence. The purpose of the roughness estimation is, however, to further analyze the vegetation effects on the L-band emission throughout the monsoon season. Hence, the $h_{\mathrm{r}}$ values derived for each beam separately is utilized to optimally account for the roughness.

Table 3.4. Roughness parameters, $h_{\mathrm{r}}$, estimated by minimizing the MAD computed using the Aquarius observed and model simulated MPDI for three angular dependence factors.

\begin{tabular}{|c|c|}
\hline Incidence angle & $h_{\mathrm{r}}$ \\
\hline $28.7^{\circ}$ & 0.28 \\
\hline $37.8^{\circ}$ & 0.46 \\
\hline $45.6^{\circ}$ & 0.59 \\
\hline
\end{tabular}

Fig.3.6 presents time series of the MPDI derived from Aquarius observations and simulations made assuming negligible vegetation effects (e.g. both $\tau$ and $\omega$ taken as 0.0 ) for the $28.7^{\circ}$ and $45.6^{\circ}$ incidence angle. The data for beam $2,37.8^{\circ}$, is not shown here for clarity as much of it overlaps with the $45.6^{\circ}$ data. The plot illustrates that the observations and simulations match fairly well in the spring season (e.g. April, May) and at the end of the warm season starting from November. Differences can be noted in winters when soil water is typically frozen and during the warm monsoon season. In general, the simulations overestimate the observed MPDI whereby the most significant deviations occur 


\section{Sensitivity of Aquarius observations over soil moisture in Maqu network}

in the period from June to October and for the $45.6^{\circ}$ angle. A decrease in computed MPDI could be facilitated by either a decrease in the soil moisture or an increase in the vegetation effects (Saleh et al. 2006). Fig.3.6 shows, however, that soil moisture remains fairly constant at a high level. As such, the discrepancy noted between the calculated and observed MPDI should be attributed to the vegetation effects.

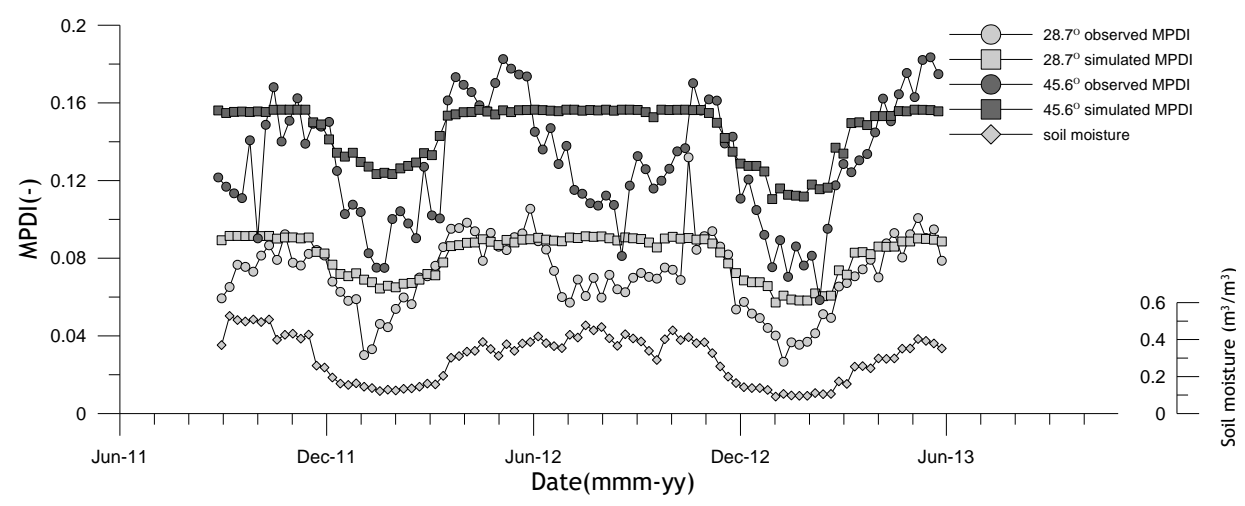

Fig. 3.6. Time series of Aquarius observed and MPDI simulated assuming negligible vegetation effects (e.g. $\tau$ and $\omega$ taken as 0.0 ) for incidence angles of $28.7^{\circ}$ and $45.6^{\circ}$. The $37.8^{\circ}$ data is excluded for clarity as it largely overlaps with the $45.6^{\circ}$ data.

The optical depth $(\tau)$ is estimated to quantify this vegetation effect, which is done by minimizing the absolute difference between the observed and simulated MPDI for each Aquarius acquisition, while assuming $\omega$ equal to 0.05 for both $\mathrm{H}$ and V polarizations in analogy with, for instance, Van de Griend et al. (1996). Fig.3.7 shows time series of the estimated $\tau$ for the three Aquarius incidence angles whereby the episode affected by soil freezing is not masked. Two peaks can be noted in the obtained $\tau$ throughout a year: i) during the winter in January/February, and ii) during the summer in July/August.

The wintertime $\tau$ estimates are surprisingly large even through the differences between observed and simulated MPDI are smaller than during the summer (see Fig. 3.6). The calculations for frozen conditions are more sensitive to soil moisture as the amount of vegetation biomass is less. As such, the uncertainties 
Chapter 3

inherent to the capacitance probe measurements below $0^{\circ} \mathrm{C}$ have a more significant impact on the $\tau$ estimates causing the larger magnitude and fluctuations. Notably, the capacitance probes are not calibrated for determining the liquid moisture condition under below $0{ }^{\circ} \mathrm{C}$ conditions and the readings may display some sensitivity to temperature as well (Robinson et al. 2008). Also, the uncertainty following from the roughness estimation procedure (e.g. 'bare soil' assumption) may propagate towards the $\tau$ estimates. However, the magnitude of $\tau$ does not become negative as would be the case if the roughness parameter, $h_{\mathrm{r}}$, was estimated from Aquarius $T_{b}$ 's on which the vegetation effect was substantial. On the other hand, a clear difference is seen among the three incidence angles, whereby the largest $\tau$ is generated using the $37.8^{\circ}$ beam data collected at early morning versus $28.7^{\circ}$ and $45.6^{\circ}$ beam data collected during the afternoon. This could suggest that the magnitude of $\tau$ is an indication for the thickness of the frozen soil layer since the sensing depth changes as function of both the dielectric constant and view angle.

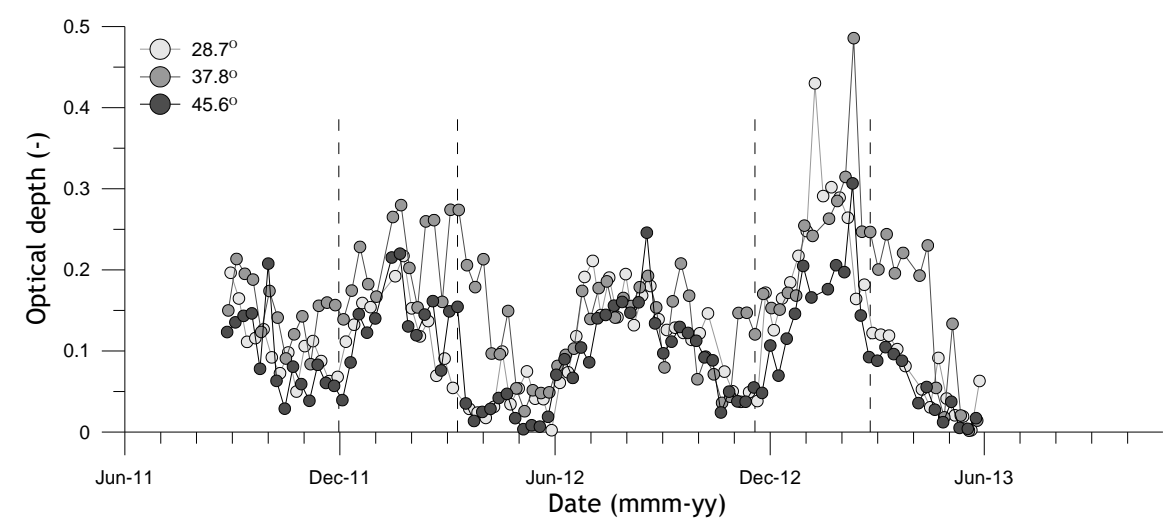

Fig.3.7. Time series of optical depth, $\tau$, estimated by the minimizing the absolute difference between the Aquarius observed and MPDI simulated using the $\tau$ - $\omega$ concept for three incidence angles (e.g. 28.7, $37.8^{\circ}$, $\left.45.6^{\circ}\right)$. The vertical dashed lines indicate when the mean daily temperature measured at a 5-cm depth is $0{ }^{\circ} \mathrm{C}$.

During the warm season, the deviations among the $\tau$ derived from Aquarius $T_{b}$ data collected at the three incidence angles dissipates demonstrating the suitability of $\tau$ as a means to define the transmissivity, $\gamma$, of vegetation. Hence, quantification of $\tau$ has always been an important component of soil moisture retrieval algorithm development (e.g. Wigneron et al. 2007). For instance, 


\section{Sensitivity of Aquarius observations over soil moisture in Maqu network}

Jackson and O'Neill (1990) were among the first to estimate $\tau$ as the product of an empirical vegetation type dependent parameter, $\mathbf{b}$, and the vegetation water content, $W$. Recognizing the difficulty in obtaining $W$ across the globe with sufficient reliability, vegetation indices deduced from readily available optical/infrared satellite products are frequently adopted as a proxy (e.g. Bindlish et al. 2003, Lawrence et al 2014). Additionally, Kim et al. (2012, 2014) studied the RVI derived from $\sigma^{0}$ measured with a ground-based scatterometer for its potential of estimating the $W$ of agricultural crops.

Fig.3.8 presents plots of $\tau$ against the NDVI and RVI for each of the three Aquarius beams for investigating their appropriateness in quantifying the effect of Tibetan alpine meadows on L-band emission. Data points are only shown of the $\tau$ estimates from Aquarius $T_{b}$ observed during days for which temperature measured at $5 \mathrm{~cm}$ remained above freezing point. In addition, Table 3.5 provides regression coefficients and $R^{2}$ values belonging to a linear equation of the form $\tau=\boldsymbol{a} R V I$ (or NDVI) $+\boldsymbol{b}$ fitted through the matchups.

Table 3.5. Regression coefficients ( $\boldsymbol{a}$ and $\boldsymbol{b}$ ) and coefficients of determination $\left(R^{2}\right)$ following form fitting a linear equation of the form $\tau=\boldsymbol{a} R V I($ or $N D V I)+\boldsymbol{b}$ through the matchups.

\begin{tabular}{|c|c|c|c|c|}
\hline \multirow{4}{*}{ RVI } & $\begin{array}{c}\text { Angle } \\
\text { (degrees) }\end{array}$ & $\boldsymbol{a}$ & $\boldsymbol{b}$ & $R^{2}$ \\
\cline { 2 - 5 } & $28.7^{\circ}$ & -0.035 & 0.110 & 0.001 \\
\cline { 2 - 5 } & $37.8^{\circ}$ & 0.873 & -0.056 & 0.226 \\
\hline \multirow{3}{*}{ NDVI } & $45.6^{\circ}$ & 0.178 & 0.023 & 0.037 \\
\cline { 2 - 5 } & $28.7^{\circ}$ & 0.201 & -0.002 & 0.405 \\
\cline { 2 - 5 } & $37.8^{\circ}$ & 0.176 & 0.019 & 0.230 \\
\hline
\end{tabular}

In general, both the table and the plots illustrate that a clear relationship exists between the $\tau$ and NDVI. The obtained $\mathrm{R}^{2}$ varying from 0.230 to 0.405 are in agreement with results recently presented in Lawrence et al. (2014) who compared the SMOS $\tau$ product with a variety of MODIS derived vegetation indices for a major agricultural area in the United State of America. It should, however, be noted that the spread among the $\tau$-NDVI matchups is quite considerable. 
Chapter 3

The relationship of $\tau$ with the RVI is less noticeable. Potentially the strongest dependence between $\tau$ and RVI is found for an incidence angle of $45.6^{\circ}$ although the scatter among data points is fairly large due to the day-to-day variability embedded within the RVI time series (see Fig.3.5). At an incidence of $28.7^{\circ}$ this dependence is virtually absent as a result of a rather small dynamic range in combination with an appreciable short-term RVI variability. On the other hand, the scatter plot of $\tau$ versus RVI derived from the $37.8^{\circ} \sigma^{0}$ observations demonstrates their agreement once the short-term variability is low in spite of the fact that the dynamic range. Hence, $\tau$ estimation using the RVI is only feasible if the signal is sufficiently stable over time.
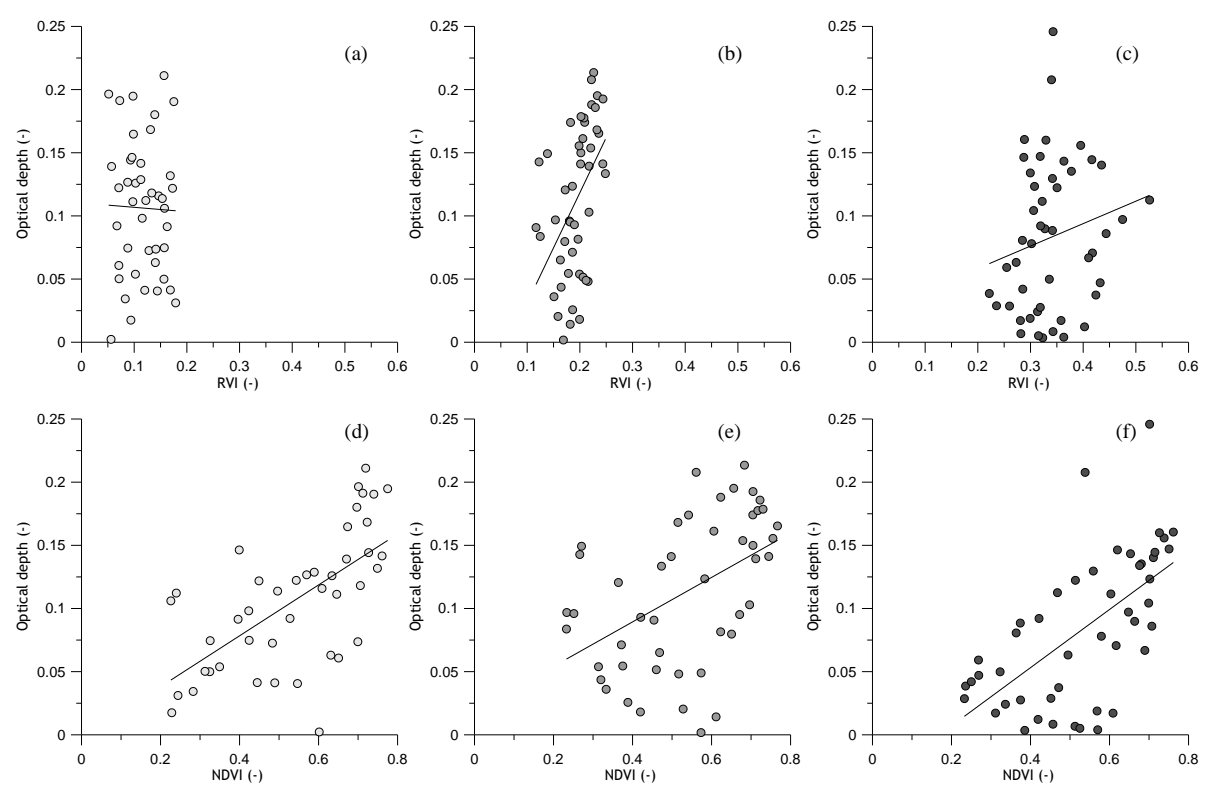

Fig.3.8. NDVI and RVI plotted against the $\tau$ estimated using the $\tau$ - $\omega$ concept from Aquarius MDPI observed from three incidence angles, whereby a) \& d) present the results for $28.7^{\circ}$, b) \& e) for $37.8^{\circ}$ and c) \& f) for $45.6^{\circ}$. 


\section{Sensitivity of Aquarius observations over soil moisture in Maqu network}

\subsection{Summary and Conclusions}

Aquarius scatterometer and radiometer measurements collected in the period from August 2011 to May 2013 are studied for the Maqu area on the northeastern part of the Tibetan Plateau, which is selected as one of the candidate international Cal/Val sites for NASA's Soil Moisture Active Passive (SMAP) mission. The impact of freeze-thaw, soil moisture and vegetation on Lband backscatter and emission is investigated using in-situ soil moisture and temperature measurements as well as the polarimetric information embedded within the Aquarius data. The $\tau$ - $\omega$ concept (Mo et al. 1982) is employed to reproduce the Microwave Polarization Difference Index (MPDI) derived from Aquarius $T_{b}$ 's and quantify the vegetation optical depth $(\tau)$, which is subsequently linked with the Radar Vegetation Index (RVI) and Normalized Difference Vegetation Index (NDVI).

The analysis of the Aquarius scatterometer/radiometer data reveals very distinctive seasonal dynamics of both backscatter $\left(\sigma^{0}\right)$ and brightness temperature $\left(T_{b}\right)$ measurements. The lowest $\sigma^{0}$ measurements are recorded in the winter season as the transformation from water to ice lowers the dielectric constant to the level of dry soil. Similarly, the passive microwave measurements converted to emissivity $(e)$ by dividing the $T_{b}$ with temperature measured at 5 $\mathrm{cm}$ soil depth attain during wintertime values (high) representative for dry conditions. The comparisons of the $\sigma^{0}$ and $e$ versus soil moisture recorded with capacitance probes installed at a $5-\mathrm{cm}$ soil depth (e.g. a direct measurement of the dielectric) illustrate that even for temperatures below $0{ }^{\circ} \mathrm{C}$ the L-band microwave observations are sensitive to the amount of liquid water within the soil matrix. This highlights once again that freeze-thaw is not an 'on/off' process and more importantly that the liquid water content for temperatures below freezing point can potentially be quantified using L-band active and/or passive microwave observations. Under wet conditions both the $\sigma^{0}$ and $e$ saturates starting from soil moisture contents of about $0.3 \mathrm{~m}^{3} \mathrm{~m}^{-3}$. This is in line with simulations performed with theoretical models in the past.

In an attempt to quantify the vegetation effects on the $\sigma^{0}$, the temporal behavior of RVI is analyzed with respect to the NDVI. In general, the seasonal dynamics of the two vegetation indices are in phase with each other demonstrating the potential of RVI for quantifying vegetation biomass. On the other hand, it is noted that the magnitude of RVI hardly exceeds 0.2 for the Aquarius $\sigma^{0}$ 


\section{Chapter 3}

observed at angles of $28.7^{\circ}$ and $37.8^{\circ}$, and is only in several occasions above 0.4 for the $45.6^{\circ} \sigma^{0}$. This suggests that vegetation has a limited impact on the scatterometer measurements over the Maqu area, which negatively affects the signal-to-noise ratio. The latter is also compromised by the additive nature of calibration errors inherent to the cross polarized $\sigma^{0}$ propagating towards the RVI.

In addition, the MPDI constructed with Aquarius $T_{b}$ measurements is reproduced by estimating the $\tau$ as part of a $\tau$ - $\omega$ modelling frame whereby soil moisture measurements are utilized to define the dielectric constant. Further the roughness parameter is estimated using Aquarius $T_{b}$ 's measured under nonfrozen soil and optically-thin vegetation conditions. The time series of the $\tau$ estimates include for all three Aquarius angles $\left(28.7^{\circ}, 37.8^{\circ}\right.$ and $\left.45.6^{\circ}\right)$ peaks in the months January/February and in July/August. The wintertime $\tau$ is remarkable larger than the summer values, which may follow from uncertainties in the calibration of the capacitance probe measurements as well as the roughness estimation procedure. On the other hand, the results could also indicate that the magnitude of $\tau$ is a measure for the frost depth when temperatures are below $0{ }^{\circ} \mathrm{C}$.

In the warm season, the behavior of $\tau$ is in line with the vegetation dynamics and positive agreements are found with the NDVI although the spread is quite considerable. Also, the relationship with the RVI is studied, which is due to its small dynamic range and the short-term RVI variability barely noticeable. On the other hand, the RVI derived from the Aquarius $37.8^{\circ}$ observations demonstrates the potential agreement with $\tau$ if the day-to-day RVI fluctuations are small. Hence, the possibility of defining the $\tau$ using the RVI needs to be further investigated using data collected over study areas with a larger dynamic range and also using additional 'noise' suppression techniques. 
Sensitivity of Aquarius observations over soil moisture in Maqu network 


\section{Chapter 4 Use of a discrete electromagnetic model for simulating Aquarius L-band active/passive observations and soil moisture retrieval ${ }^{*}$}

\subsection{Introduction}

The combination of active and passive L-band observations is recognized as a viable approach for reliable soil moisture estimation at high resolution across the globe (e.g. Entekhabi et al., 2004). Passive microwave sensors or radiometers enable, through brightness temperature $\left(T_{b}\right)$ measurement, quantification of the effective land surface emissivity (hereafter referred to as emissivity for brevity), which is the complement of the reflectivity that can be calculated by integrating the bistatic scattering coefficients as formulated in Peake (1959). Active microwave sensors or radars measure the scattering coefficient in the backward direction also known as the backscattering coefficients $\left(\sigma^{0}\right)$. The launch of the Aquarius/Satellite de Aplicaciones Cientificas (SAC)-D and the Soil Moisture Active/Passive (SMAP) missions, in 2011 and 2015 respectively, marked the start of the worldwide measurement of concurrent L-band $T_{b}$ and $\sigma^{0}$.

Several initiatives were undertaken to deliver operational global soil moisture products from the observations collected by both satellite missions at various spatial scales (e.g. Entekhabi et al., 2010; Bindlish et al., 2015). The SMAP mission (of which radar failed on 7 July 2015) was intended to specifically accommodate the use of both active and passive responses for operational soil moisture estimation at an intermediate $9-\mathrm{km}$ resolution. This was to be accomplished through statistical downscaling of the coarse resolution (36-km) $T_{b}$, supported by the fine resolution (3-km) $\sigma^{0}$, after which soil moisture was estimated at the target resolution using a similar approach to the one used for

\footnotetext{
* This chapter is based on Wang, Q., van der Velde.,R., and Su, Z. (2018) Use of a discrete electromagnetic model for simulating Aquarius L-band active/passive observations and soil moisture retrieval. Remote Sensing of Environment, 205, 434-452. DOI:10.1016/j.rse.2017.10.044
} 


\section{Use of a discrete electromagnetic model for simulating Aquarius $\mathbf{L}$ - band active/passive observations and soil moisture retrieval}

the radiometer-only product (Das et al., 2014). The procedure selected for the combined active/passive product has evolved from an earlier version (Das et al., 2011) based on change detection, which stems from developments based on airborne field campaign and synthetically generated data sets (Njoku et al., 2002; Narayan et al., 2006; Piles et al., 2009). A very similar approach was recently applied to satellite observations (van der Velde et al., 2015) and a review on the current state of spatial downscaling remotely sensed soil moisture has been documented in Peng et al. (2017).

On the other hand, developments aimed at a more physical interpretation of the concurrent active and passive L-band microwave responses are also ongoing. For instance, for vegetation monitoring purposes, Colliander and Xu (2013) introduced the normalized residual scattering index (NRSI), as measure for the directionality of scattering obtained by evaluating $\sigma^{0}$ with respect to reflectivity derived from $T_{b}$ measurements. Guerriero et al. (2012) used the Tor Vergata University of Rome discrete electromagnetic model (TV-DEM) to assess the $\sigma^{0}$ - $T_{b}$ relationship. They were able to confirm that the ratio of $\sigma^{0}$ over reflectivity was sensitive to vegetation biomass and relatively unaffected by soil moisture.

Indeed, Ferrazzoli et al. (1989), Chauhan et al. (1994) and Saatchi et al. (1994) had previously recognized that discrete electromagnetic models are powerful tools for interpreting active and passive microwave observations, an important step in optimizing soil moisture retrieval algorithms. At present, confidence in the performance of discrete electromagnetic models is such that they form an integral part of the Level-2 radiometer-only or radar-only processors used in soil moisture satellites. The Soil Moisture and Ocean Salinity (SMOS) retrieval algorithm, for instance, uses radiative transfer parameters simulated by the TVDEM to correct for the effect of forest emissions (Rahmoune et al., 2013). Furthermore, the experimental SMAP radar-only soil moisture product is based on searching a data cube or look up table built using forward model simulations (Kim et al., 2014). In their work, the discrete electromagnetic model based on the distorted Born approximation is used to compensate for the effects of vegetation (Lang and Sidhu, 1983).

However, the use of discrete electromagnetic models for satellite missions, in the context of combined active/passive soil moisture retrieval, is still under development. One of the first studies in this domain was by Dente et al. (2014). They used observations over the Maqu study area in the north-eastern part of the Tibetan Plateau made with the C-band Metop Advanced Scatterometer 


\section{Chapter 4}

(ASCAT) and the Advanced Microwave Scanning Radiometer (AMSR-E) on the Earth Observing system. By using both active and passive microwave data, they concluded that litter in the Maqu study area has an important absorbing effect leading to an increase in the $T_{b}$ and a decrease in the $\sigma^{0}$ observed by the two individual satellites. As such, the evaluation TV-DEM simulations with respect to combined active and passive microwave satellite observations led to a better understanding of emission and scattering processes.

The Aquarius instrument had been accumulating a record of concurrent L-band active and passive measurements for a period of 3 years and 8 months when the SAC-D platform failed on 7 June 2015. In this investigation, we have applied the TV-DEM to the available Aquarius active and passive data collected over the Maqu study area with the following three objectives:

(i) To analyze the model's ability in reproducing concurrent L-band active and passive measurements from a single platform;

(ii) To better understand the scattering and emission processes observed by Aquarius instruments;

(iii) To demonstrate soil moisture retrieval from both active and passive microwave data using an algorithm based on a single radiative transfer model (e.g. TV-DEM).

The key scientific literature in relation to these objectives is summarized in Table 4.1. In this manuscript, TV-DEM's sensitivity to its extensive parameterization of the soil-vegetation system is evaluated. These results are used to select the most critical parameters for calibration using data from the warm seasons of 2012 and 2013. The calibrated TV-DEM is subsequently deployed for soil moisture retrieval from three combinations of the Aquarius active and passive data from the 2014 and 2015 warm seasons. The performance of these retrievals is assessed through comparisons with in-situ measurements. In addition, the performance of the TV-DEM estimates is evaluated with respect to that of the soil moisture obtained with three algorithms based on application of the commonly used $\tau$ (optical depth) - $\omega$ (single scattering albedo) model, including the official Aquarius product. Further, uncertainties resulting from simplification of the TV-DEM application are quantified. 
Use of a discrete electromagnetic model for simulating Aquarius $L$ band active/passive observations and soil moisture retrieval

Table 4.1 List of cited scientific literature and summary of the key findings in relation to the objectives of the present investigation; the number (i), (ii), (iii) refer to the objectives defined in the introduction

\begin{tabular}{|c|c|c|c|c|}
\hline Literature & Data & $\begin{array}{l}\text { Model and/or } \\
\text { method }\end{array}$ & Study area & Key findings \\
\hline $\begin{array}{l}\text { 1. Bindlish } \\
\text { et al. (2015) }\end{array}$ & - Aquarius $T_{b}$ & $\begin{array}{l}\text { - } \tau \text { - } \omega \text { model } \\
\text { implemented as } \\
\text { single channel } \\
\text { algorithm (SCA) }\end{array}$ & $\begin{array}{l}\text { - Globally } \\
\text { applied } \\
\text { - Validated for } \\
\text { USA soil } \\
\text { moisture } \\
\text { networks }\end{array}$ & $\begin{array}{l}\text { i. not applicable } \\
\text { ii. Reliability SCA } \\
\text { retrievals are not } \\
\text { compromised by varying } \\
\text { incidence angles; } \\
\text { iii. error metrics for soil } \\
\text { moisture retrievals are: } \\
\mathrm{RMSE}=0.031 \mathrm{~m}^{3} \mathrm{~m}^{-3}, \mathrm{R} \\
=0.855 \text { and bias }=- \\
0.007 \mathrm{~m}^{3} \mathrm{~m}^{-3}\end{array}$ \\
\hline $\begin{array}{l}\text { 2. Chauhan } \\
\text { et al. (1994) }\end{array}$ & $\begin{array}{l}\text { - Airborne } \\
\text { Synthetic } \\
\text { Aperture Radar } \\
\text { (AIRSAR) } \sigma^{\circ} \\
\text { - Aircraft } \\
\text { mounted } \\
\text { Pushbroom } \\
\text { Microwave } \\
\text { Radiometer } \\
\text { (PBMR) } T_{b}\end{array}$ & $\begin{array}{l}\text { - Distorted born } \\
\text { approximation } \\
\text { based discrete } \\
\text { electromagnetic } \\
\text { model (DEM, Lang } \\
\text { and Sidhu 1983) }\end{array}$ & $\begin{array}{l}\text { Corn field in } \\
\text { Pennsylvania, } \\
\text { USA }\end{array}$ & $\begin{array}{l}\text { i. Selected DEM is able } \\
\text { to predict both } \sigma^{\text {o }} \text { and } T_{b} \\
\text { using a single set of } \\
\text { measured vegetation } \\
\text { ii. a) Coherent 'direct- } \\
\text { reflected's scattering } \\
\text { component is an } \\
\text { important contribution. } \\
\text { b) Stalks of corn plants } \\
\text { are crucial for the } \\
\text { AIRSAR observed } \\
\text { polarization difference. } \\
\text { iii. not applicable }\end{array}$ \\
\hline $\begin{array}{l}\text { Colliander } \\
\& \mathrm{Xu} \\
(2013)\end{array}$ & $\begin{array}{l}\text { - Passive Active } \\
\text { L- and S-band } \\
\text { (PALS) airborne } \\
\text { sensor data sets } \\
\text { across the USA } \\
\text { from } 1999 \text { and } \\
2008 \\
\text { - Aquarius } T_{b} \text { and } \\
\sigma^{0}\end{array}$ & $\begin{array}{l}\text { - Normalized } \\
\text { Residual Scattering } \\
\text { Index (NRSI) }\end{array}$ & $\begin{array}{l}\text { - Field campaign } \\
\text { study areas } \\
\text { across the USA } \\
\text { for PALS data } \\
\text { - Globally } \\
\text { applied on } \\
\text { Aquarius data }\end{array}$ & $\begin{array}{l}\text { i. not applicable } \\
\text { ii. NRSI, derived from a } \\
\text { combination of active } \\
\text { and passive data, is } \\
\text { sensitive to land cover } \\
\text { features while being } \\
\text { unaffected by soil } \\
\text { moisture changes } \\
\text { iii. not applicable }\end{array}$ \\
\hline 4. Das et al. & - PALS data set & - Statistical & - Corn and & i. not applicable \\
\hline
\end{tabular}


Chapter 4

\begin{tabular}{|c|c|c|c|c|}
\hline (2011) & $\begin{array}{l}\text { from the Soil } \\
\text { Moisture } \\
\text { Experiments } \\
2002 \text { (SMEX02) } \\
\text { - Observation } \\
\text { System } \\
\text { Simulation } \\
\text { Experiment } \\
\text { (OSSE) data }\end{array}$ & $\begin{array}{l}\text { downscaling of soil } \\
\text { moisture retrieved } \\
\text { using the } \tau \text { - } \omega \text { model } \\
\text { based SCA and fine } \\
\text { resolution } \sigma^{\circ}\end{array}$ & $\begin{array}{l}\text { soybean fields in } \\
\text { Iowa (USA) for } \\
\text { SMEX02 PALS } \\
\text { data } \\
\text { - Red Arkansas } \\
\text { river basin for } \\
\text { the OSSE data }\end{array}$ & $\begin{array}{l}\text { ii. not applicable } \\
\text { iii. Addition of radar } \\
\text { data improves the RMSE } \\
\text { of soil moisture } \\
\text { retrievals by } 0.015-0.02 \\
\mathrm{~m}^{3} \mathrm{~m}^{-3} \text { w.r.t. minimum } \\
\text { performance }\end{array}$ \\
\hline $\begin{array}{l}\text { 5. Das et al. } \\
\text { (2014) }\end{array}$ & $\begin{array}{l}\text { - PALS data from } \\
\text { the SMEX02 } \\
\text { - Global-scale } \\
\text { simulation } \\
\text { (GloSim) for the } \\
\text { SMAP mission }\end{array}$ & $\begin{array}{l}\text { - Statistical } \\
\text { downscaling of } T_{b} \\
\text { using fine } \\
\text { resolution } \sigma^{\circ} \text { for } \\
\text { which soil moisture } \\
\text { retrieved with the } \tau \text { - } \\
\omega \text { model based } \\
\text { SCA }\end{array}$ & $\begin{array}{l}\text { - Corn and } \\
\text { soybean fields in } \\
\text { Iowa (USA) for } \\
\text { SMEX02 PALS } \\
\text { data } \\
\text { - Globally } \\
\text { applied on } \\
\text { GloSim data }\end{array}$ & $\begin{array}{l}\text { i. not applicable } \\
\text { ii. not applicable } \\
\text { iii. Radar data has the } \\
\text { ability to resolve sub- } \\
\text { grid } T_{b} \text { heterogeneity and } \\
\text { assist in obtaining a } \\
\text { RMSE of } 0.033 \mathrm{~m}^{3} \mathrm{~m}^{-3} \\
\text { for soil moisture } \\
\text { retrievals. }\end{array}$ \\
\hline $\begin{array}{l}\text { 6. Dente et } \\
\text { al. }(2014)\end{array}$ & $\begin{array}{l}\text { - Metop } \\
\text { Advanced } \\
\text { Scatterometer } \\
\text { (ASCAT) } \sigma^{\circ} \\
\text { - Advanced } \\
\text { Microwave } \\
\text { Scanning } \\
\text { Radiometer } \\
\text { (AMSR-E) } T_{b}\end{array}$ & $\begin{array}{l}\text { - Matrix doubling } \\
\text { based DEM, herein } \\
\text { referred to as TV- } \\
\text { DEM }\end{array}$ & $\begin{array}{l}\text { - Alpine } \\
\text { meadows in } \\
\text { Maqu (Tibetan } \\
\text { Plateau) }\end{array}$ & $\begin{array}{l}\text { i. TV-DEM is able to } \\
\text { reproduce C-band } \sigma^{\circ} \text { and } \\
T_{b} \text { observed from the } \\
\text { two separate satellites. } \\
\text { ii. Litter is found } \\
\text { important for } \\
\text { quantifying microwave } \\
\text { emission. } \\
\text { iii. not applicable }\end{array}$ \\
\hline $\begin{array}{l}7 . \\
\text { Ferrazzoli } \\
\text { et al. (1989) }\end{array}$ & $\begin{array}{l}\text { - Airborne X- } \\
\text { band SAR } \sigma^{0} \text { and } \\
\text { radiometer } T_{b}\end{array}$ & $\begin{array}{l}\text { - Matrix doubling } \\
\text { based DEM similar } \\
\text { to the TV-DEM }\end{array}$ & $\begin{array}{l}\text { - Oltrepò Pavese, } \\
\text { Italy }\end{array}$ & $\begin{array}{l}\text { i. not applicable } \\
\text { ii. Non-isotropic } \\
\text { scattering behavior of } \\
\text { land surface causes the } \\
\text { non-unique relationship } \\
\text { between } \sigma^{\circ} \text { and } \\
\text { emissivity }(e) \text {, which } \\
\text { depend on vegetation } \\
\text { type and biomass. } \\
\text { iii. not applicable }\end{array}$ \\
\hline $\begin{array}{l}\text { 8. Guerriero } \\
\text { et al. (2012) }\end{array}$ & $\begin{array}{l}\text { - Phased Array L- } \\
\text { band Synthetic } \\
\text { Aperture Radar }\end{array}$ & - TV-DEM & $\begin{array}{l}\text { - Central Africa } \\
\text { (dense forest), } \\
\text { South Central }\end{array}$ & $\begin{array}{l}\text { i. TV-DEM model } \\
\text { simulations confirm the } \\
\sigma^{\text {o}}-e \text { relationship }\end{array}$ \\
\hline
\end{tabular}


Use of a discrete electromagnetic model for simulating Aquarius $L$ band active/passive observations and soil moisture retrieval

\begin{tabular}{|c|c|c|c|c|}
\hline & $\begin{array}{l}\left(\text { PALSAR) } \sigma^{\circ}\right. \\
\text { - Soil Moisture } \\
\text { and Ocean } \\
\text { Salinity (SMOS) } \\
T_{b}\end{array}$ & & $\begin{array}{l}\text { Africa (sparse } \\
\text { forest), Sahara } \\
\text { (desert) and } \\
\text { Pampas } \\
\text { (agriculture, } \\
\text { Argentina) }\end{array}$ & $\begin{array}{l}\text { observed across a broad } \\
\text { range of vegetation } \\
\text { densities. } \\
\text { ii. not applicable } \\
\text { iii. not applicable }\end{array}$ \\
\hline $\begin{array}{l}\text { 9. Kim et al. } \\
\text { (2014) }\end{array}$ & $\begin{array}{l}\text { - Aircraft and } \\
\text { truck mounted L- } \\
\text { band radar } \sigma^{\circ} \\
\text { - Aquarius } \sigma^{\circ}\end{array}$ & $\begin{array}{l}\text { - Numerical } \\
\text { Maxwell model in } \\
\text { three-dimensions } \\
\text { for bare soil } \\
\text { - Distorted born } \\
\text { approximation } \\
\text { based DEM for } \\
\text { vegetation covered } \\
\text { land }\end{array}$ & $\begin{array}{l}\text { - Field campaign } \\
\text { study areas } \\
\text { across the USA } \\
\text { for the aircraft } \\
\text { and truck } \\
\text { mounted radar } \\
\text { data sets } \\
\text { - Globally } \\
\text { applied on } \\
\text { Aquarius data }\end{array}$ & $\begin{array}{l}\text { i. Simulations performed } \\
\text { with physically based } \\
\text { scattering models that } \\
\text { make use of simplified } \\
\text { land surface } \\
\text { parameterizations } \\
\text { resemble } \sigma^{\text {o }} \\
\text { measurements } \\
\text { reasonably well } \\
\text { ii. not applicable } \\
\text { iii. A prototype retrieval } \\
\text { algorithm based on } \\
\text { output of physically } \\
\text { based scattering models } \\
\text { is tested and presented } \\
\text { for application to global } \\
\text { Soil Moisture } \\
\text { Active/Passive (SMAP) } \\
\sigma^{\circ} \text { data }\end{array}$ \\
\hline $\begin{array}{l}\text { 10. Lang \& } \\
\text { Sidhu } \\
\text { (1983) }\end{array}$ & $\begin{array}{l}\text { - L-band } 1.8 \mathrm{GHz} \\
\text { ground based } \\
\text { radar } \sigma^{\circ}\end{array}$ & $\begin{array}{l}\text { - Distorted born } \\
\text { approximation } \\
\text { based DEM }\end{array}$ & - Soybean field & $\begin{array}{l}\text { i. A good match is found } \\
\text { between model } \\
\text { simulation and } \sigma^{\circ} \\
\text { measurements after } \\
\text { adjusting model } \\
\text { parameters } \\
\text { ii. Soil scattering is the } \\
\text { dominant term when } \\
\text { vegetation can be } \\
\text { considered as a weakly } \\
\text { scattering medium } \\
\text { iii. not applicable }\end{array}$ \\
\hline $\begin{array}{l}\text { 11. Narayan } \\
\text { et al. (2006) }\end{array}$ & $\begin{array}{l}\text { - PALS and } \\
\text { AIRSAR data } \\
\text { from the }\end{array}$ & $\begin{array}{l}\text { - Change detection } \\
\text { whereby vegetation } \\
\text { effects on the } \sigma^{\circ}\end{array}$ & $\begin{array}{l}\text { - Corn and } \\
\text { soybean fields in } \\
\text { Iowa (USA) }\end{array}$ & 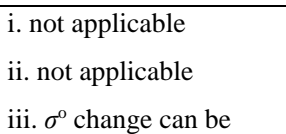 \\
\hline
\end{tabular}


Chapter 4

\begin{tabular}{|c|c|c|c|c|}
\hline & SMEX02 & $\begin{array}{l}\text { sensitivity to soil } \\
\text { moisture is } \\
\text { accounted for using } \\
\text { the optical depth, } \tau\end{array}$ & & $\begin{array}{l}\text { related to the soil } \\
\text { moisture change at the } \\
\text { sub footprint scale of the } \\
\text { PALS radiometer }\end{array}$ \\
\hline $\begin{array}{l}\text { 12. Njoku et } \\
\text { al. (2002) }\end{array}$ & $\begin{array}{l}\text { - PALS data from } \\
\text { the SGP99 } \\
\text { experiment }\end{array}$ & $\begin{array}{l}\text { - Retrieval concepts } \\
\text { based on changes in } \\
T_{b} \text { and } \sigma^{\circ}\end{array}$ & $\begin{array}{l}\text { - Pastures, bare } \\
\text { and corn field in } \\
\text { Oklahoma (USA) }\end{array}$ & $\begin{array}{l}\text { i. not applicable } \\
\text { ii. Both active and } \\
\text { passive microwave data } \\
\text { display a sensitivity to } \\
\text { soil moisture even over } \\
\text { dense vegetation } \\
\text { iii. not considered }\end{array}$ \\
\hline $\begin{array}{l}\text { 13. Piles et } \\
\text { al. (2009) }\end{array}$ & $\begin{array}{l}\text { - PALS data from } \\
\text { the SMEX02 } \\
\text { - OSSE data }\end{array}$ & $\begin{array}{l}\text { - Retrieval } \\
\text { algorithm } \\
\text { quantifying soil } \\
\text { moisture changes } \\
\text { within radiometer } \\
\text { footprints using } \sigma^{\circ} \\
\text { changes }\end{array}$ & $\begin{array}{l}\text { - Corn and } \\
\text { soybean fields in } \\
\text { Iowa (USA) for } \\
\text { SMEX02 PALS } \\
\text { data } \\
\text { - Red Arkansas } \\
\text { river basin for } \\
\text { the OSSE data }\end{array}$ & $\begin{array}{l}\text { i. not applicable } \\
\text { ii. not applicable } \\
\text { iii. Algorithm for } \\
\text { retrieving soil moisture } \\
\text { at high resolution from } \\
\text { active and passive } \\
\text { microwave data }\end{array}$ \\
\hline $\begin{array}{l}14 . \\
\text { Rahmoune } \\
\text { et al. (2013) }\end{array}$ & $\begin{array}{l}\text { - Soil Moisture } \\
\text { and Ocean } \\
\text { Salinity (SMOS) } \\
T_{b}\end{array}$ & $\begin{array}{l}\text { - } \tau \text { - } \omega \text { model } \\
\text { - TV-DEM }\end{array}$ & $\begin{array}{l}\text { - Forest across } \\
\text { the globe }\end{array}$ & $\begin{array}{l}\text { i. not applicable } \\
\text { ii. not applicable } \\
\text { iii. TV-DEM output is } \\
\text { used to quantify forest } \tau \\
\text { and } \omega \text { for global soil } \\
\text { moisture retrieval }\end{array}$ \\
\hline $\begin{array}{l}\text { 15. Saatchi } \\
\text { et al. (1994) }\end{array}$ & $\begin{array}{l}\text { - Truck mounted } \\
\text { C-band } \\
\text { scatterometer } \sigma^{\circ} \\
\text { - Aircraft } \\
\text { mounted } \\
\text { Pushbroom } \\
\text { Microwave } \\
\text { Radiometer } \\
\text { (PBMR) } T_{b}\end{array}$ & $\begin{array}{l}\text { - Distorted born } \\
\text { approximation } \\
\text { based DEM (Lang } \\
\text { and Sidhu 1983) }\end{array}$ & $\begin{array}{l}\text { - Konza prairie } \\
\text { (grass canopies) } \\
\text { in Kansas (USA) }\end{array}$ & $\begin{array}{l}\text { i. Selected DEM is able } \\
\text { to predict both } \sigma^{\circ} \text { and } T_{b} \\
\text { measured from different } \\
\text { platforms (respectively } \\
\text { aircraft and truck) } \\
\text { ii. Thatch or litter causes } \\
\text { grass canopies to appear } \\
\text { warm from the passive } \\
\text { microwave perspective } \\
\text { and reduces the } \sigma^{\circ} \\
\text { measured by active } \\
\text { sensors } \\
\text { iii. not applicable }\end{array}$ \\
\hline $\begin{array}{l}\text { 16. van der } \\
\text { Velde et al. }\end{array}$ & $\begin{array}{l}\text { - PALSAR } \sigma^{\circ} \\
\text { - VUA-NASA }\end{array}$ & $\begin{array}{l}\text { - Statistical } \\
\text { downscaling of soil }\end{array}$ & $\begin{array}{l}\text { - Pastures and } \\
\text { corn fields in }\end{array}$ & $\begin{array}{l}\text { i. not applicable } \\
\text { ii. not applicable }\end{array}$ \\
\hline
\end{tabular}


Use of a discrete electromagnetic model for simulating Aquarius Lband active/passive observations and soil moisture retrieval

\begin{tabular}{|c|c|c|c|c|}
\hline (2015) & $\begin{array}{l}\text { AMSR-E soil } \\
\text { moisture products }\end{array}$ & $\begin{array}{l}\text { moisture retrieved } \\
\text { following a similar } \\
\text { approach as } \\
\text { described in Das et } \\
\text { al. ( } 2011\end{array}$ & $\begin{array}{l}\text { Twente (The } \\
\text { Netherlands) }\end{array}$ & $\begin{array}{l}\text { iii. Soil moisture maps } \\
\text { obtained by downscaling } \\
\text { the coarse resolution } \\
\text { passive microwave data } \\
\text { capture hydrological and } \\
\text { hydrometeorological } \\
\text { information. }\end{array}$ \\
\hline $\begin{array}{l}\text { 17. This } \\
\text { study }\end{array}$ & $\begin{array}{l}\text { - Aquarius } T_{b} \text { and } \\
\sigma^{\mathrm{o}}\end{array}$ & - TV-DEM & $\begin{array}{l}\text { - Alpine } \\
\text { meadows in } \\
\text { Maqu (Tibetan } \\
\text { Plateau) }\end{array}$ & $\begin{array}{l}\text { i. TV-DEM is able to } \\
\text { reproduce L-band } \sigma^{\circ} \text { and } \\
T_{b} \text { observed by Aquarius } \\
\text { with reasonable accuracy } \\
\text { ii Soil and litter } \\
\text { contributions dominate } \\
\text { for L-band land surface } \\
\text { emissivity } \\
\text { iii. Soil moisture } \\
\text { retrieved from } \\
\text { active/passive data using } \\
\text { the TV-DEM is better } \\
\text { than retrievals from } \\
\text { passive data alone }\end{array}$ \\
\hline
\end{tabular}

\subsection{Methods}

\subsubsection{Tor Vergata-Discrete electromagnetic model}

The discrete electromagnetic model developed at the Tor Vergata University of Rome (TV-DEM) represents vegetation as a medium of discrete scatterers and soil as a rough dielectric surface for simulating the bistatic scattering coefficients in all directions following the radiative transfer theory (Bracaglia et al., 1995), which include three main components as expressed by:

$\sigma^{0}\left(\theta, \varphi ; \theta_{s}, \varphi_{s}\right)=\sigma_{v}^{0}\left(\theta, \varphi ; \theta_{s}, \varphi_{s}\right)+\sigma_{s v}^{0}\left(\theta, \varphi ; \theta_{s}, \varphi_{s}\right)+\sigma_{s}^{0}\left(\theta, \varphi ; \theta_{s}, \varphi_{s}\right)$

where $\sigma^{0}\left(\theta, \varphi ; \theta_{s}, \varphi_{s}\right)$ stands for the total bistatic scattering coefficient calculated for an arbitrary zenith and azimuth angle of the incident signal ( $\theta$ and $\varphi$, respectively) and of the scattered signal $\left(\theta_{\mathrm{s}}\right.$ and $\varphi_{\mathrm{s}}$, respectively); subscripts $v$, 


\section{Chapter 4}

$s v$, and $s$ indicate the scattering contributions coming from i) vegetation directly, ii) soil-vegetation pathways and iii) soil surface, respectively. Note that the polarization dependence is suppressed here for brevity.

The scattering coefficient in the backward direction, viz. backscattering coefficient, is obtained for the case that $\left(\theta_{\mathrm{s}}, \varphi_{\mathrm{s}}\right)$ equals $(\theta, \varphi)$. Calculation of the emissivity follows from integration of all bistatic scattering coefficients across the hemisphere that yields the reflectivity. The assumption of thermal equilibrium across the soil-vegetation system and application of energy conservation implies that the absorption must be equal to the emission (Saatchi et al. 1994). Hence, the emissivity can be calculated as the complement of the reflectivity according to:

$$
e_{p}(\theta, \varphi)=1-\frac{1}{4 \pi \cos \theta} \int_{\Omega s} \sigma_{p p}^{0}\left(\theta, \varphi ; \theta_{s}, \varphi_{s}\right)+\sigma_{p q}^{0}\left(\theta, \varphi ; \theta_{s}, \varphi_{s}\right) d \Omega_{s}
$$

where subscript $p$ indicates the polarization orthogonal to the polarization represented by subscript $q$ and $d \Omega_{\mathrm{s}}=\sin \theta_{\mathrm{s}} \mathrm{d} \theta_{\mathrm{s}} \mathrm{d} \varphi_{\mathrm{s}}$.

The TV-DEM handles the morphology of a canopy by treating stems and branches as cylinders and leaves as discs. The Rayleigh-Gans approximation (Eom and Fung, 1984; Osborn, 1945) is used to represent the electromagnetic behavior of discs and cylinders at frequencies lower than $5.0 \mathrm{GHz}$. The Integral Equation Method (IEM, Fung et al., 1992) is adopted for calculating the bistatic scattering coefficients from a rough dielectric surface. A module is included to represent litter as a layer consisting of a mixture of air and dielectric material representing fallen vegetation, for which an effective permittivity is obtained by matching the reflectivities calculated with a coherent multiple-reflection model and the Fresnel formulas for a homogeneous 'equivalent' medium (Della Vecchia et al. 2007). The permittivity of vegetation is computed using Mätzler's (1994) model, while the mixing model developed by Mironov et al. (2009) is used to calculate the soil permittivity. With the definition of the geometry and permittivity for each element, the scattering and extinction coefficients of the individual scatterers within the vegetation canopy can be calculated. The matrix doubling algorithm (e.g. Eom and Fung, 1984) is employed to combine the individual contributions across all vegetation-soil pathways, including multiple scattering. Additional information on the active and passive TV-DEM versions 
Use of a discrete electromagnetic model for simulating Aquarius Lband active/passive observations and soil moisture retrieval

is available in Bracaglia et al. (1995) and Ferrazzoli and Guerriero (1996), respectively.

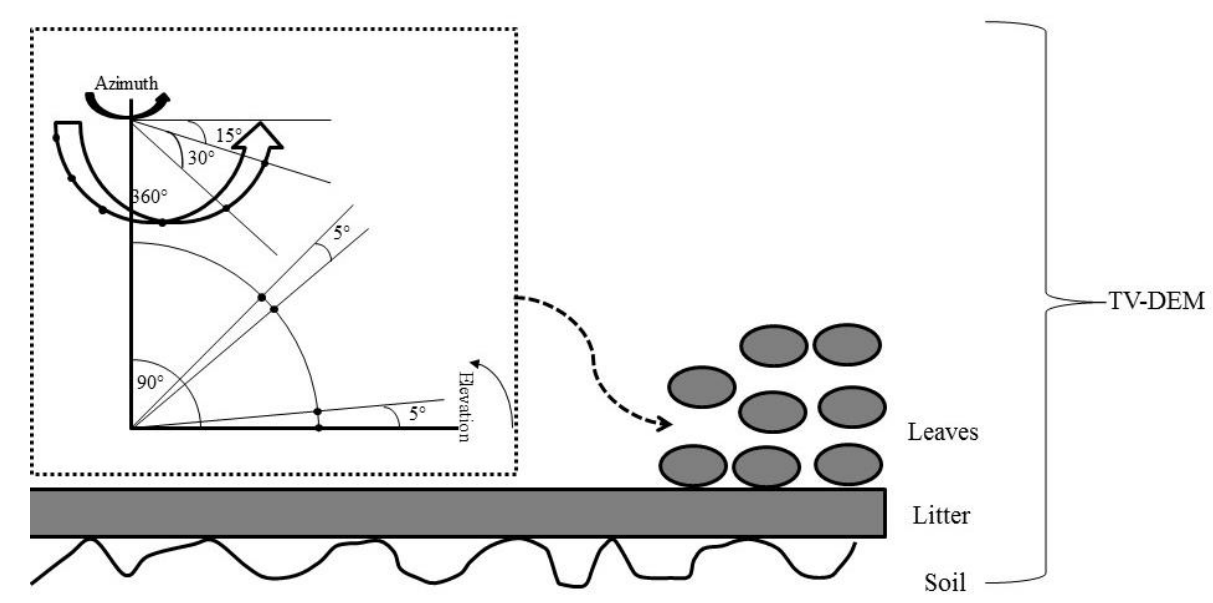

Fig. 4.1. Schematization of the morphology selected for the TV-DEM setup for the Maqu study area.

\subsubsection{Application to Maqu}

The dominant land cover in the study region consists of alpine meadows with a soil litter layer that is several centimeters thick. The soil-vegetation system is, therefore, assumed to consist only of foliage that can be represented as leaves, on top of a rough soil surface covered by litter, as previously described in Dente et al. (2014) and illustrated in Fig.4.1. The parameterization of the morphology largely follows the same rationale as the setup presented in Dente et al. (2014).

The leaves are represented as a collection of thin dielectric discs of fixed radius, uniformly distributed across the upper hemisphere. This is accomplished by positioning the elements representing the green vegetation from $5^{\circ}$ to $90^{\circ}$ in the elevation plane and from $15^{\circ}$ to $345^{\circ}$ in the azimuth plane at intervals of $5^{\circ}$ and $30^{\circ}$, respectively. The number of discs included in the canopy is calculated from the MODIS LAI product (see section 2.5.2), by dividing the area of an individual disc as determined from its radius. The plant moisture content (needed to determine permittivity of the vegetation), disc radius and thickness are unknowns of the TV-DEM's vegetation component for the Maqu study area. Surface roughness must be parameterized to facilitate simulation of the surface scattering component. To this end, data on the standard deviation of height variations $(s)$, autocorrelation length $(l)$ and autocorrelation length function 


\section{Chapter 4}

(ACF) is required. The $l$ is set to a fixed value, as previous studies (i.e. Altese et al., 1996; Joseph et al., 2010; van der Velde, 2010) demonstrated that it is less sensitive than $s$. An exponential function was selected for the ACF because this is considered to be best suited to natural land covers (i.e. van der Velde et al. 2012).

The soil litter layer is represented as a mixture of air and dielectric material. The effective permittivity of this homogeneous half-space is obtained by matching the reflectivities calculated by a coherent multiple-reflection model and the Fresnel formulas for a homogeneous 'equivalent' medium as described in Della Vecchia et al. (2007). An empirical linear relationship, found by Grant et al. (2007) and modified by Dente et al. (2014) for grassland, is adopted to define the litter thickness as function of its biomass, which is assumed to be $0.07 \mathrm{~g} \mathrm{~cm}$ ${ }^{2}$. Furthermore, the amount of litter moisture is linearly related to the soil moisture content; an assumption that also follows from the in-situ measurements presented in Grant et al. (2007) and has been applied in this context by Della Vecchia et al. (2007) for forest and Dente et al. (2014) for Maqu alpine meadows.

Uncertainties introduced by assumptions regarding the parameterization of the surface roughness are assessed in sections 4.4.1. An overview of all parameters needed to operate TV-DEM is provided in Table 4.2. In addition, the manner in which each parameter is treated (e.g. known/available/assumed/calibrated and constant/variable), its data source, and its value/initial estimate is given as well. The choice for calibrating certain parameters is motivated by using the sensitivity analysis presented in Section 4.3.1.

Table 4.2 List of input parameters needed to operate the TV-DEM using the setup selected for the Maqu area

\begin{tabular}{|c|c|c|c|c|}
\hline \multirow{2}{*}{ Parameter } & \multicolumn{2}{|c|}{ Data source } & Type & Value/(Initial) Estimate \\
\hline \multirow{2}{*}{ Frequency } & $\begin{array}{c}\text { Satellite } \\
\text { configuration }\end{array}$ & known & constant & $1.26 \mathrm{GHz}$ scatterometer \\
\hline View angle & $\begin{array}{c}\text { Satellite } \\
\text { configuration }\end{array}$ & known & constant & \\
\end{tabular}


Use of a discrete electromagnetic model for simulating Aquarius $L$ band active/passive observations and soil moisture retrieval

\begin{tabular}{|c|c|c|c|c|}
\hline Soil moisture & Measurements & available & variable & $\begin{array}{c}\text { spatial mean of } \text { in-situ } \\
\text { measurements collected at } 12 \\
\text { sites }\end{array}$ \\
\hline Soil texture & Measurements & available & variable & $\begin{array}{c}\text { spatial mean of } \text { in-situ } \\
\text { measurements collected at } 12 \\
\text { sites }\end{array}$ \\
\hline LAI & MODIS product & available & variable & $\mathrm{n} / \mathrm{a}$ \\
\hline $\begin{array}{c}\text { Standard } \\
\text { deviation of } \\
\text { height variations }\end{array}$ & Dente14 & calibrated & constant & $0.90 \mathrm{~cm}$ \\
\hline $\begin{array}{l}\text { Autocorrelation } \\
\text { length }\end{array}$ & Dente14 & assumed & constant & $9 \mathrm{~cm}$ \\
\hline $\begin{array}{l}\text { Autocorrelation } \\
\text { function }\end{array}$ & Dente14 & assumed & constant & Exponential function \\
\hline $\begin{array}{l}\text { Litter moisture } \\
\text { factor }\end{array}$ & Dente14. & calibrated & constant & 2.0 \\
\hline Litter biomass & Dente14 & calibrated & constant & $0.07 \mathrm{~g} \mathrm{~cm}^{-2}$ \\
\hline Disc radius & Dente14. & assumed & constant & $1.4 \mathrm{~cm}$ \\
\hline Disc thickness & Dente14. & assumed & constant & $0.02 \mathrm{~cm}$ \\
\hline $\begin{array}{l}\text { Disc angular } \\
\text { distribution }\end{array}$ & Dente14 & assumed & constant & Uniform \\
\hline Plant moisture & Dente14. & calibrated & constant & $0.80 \mathrm{~kg} \mathrm{~kg}^{-1}$ \\
\hline
\end{tabular}


Chapter 4

\begin{tabular}{|l|l|l|l|l|}
\hline content & & & & \\
\hline
\end{tabular}

\subsubsection{Automated calibration}

Automated calibration of selected model parameters is performed using the Parameter Estimation (PEST) software package (Doherty, 2004) that has often been used for similar purposes in land surface hydrology (e.g. Goegebeur and Pauwels, 2007; Immerzeel and Droogers, 2008; van der Velde et al., 2009). PEST can operate, by writing and reading model input and output files via supplied templates, as a shell around any model that can be run from a command line. Optimum model parameters are found by minimizing an objective function $(\phi)$ taken as the sum of weighted squared differences between observations and simulations. A Gauss-Levenberg-Marquardt (GLM) algorithm (Skahill and Doherty 2006) is utilized to direct parameter changes within and across iterations as a function of the partial derivatives of $\phi$ with respect to the parameter space. The PEST implementation of the GLM algorithm makes use of a forward difference scheme to determine the partial derivatives at the start of the calibration process and switches to a central difference scheme when improvements in $\phi$ drop below a user-defined threshold. Here, the default configuration is adopted and the other PEST settings needed for the GLM algorithm can be found along with further information in Doherty (2004) and Gallagher and Doherty (2007).

The objective function $(\phi)$ when PEST is applied to the TV-DEM with input of the active and passive Aquarius observations reads:

$$
\phi(\mathbf{b})=\sum_{i} \sum_{p}\left[w_{p}\left(\sigma_{p p, m}^{0}(i, \mathbf{b})-\sigma_{p p, 0}^{0}(i)\right)^{2}+v_{p}\left(e_{p, m}(i, \mathbf{b})-e_{p, 0}(i)\right)^{2}\right]
$$


Use of a discrete electromagnetic model for simulating Aquarius Lband active/passive observations and soil moisture retrieval

where $\mathbf{b}$ stands for the vector of calibrated parameters, $w$ and $v$ represent weights assigned to the $\sigma^{0}$ and $e$, respectively, $p$ represents the polarization dependence, $i$ stands for an individual model simulation or satellite observation, respectively, and subscripts $o$ and $m$ indicate that the variable follows from an observation or model simulation, respectively. The $e_{\mathrm{p}, \mathrm{o}}$ is derived from the $T_{b}$ measured by the Aquarius radiometer according to,

$$
e_{p}=\frac{T_{b}^{p}}{T_{e f f}}
$$

where $T_{\text {eff }}$ is the effective temperature of emitting layer $(\mathrm{K})$, which is obtained through application of the approach reported in Lv et al. (2014) with input of soil moisture and temperature measured at depths of $5 \mathrm{~cm}$ and $80 \mathrm{~cm}$.

Specific weights can be assigned to $\sigma_{p p}^{0}$ and $e_{\mathrm{p}}$, which would certainly be needed when $\sigma_{p p}^{o}$ expressed in $\mathrm{dB}$ would be part of $\phi$, because its statistical moments differ inherently from $e_{\mathrm{p}}$. However, the standard deviation of $\sigma_{p p}^{o}$ expressed in linear units is remarkably similar to that of $e_{\mathrm{p}}$ for the warm seasons of the available Aquarius data sets, namely 0.038, 0.036, 0.030, and 0.036 for $\sigma_{h h}^{0}, \sigma_{v v}^{0}, e_{h}$, and $e_{v}$, respectively. This would lead to comparable weights for the respective $\sigma_{p p}^{0}$ and $e_{\mathrm{p}}$ sets. Hence, we have chosen to assign equal weights for the matchup sets, and include in $\phi$ the $\sigma_{p p}^{0}$ expressed in linear units.

\subsection{Results}

\subsubsection{Parameter sensitivity}

A sensitivity analysis is performed for the unknown constant parameters, viz. labelled 'available/assumed/calibrated' and 'constant' in Table 4.2, of the TVDEM setup described above (Section 4.2.2) with exception of the autocorrelation length function and the disc angular distribution. The aim of this exercise is to gain insight into their impact on the TV-DEM $e$ and $\sigma^{0}$ simulations, and support for choosing to calibrate certain parameters. The analysis is based on varying each of the unknown constant parameters individually across the range of $-50 \%$ and $+50 \%$ of its reference value listed in Table 3 with an interval of $10 \%$ for all except the plant water content. A range of 0.40 to $0.90 \mathrm{~kg} \mathrm{~kg}^{-1}$ with a $0.05 \mathrm{~kg} \mathrm{~kg}^{-1}$ interval is used for the plant water 


\section{Chapter 4}

content. Note that all other parameters are kept as reference, with values are optimized for Maqu by Dente et al. (2014) using C-band active (ASCAT) and passive (AMSR-E) microwave observations. The reason for choosing multiplicative factors to vary the parameters is that the optimized set of values reported in Dente et al. (2014) is already expected to provide already a reasonable initial guess. In other words, the sensitivity of the TV-DEM for a set of parameters is determined locally one-at-a-time (Göhler et al. 2013). This set is more objectively quantified when each parameter is varied by equal multiplicative factor, rather than along an arbitrary range specified for each parameter.

The mean ratio of the TV-DEM simulation results obtained with a perturbed parameter set over the results achieved with the reference parameter set $\left(\mu_{\text {ratio }}\right)$ is used to assess the sensitivity of the calculated $e$ and $\sigma^{0}$ for a specific parameter, and can be expressed as,

$$
\mu_{\text {ratio }}=\frac{1}{n} \sum_{i} \frac{Y_{i}}{Y_{\text {ref }}}
$$

where $Y$ represents either the TV-DEM $e$ or $\sigma^{0}$ simulation, $n$ is the total number of samples, and subscript ref indicates the reference simulation. The $\mu_{\text {ratio }}$ is determined using the TV-DEM simulations performed with measured soil moisture and MODIS LAI data for the instances Aquarius passed over Maqu during the warm seasons of 2012 and 2013. A warm season is here defined as the period when the temperature of the top $5 \mathrm{~cm}$ of soil is above freezing point $\left(0{ }^{\circ} \mathrm{C}\right)$.

Figs.4.2 and 4.3 present the $\mu_{\text {ratio }}$ as function of the parameter change and plant water content, respectively, for $\mathrm{H}$ (a) and $\mathrm{V}$ (b) polarized $e$, and $\mathrm{HH}$ (c) and $\mathrm{VV}$ (d) polarized $\sigma^{0}$ computed by the TV-DEM. In general, the plots illustrate that variations of $-50 \%$ and $+50 \%$ in the magnitude of the constant parameters result on average in a maximum deviation of about $5 \%$ from the reference simulated $e$. The litter moisture factor and litter biomass relatively have the largest impact on the computed $e$, while the average effect of both the surface roughness (e.g. $s$ and $l$ ) and disc (e.g. radius and thickness) parameters is less than $2 \%$. The influence of the plant moisture content is also inferior to that of litter.

Figs.4.2c, $4.2 \mathrm{~d}$ and 4.3 show that overall sensitivities of the simulated $\sigma^{0}$ for the constant parameters are larger than in the passive case and dominated by the $s$. 


\section{Use of a discrete electromagnetic model for simulating Aquarius $\mathbf{L}$ - band active/passive observations and soil moisture retrieval}

For instance, a change of $-50 \%$ in the $s$, on average reduces the computed $\sigma^{0}$ almost four times and a $+50 \%$ perturbation results in a twofold increase. The sensitivity found for litter (moisture and biomass) is appreciable with a maximum average difference of about $20 \%$ from the reference, which is comparable to that of the $l$ roughness parameter. The $\sigma^{0}$ simulations are clearly less sensitive to plant moisture content and disc parameters.

The effect of litter on the $e$ and $\sigma^{0}$ simulations, found here, is as described in the scientific literature; it induces $e$ and reduces $\sigma^{0}$ for optically thin layers (Saatchi et al., 1994), and vice versa for optically thick layers (Tsang et al., 1977). The increase in litter biomass essentially implicates that the thickness of the layer increases, while the optical density remains identical. On the other hand, an increase in the litter moisture factor causes an increase in the optical density for the same litter layer thickness. The effect of this physical change in the morphology is that the $e$ increases and $\sigma^{0}$ decreases almost linearly as function of litter biomass, whereas for an increase in litter moisture results in an $e$ increase and $\sigma^{0}$ decrease at first. This trend then levels off, to be followed by the opposite effect; an $e$ decrease and $\sigma^{0}$ decrease. The latter phenomenon is also referred to as scatter darkening (i.e. Tsang et al., 1977).

Moreover, the low sensitivity of both the active and passive TV-DEM for the evaluated vegetation parameters may be caused by the wavelength $(\sim 21.2 \mathrm{~cm}$ radiometer and $23.8 \mathrm{~cm}$ scatterometer) at L-band being much larger than the dimensions of the scatterers of the setup selected for the Maqu study area. This does, however, not implicate that L-band microwave signals are unaffected by vegetation; notably, the vegetation water content (VWC), expressed in $\mathrm{kg} \mathrm{m}^{-2}$, is used in many retrieval algorithms to correct for the effects of vegetation (i.e. Jackson et al., 1999). The TV-DEM uses the plant moisture content, expressed in $\mathrm{kg} \mathrm{kg}^{-1}$, to define the permittivity of the scatterers representing vegetation, following Mätzler (1994), while the density of the scatterers is parameterized via LAI. As such, the combination of the permittivity (e.g. plant moisture content) and density of the scatterers (e.g. LAI) should be recognized as a proxy for the VWC. It should, however, be noted that the low sensitivity for the vegetation parameters presented here is the result of numerical experiments. Evaluations based on detailed field measurements are needed to verify these findings, however this extends beyond the scope of this investigation.

The sensitivity of the TV-DEM for the surface roughness parameters is also somewhat expected. Notably, the effect on the simulations is limited in the 


\section{Chapter 4}

passive case and utterly dominant in the active case, especially for $s$. The control of the surface roughness effects on $\sigma^{0}$ is widely recognized as important source of uncertainty that hampers the development of readily available soil moisture products from high resolution Synthetic Aperture Radar (SAR) $\sigma^{0}$ datasets (e.g. Verhoest et al., 2008, Kornelsen and Coulibaly, 2013). Surface roughness influences passive microwaves signals much less, which clearly reduces the ambiguities in soil moisture retrieval from such datasets.

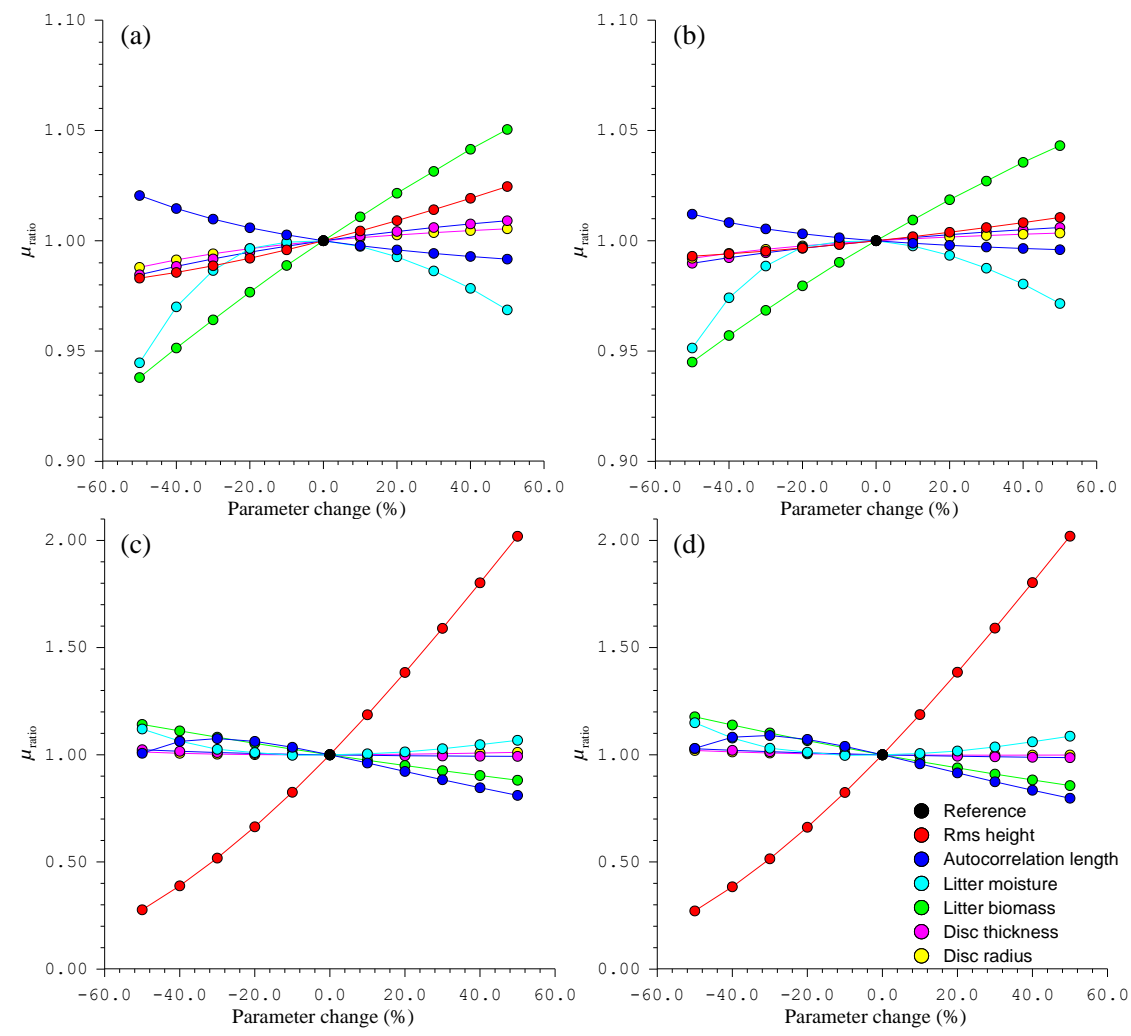

Fig. 4.2 Mean ratio of TV-DEM simulation results obtained with a perturbed parameter set over the simulation results achieved with the reference parameter set as functions of the parameter change. a) $\mathrm{H}$-pol emissivity, b) V-pol emissivity, c) HH-pol backscatter and d) VV-pol backscatter. 
Use of a discrete electromagnetic model for simulating Aquarius Lband active/passive observations and soil moisture retrieval

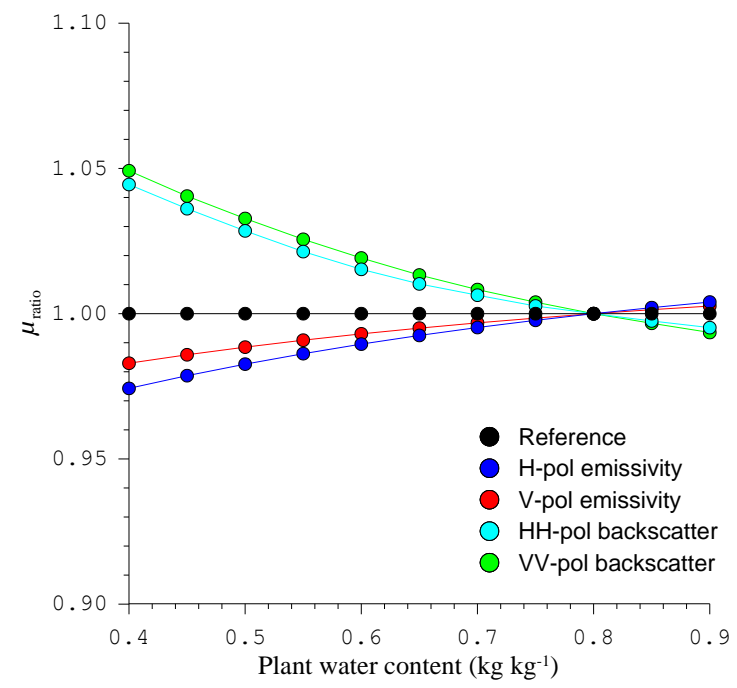

Fig. 4.3. Same as Fig. 4.2 except as function of plant water content.

\subsubsection{Calibration and validation}

Supported by the results from the sensitivity analysis, we have chosen to optimize four TV-DEM parameters, namely $s$, litter moisture factor, litter biomass and plant moisture content. The values reported in Table 4.2 are utilized for the other parameters. Arguably, the sensitivity of the TV-DEM for $l$ would also opt for its calibration. However, this enlarges the parameter space posing additional challenges on obtaining a unique solution for the optimization problem. Moreover, van der Velde (2010) showed that the two roughness parameters, $s$ and $l$, are highly correlated in the context of IEM simulations, viz. effects of a change in $s$ on surface scattering calculations can be countered by a proportional change in $l$, which further complicates the search for a unique solution in a steepest gradient setting. On the other hand, the latter also implies that imperfections in the selected value for $l$ can be accounted for in the calibrated value of $s$. For these reasons, $l$ has not been included in the optimization process and an 'effective' surface roughness parameterization has been derived; an approach, which has been taken previously (e.g. Su et al., 1997; Joseph et al., 2010; van der Velde et al., 2012).

In the PEST optimization process, the Aquarius $T_{b}$ and $\sigma^{0}$ datasets collected during the warm seasons of 2012 and 2013, i.e. with a top 5-cm soil temperature $>0{ }^{\circ} \mathrm{C}$, serve as the observations ( 252 \# in total) in $\phi$, Eq. 4.3 , whereby $T_{\text {eff }}$ 60 
Chapter 4

determined using Eq. 4.4 is adopted to derive the $e$ from the Aquarius $T b$. The simulations follow from TV-DEM runs, setup similarly to the ones presented in the sensitivity analysis, with soil moisture measurements and MODIS LAI as model input. The complete optimization process is performed several times with different initial values, randomly picked from the preselected parameter range, to avoid local minima. Table 4.3 lists the TV-DEM parameters selected for optimization, their initial values, lower and upper limits, as well as the calibrated values. In obtaining the final calibrated parameters PEST reached convergence after 5 of the maximum 30 iterations with a $\phi$, sum of squared differences, of 0.9649 (-).

Table 4.3 PEST optimized values, as well as initial, lower and upper limits adopted for the PEST setup designed for calibrating selected TV-DEM parameters using Aquarius active and passive L-band observations collected over the Maqu study area.

\begin{tabular}{|l|c|c|c|c|}
\hline & \multicolumn{3}{|c|}{ Parameter values } \\
\hline Parameter name & $\begin{array}{c}\text { PEST } \\
\text { calibrated }\end{array}$ & Initial & Lower limit & Upper limit \\
\hline $\begin{array}{l}\text { Standard deviation of height } \\
\text { variation, } s(\mathrm{~cm})\end{array}$ & 2.67 & 1.00 & 0.30 & 3.50 \\
\hline Litter moisture factor (-) & 1.06 & 1.40 & 0.80 & 2.00 \\
\hline Litter biomass $\left(\mathrm{g} \mathrm{cm}^{-2}\right)$ & 0.03 & 0.10 & 0.01 & 0.20 \\
\hline Plant moisture content $\left(\mathrm{kg} \mathrm{kg}^{-1}\right)$ & 0.59 & 0.60 & 0.40 & 0.90 \\
\hline
\end{tabular}

The model performance is assessed for the calibration period and an independent validation period, for which data from the warm seasons of 2014 and 2015 (30 \# Aquarius matchups) are utilized. The mean absolute difference (MAD), root mean squared difference (RMSD), Mean Difference (MD), unbiased RMSD (ubRMSD) and coefficient of determination $\left(\mathrm{R}^{2}\right)$ computed for each specific observation type are adopted as the error metrics, and expressed as:

$$
\begin{gathered}
\text { MAD }=\frac{1}{n} \sum_{i=1}^{n}\left(\left|Y_{e}^{i}-Y_{o}^{i}\right|\right) \\
\text { RMSD }=\sqrt{\frac{\sum_{i=1}^{n}\left(Y_{e}^{i}-Y_{o}^{i}\right)^{2}}{n}}
\end{gathered}
$$


Use of a discrete electromagnetic model for simulating Aquarius $L$ band active/passive observations and soil moisture retrieval

$$
\begin{aligned}
& \mathrm{MD}=\frac{1}{n} \sum_{i=1}^{n}\left(Y_{e}^{i}-Y_{o}^{i}\right) \\
& \mathrm{ubRMSD}=\sqrt{\frac{\sum_{i=1}^{n}\left(\left(Y_{e}^{i}-\mathrm{MD}\right)-Y_{o}^{i}\right)^{2}}{n}} \\
& \mathrm{R}^{2}=1-\frac{\sum_{i=1}^{n}\left(Y_{e}^{i}-\hat{Y}_{o}^{i}\right)^{2}}{\sum_{i=1}^{n}\left(Y_{o}^{i}-\overline{Y_{o}}\right)^{2}}
\end{aligned}
$$

where $Y_{e}^{i}$ represents the $\mathrm{i}^{\text {th }}$ estimated or simulated quantity $Y, Y_{o}^{i}$ represents the $\mathrm{i}^{\text {th }}$ observed or measured quantity $Y$, and $\mathrm{n}$ is the number of observations of a quantity, in this case of Aquarius $T_{b}^{\mathrm{h}}, T_{b}^{\mathrm{v}}, \sigma_{\mathrm{hh}}^{0}$ and $\sigma_{\mathrm{vv}}^{0}$.

Fig.4.4 shows time series of the Aquarius $T_{b}^{\mathrm{h}}, T_{b}^{\mathrm{v}}, \sigma_{\mathrm{hh}}^{0}$ and $\sigma_{\mathrm{vv}}^{0}$ observations and the TV-DEM simulations obtained for the calibration and validation periods and Table 4.4 presents the associated error statistics. The plots illustrate that the TV-DEM is generally capable of reproducing the seasonal dynamics of the Aquarius $T_{b}$ and $\sigma^{0}$ observations. The $T_{b}$ and $\sigma^{0}$ rise from the spring to the middle of summer and the decline towards the winter are noticeable within both Aquarius observations and TV-DEM simulations. Also, variations observed over short time scales are captured by the simulations. An excellent example of this is 20 August 2013 where the soil moisture content drops to a value below $0.20 \mathrm{~m}^{3} \mathrm{~m}^{-3}$ leading to a $T_{b}$ increase of about $20 \mathrm{~K}$ and a $\sigma^{0}$ decrease of about 3 $\mathrm{dB}$ in the observations as well as simulations. Interesting about this example as well is also that it highlights the contrasting responses of active and passive microwave observations, which is in line with the theory and thereby provides confidence in the consistency of both observations and simulations. The observed agreement between the Aquarius observations and TV-DEM simulations lead to $\mathrm{R}^{2 \text {, }}$ s of 0.75 to 0.86 and 0.36 to $0.68(-)$, and ubRMSDs of 3.81 to $5.72(\mathrm{~K})$ and 0.26 to $0.53(\mathrm{~dB})$, respectively, computed using the $T_{b}$ and $\sigma^{0}$ matchups. Such error statistics are comparable to the results previously reported for comparisons between model simulations and satellite observations (e.g. Dente et al., 2014; Montzka et al., 2013) as well as between model simulations and ground-based radiometer observations (e.g. Escorihuela et al., 2010; Pardé et al., 2004; Joseph et al., 2010).

Imperfections can also be noted in the matchups between the observations and simulations. Most notably, the $T_{\mathrm{b}}^{\mathrm{h}}$ observations are systematically overestimated, by $5.20(\mathrm{~K})$, and the $\sigma_{\mathrm{hh}}^{\mathrm{o}}$ observations are underestimated, by 
Chapter 4

$1.88(\mathrm{~dB})$, and vice versa for the vertical polarization. Topography is a possible explanation for this polarization dependent bias. Pierdicca et al. (2010) and Pulvirenti et al. (2011) are among the first to investigate the topographic effects on space borne radiometry. Based on model simulations, they concluded that topography increases $T_{\mathrm{b}}^{\mathrm{h}}$ and decreases $T_{\mathrm{b}}^{\mathrm{v}}$; in other words, it has a depolarizing effect on the microwave emission from a flat land surface. Utku and Le Vine (2014) drew similar conclusions based on model simulations and Aquarius $T_{b}$ observations, but found that topography affects $\sigma_{\mathrm{hh}}^{0}$ and $\sigma_{\mathrm{vv}}^{0}$ in an equal manner.

For Maqu, however, $\sigma_{\mathrm{hh}}^{0}$ and $\sigma_{\mathrm{vv}}^{0}$ recorded by Aquarius display a remarkable resemblance (with differences typically being less than $0.1 \mathrm{~dB}$ ) indicating that an external factor has a depolarizing influence on the observations. As topography has been shown to have an impact on land surface emission, this may also be the case for microwave scattering from land since the two quantities are physically connected. The clear distinction between the $\sigma^{0}$ observations and simulations in Fig 4.4 suggests that, for Maqu, the depolarizing effect is more profound on L-band scattering than on emission. The large temporal variability in the $T_{b}$ somewhat influences this perception, but a detailed investigation is beyond the scope of this research. In section 4.4.3, we do elaborate on the impact of the depolarization on the calibration results.

In support of further analyses, Fig.4.5 presents mean monthly differences between simulations and observations, whereby the error bars stand for the standard deviation. The plots show that the mean errors fluctuate across the months March to October quite considerably with respect to observed temporal variability, namely $8.5(\mathrm{~K})$ and $0.93(\mathrm{~dB})$ on average for $T_{b}$ and $\sigma^{0}$, respectively. Yet, the differences in the errors obtained for the horizontal and vertical polarizations remain fairly constant, implicating persistence of the polarization imbalance.

Fig.4.5 also shows that the standard deviation in the error varies by month with the largest spread found around the season transitions (e.g. March, April and October) and the least difference seen in the summer months, with the exception of July. The variability in errors seen during the season transitions may be attributed to a spatially variable freeze-thaw state within the Aquarius footprints. Although only observations have been selected during which the measured top $5-\mathrm{cm}$ soil temperature is above freezing point, the soil temperature and thus the freeze-thaw state may vary spatially due to topography or spatially 
Use of a discrete electromagnetic model for simulating Aquarius $\mathbf{L}$ band active/passive observations and soil moisture retrieval

varying atmospheric forcings (e.g. air temperature, wind and solar radiation). This leads to an uncertain and, most likely, a smaller soil dielectric constant than used for the TV-DEM simulations, which will result typically in a larger $T_{b}$ and lower $\sigma^{0}$ as is seen in Fig.4.4 for March 2013. This source of uncertainty does not play a role during the summer months. Instead the large volume of monsoon rains may cause inundations, which are accounted for in the TV-DEM and may enlarge the spread in errors as noted in Fig.4.5 for July. 


\section{Chapter 4}
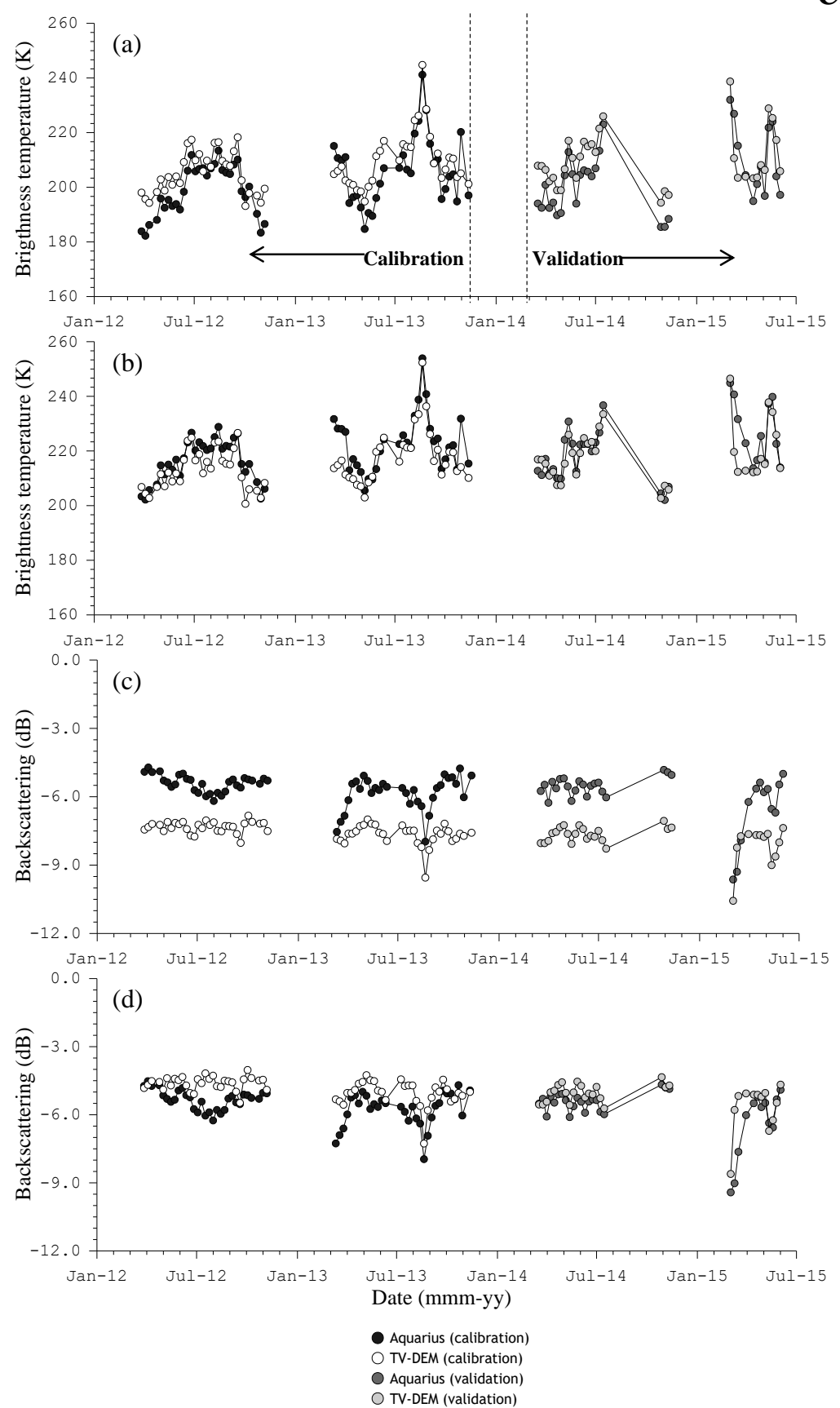

Fig. 4.4. Aquarius observations and TV-DEM simulations obtained for the calibration (2012 and 2013 warm seasons) and validation (2014 and 2015 warm seasons) periods; a) $\mathrm{H}$ polarized $T_{b}$, b) V polarized $T_{b}, \mathrm{c}$ ) $\mathrm{HH}$ polarized $\sigma^{0}$ and d) $\mathrm{VV}$ polarized $\sigma^{0}$ 
Use of a discrete electromagnetic model for simulating Aquarius $\mathbf{L}$ band active/passive observations and soil moisture retrieval
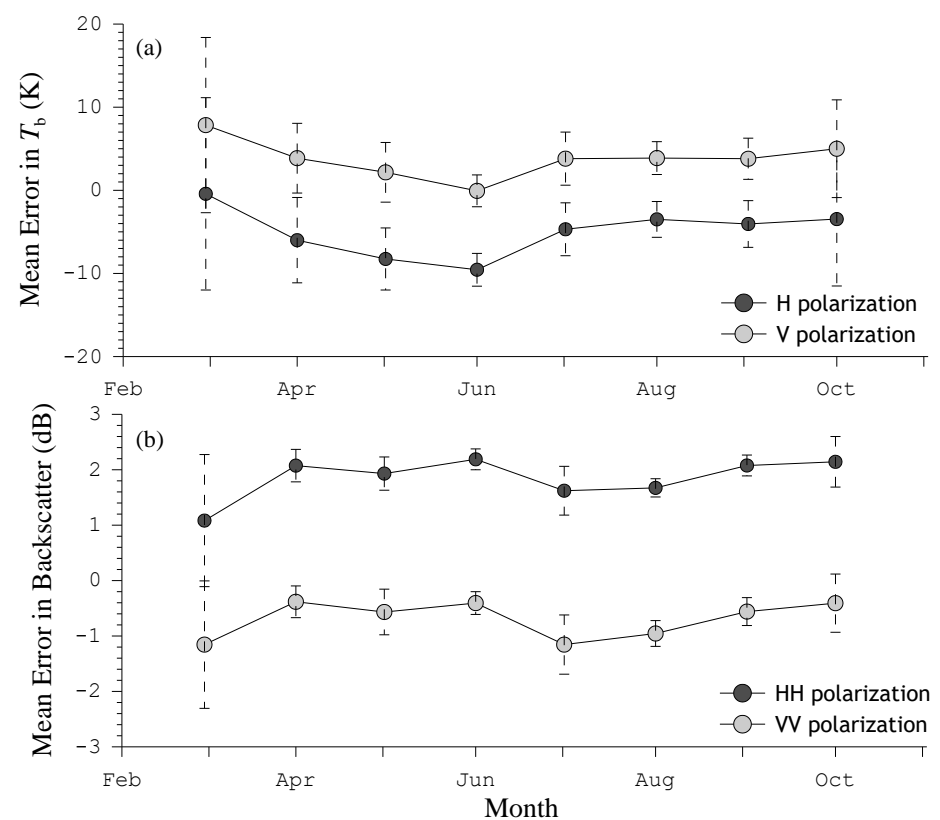

Fig.4.5. Mean error computed between Aquarius observations and TV-DEM simulations for each month of the 2012, 2013, 2014 and 2015 warm seasons, whereby the error bars indicate the standard deviation; a) for $T_{b}$ and b) for $\sigma^{0}$. 


\section{Chapter 4}

Table 4.4 Error statistics computed for matchups of TV-DEM simulations and Aquarius observations of $\sigma^{\circ}$ and $T_{b}$ for the calibration and validation period

\begin{tabular}{|c|c|c|c|c|c|c|}
\hline & & MAD & RMSD & MD & ubRMSD & $\mathrm{R}^{2}$ \\
\hline & & \multicolumn{4}{|c|}{$(\mathrm{K}$ or $\mathrm{dB})$} & $(-)$ \\
\hline \multirow{4}{*}{ Calibration } & $T_{b}^{H}$ & 6.72 & 7.73 & 5.20 & 5.72 & 0.75 \\
\hline & $T_{b}^{V}$ & 4.57 & 6.10 & -4.00 & 4.61 & 0.77 \\
\hline & $\sigma_{H H}^{0}$ & 1.88 & 1.93 & -1.88 & 0.47 & 0.42 \\
\hline & $\sigma_{V V}^{0}$ & 0.75 & 0.89 & 0.72 & 0.53 & 0.36 \\
\hline \multirow{4}{*}{ Validation } & $T_{b}^{H}$ & 7.68 & 8.60 & 7.64 & 3.93 & 0.86 \\
\hline & $T_{b}^{V}$ & 3.20 & 4.06 & -1.41 & 3.81 & 0.83 \\
\hline & $\sigma_{H H}^{0}$ & 2.12 & 2.13 & -2.12 & 0.26 & 0.68 \\
\hline & $\sigma_{V V}^{0}$ & 0.40 & 0.46 & 0.35 & 0.30 & 0.65 \\
\hline
\end{tabular}

\subsubsection{Scattering and emission components}

Figs.4.6 and 4.7 show the individual emission and scattering contributions and transmissivity for the 2012 and 2013 warm seasons following from the calibrated TV-DEM simulations. Note that the vegetation contributions are plotted on the lower secondary y-axis because the seasonal dynamics of these contributions would not be visible on main y-axis, as they are an order of magnitude smaller than the total and soil surface- soil litter contributions. Fig.4.6 demonstrates that the total L-band emission in both polarizations depends highly on the soil surface- soil litter component. Even in mid-summer when the LAI is highest, the transmissivity values remains above $0.93(-)$. This implicates that the effects of vegetation in the Maqu region relatively have little impact on the total land surface emission, but still remains at a level that would require consideration in passive microwave retrieval algorithms. 
Use of a discrete electromagnetic model for simulating Aquarius $L$ band active/passive observations and soil moisture retrieval

Fig.4.7 shows that the total backscattering is virtually composed only of the contributions coming from the soil surface and soil litter layer. Scattering coming from the vegetation directly as well as from the soil-vegetation pathways do fluctuate across the season and the latter even displays some response to soil moisture, but the magnitudes of these components remain insignificant with respect to the soil surface-soil litter contribution. Van der Velde and $\mathrm{Su}$ (2009) obtained similar findings through a statistical analysis of a time series of Advanced SAR (ASAR) C-band $\sigma^{0}$ observed over alpine meadows in the Naqu region in the central part of the Tibetan Plateau. They showed that the NDVI, as a proxy for vegetation, has a limited value for explaining the temporal $\sigma^{0}$ variation. Hence, an algorithm that considers only surface scattering has the potential to retrieve soil moisture reliably from $\sigma^{0}$ data collected over these Tibetan alpine meadows as was demonstrated in van der Velde et al. (2012a).

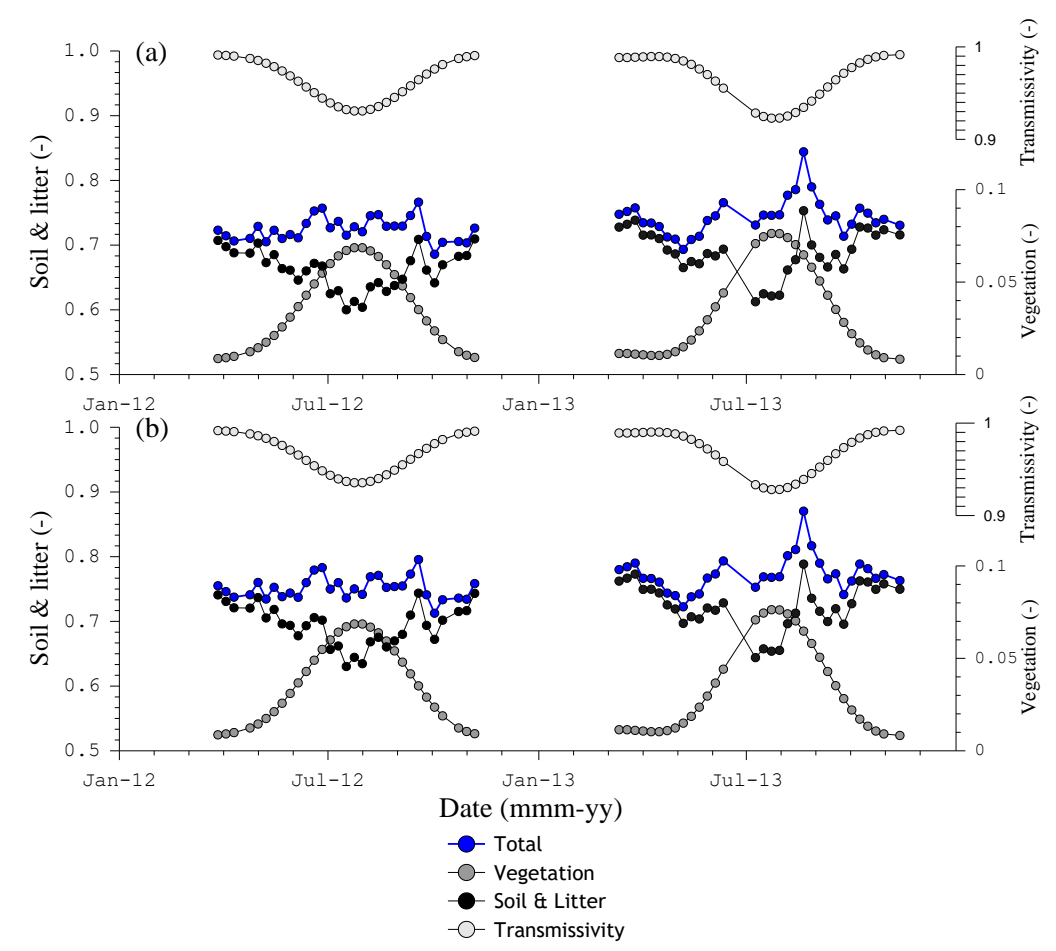

Fig. 4.6. TV-DEM simulated emission components from soil and litter (left Y-axis) and vegetation (right yaxis), total emission (left y-axis) and transmissivity (y-axis) for the Maqu in warm seasons of 2012 and 2013; Results for the horizontal polarization are shown in a) and for the vertical polarization in $b$ ). 


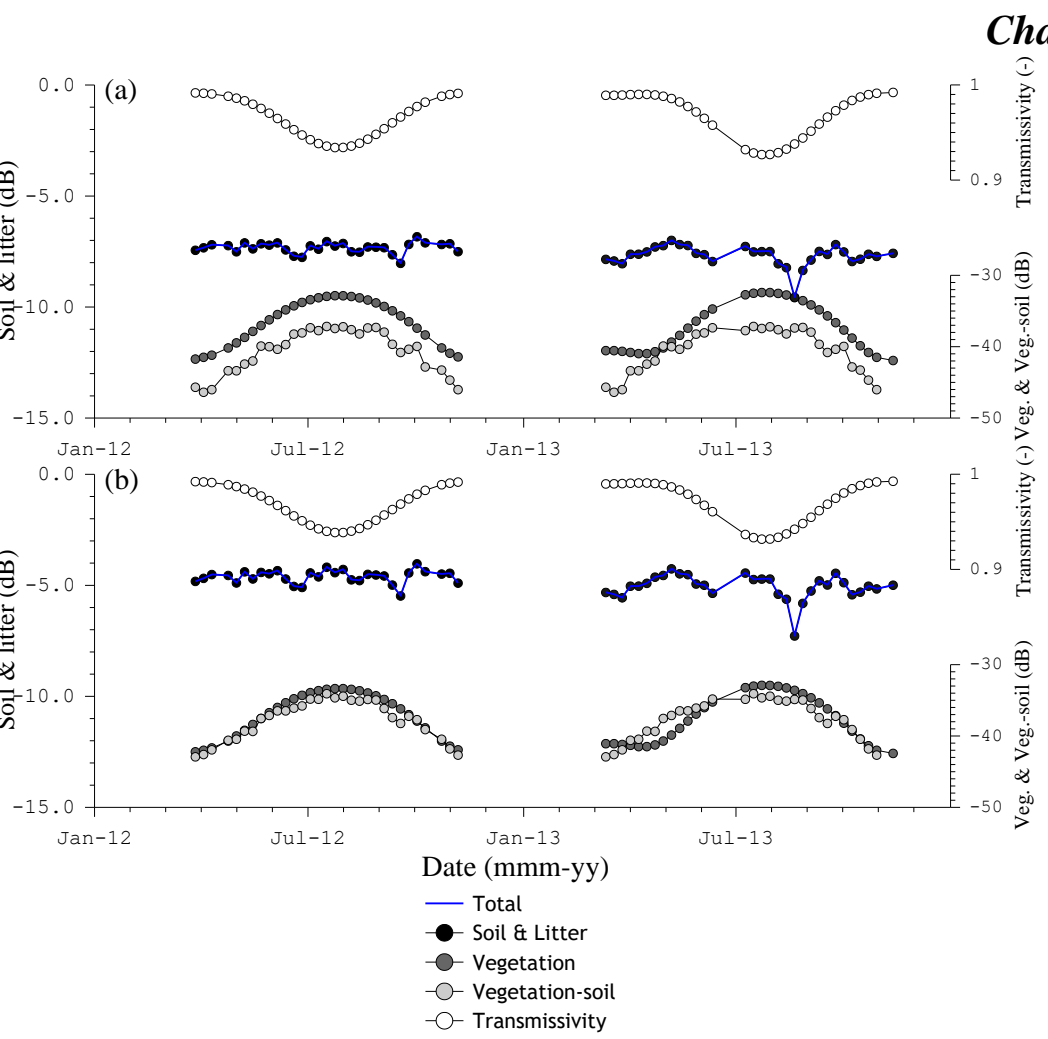

Fig.4.7. Same as Fig. 8 but for scattering components; a) horizontal and b) vertical polarization

\subsubsection{Soil moisture estimates}

Soil moisture is retrieved with the calibrated TV-DEM for the 2014 and 2015 warm seasons from three combinations of Aquarius active and passive data, namely:

i) $T_{b}^{h}$ alone, hereafter Single Channel Algorithm (SCA),

ii) $T_{b}^{h}$ and $T_{b}^{v}$, hereafter Dual Channel Algorithm (DCA),

iii) $T_{b}^{h}, T_{b}^{v}, \sigma_{\mathrm{hh}}^{\mathrm{o}}$ and $\sigma_{\mathrm{vv}}^{\mathrm{o}}$, hereafter Active/Passive (A/P) algorithm.

The following objective functions are formulated for the retrieval of soil moisture $(\mathrm{sm})$ from the above defined data inputs:

$$
\begin{gathered}
\phi_{\mathrm{SCA}}(\mathrm{sm})=\left|e_{h, m}(\mathrm{sm})-e_{h, 0}\right| \\
\phi_{\mathrm{DCA}}(\mathrm{sm})=\sum_{p=h, v}\left(e_{p, m}(\mathrm{sm})-e_{p, 0}\right)^{2}
\end{gathered}
$$


Use of a discrete electromagnetic model for simulating Aquarius $L$ band active/passive observations and soil moisture retrieval

$$
\phi_{\mathrm{A} / \mathrm{P}}(\mathrm{sm})=\sum_{p=h, v}\left(e_{p, m}(s m)-e_{p, \mathrm{o}}\right)^{2}+\sum_{p=h, v}\left(\sigma_{p p, m}^{0}(\mathrm{sm})-\sigma_{p p, o}^{0}\right)^{2}
$$

whereby the $e_{p, o}$ is obtained from the Aquarius $T_{b}^{p}$ as described in section 4.2.3 (Eq. 4.4). Retrieval is achieved for the minimum $\phi$ within the one-dimensional parameter space composed of the variable soil moisture. For this, TV-DEM simulations are performed by varying soil moisture from 0.03 to $0.60 \mathrm{~m}^{3} \mathrm{~m}^{-3}$ with increments of $0.001 \mathrm{~m}^{3} \mathrm{~m}^{-3}$, while keeping the other parameters fixed at their calibrated values and using the LAI from MCD15A2 product. The performance of forthcoming estimates is assessed using the in-situ measured soil moisture via scatter plots shown in Figs.4.8(a)-(c) and via the error metrics MAD, RMSD, MD, ubRMSD and $\mathrm{R}^{2}$ computed from the matchups listed in Table 4.5.

Further, the reliability of the TV-DEM retrieval is evaluated with respect to that of the official Aquarius soil moisture product (Bindlish et al. 2015; Bindlish and Jackson, 2015), which uses the $\tau$ - $\omega$ radiative transfer model (Mo et al. 1982) as backbone of the algorithm, and formulated as:

$$
T_{b}^{p} / T_{\text {eff }}=e_{p}=\left[\left(1+R_{s}^{p} \gamma\right)(1-\gamma)(1-\omega)+\left(1-R_{s}^{p}\right) \gamma\right]
$$

with

$$
\begin{gathered}
R_{s}^{p}=R_{\mathrm{o}}^{p} \exp \left(-h_{r} \cos ^{2} \theta\right) \\
\gamma=\exp (-\tau \sec \theta)
\end{gathered}
$$

where $R_{\mathrm{o}}^{p}$ is the $p$ polarized Fresnel reflection coefficient (-), $h_{\mathrm{r}}$ is an effective surface roughness parameter (-) and $\tau$ is computed as $b \times W$ with $W$ as the vegetation water content $\left(\mathrm{kg} \mathrm{m}^{-2}\right)$ and $b$ as an empirical vegetation parameter $\left(\mathrm{m}^{2} \mathrm{~kg}^{-2}\right)$.

For the global Aquarius product, soil moisture is retrieved from the $\mathrm{H}$ polarized $T_{b}$ in a similar fashion as the SCA defined here, whereby $\omega, b$ and $h_{\mathrm{r}}$ are taken as $0.05(-), 0.08\left(\mathrm{~m}^{2} \mathrm{~kg}^{-2}\right)$, and $0.1(-)$, respectively, and $W$ is estimated from a MODIS NDVI climatology as described in Bindlish et al. (2015). TV-DEM is calibrated here using local data and, therefore, the $b$ and $h_{\mathrm{r}}$ parameters of the $\tau$ - $\omega$ model are also calibrated using the Aquarius and in-situ measurements collected over the Maqu study area during the 2012 and 2013 warm seasons for an objective comparison. The $\omega$ is kept at $0.05(-), T_{\text {eff }}$ is calculated as described in section 4.2.3 and $W$ is derived from the 16-day MODIS NDVI product 


\section{Chapter 4}

(MOD13Q1) following the approach adopted for SMAP products described in Chan et al. (2013). A calibrated $b$ and $h_{\mathrm{r}}$ of $0.135\left(\mathrm{~m}^{2} \mathrm{~kg}^{-1}\right)$ and $0.109(-)$, respectively, are obtained with a $\mathrm{R}^{2}$ of $0.75(-)$, and ubRMSD computed from the $T_{b}$ matchups of $5.22 \mathrm{~K}$, respectively.

Subsequently, the calibrated $b$ and $h_{\mathrm{r}}$ are used for the soil moisture retrieval from Aquarius $T_{b}$ data collected during the 2014 and 2015 warm seasons, for which the results are plotted in Figs.4.8 (d)-(f) and the computed error metrics are listed in Table 4.5. The scatter plots of Fig.4.8 show that the matchup of the TV-DEM, and the SCA and DCA $\tau$ - $\omega$ model retrievals with the measurements lead to data points centered around the 1:1 line with a fairly small spread with an $\mathrm{R}^{2}$ varying from 0.76 to $0.79(-)$. A larger scatter (e.g. $\mathrm{R}^{2}=0.35$ ) around the 1:1 line can be noted for the data points following from the matchup of the official Aquarius product with the measurements. This may be attributed to two inherent differences between the official Aquarius processor and the application of the $\tau$ - $\omega$ model SCA and DCA presented here. Firstly, the Aquarius processor makes use of a NDVI climatology for calculating the $W$, whereas the 16-day MODIS NDVI product is adopted for the SCA and DCA. Secondly, surface temperature simulations by a Numerical Weather Prediction model is used as $T_{\text {eff, }}$ while the in-situ measured soil temperature is used for the SCA and DCA.

Overall, the error metrics obtained with the calibrated TV-DEM and $\tau-\omega$ model belong to the lower limit of results recently reported for state-of-the-art global soil moisture products. For instance, Bindlish et al. (2015) found that the matchup of the official Aquarius product with measurements collected in the Little Washita and Litter River (USA) watersheds resulted in a RMSD of 0.031 $\mathrm{m}^{3} \mathrm{~m}^{-3}$. Also for measurements collected across USA watersheds, Jackson et al. (2010) and Jackson et al. (2012) describe that soil moisture retrievals from AMSR-E and SMOS observations may yield RMSDs of, on average, 0.040 and $0.043 \mathrm{~m}^{3} \mathrm{~m}^{-3}$, respectively, before flagging for invalid land surface conditions. More recently, Colliander et al. (2017) documented the validation of SMAP L2 soil moisture product using soil moisture collected by measurement networks across the globe and found ubRMSDs varying from 0.021 to $0.056 \mathrm{~m}^{3} \mathrm{~m}^{-3}$. As such, it can be concluded that the performance of the algorithm with the calibrated radiative transfer models is in line with state-of-the-art products, and also complies with the accuracy requirement of $0.04 \mathrm{~m}^{3} \mathrm{~m}^{-3}$ ubRMSD for the SMAP L2 soil moisture product (e.g. Entekhabi et al. 2010). 

Use of a discrete electromagnetic model for simulating Aquarius L-
band active/passive observations and soil moisture retrieval

Comparison of the results obtained using the algorithms based on both calibrated models reveals quite similar error metrics. The TV-DEM retrievals produce, however, systemically lower biases (MD) and ubRMSDs with the minimum values of $-0.008 \mathrm{~m}^{3} \mathrm{~m}^{-3}$ and $0.021 \mathrm{~m}^{3} \mathrm{~m}^{-3}$, respectively, obtained with the $\mathrm{A} / \mathrm{P}$ algorithm. On the other hand, better $\mathrm{R}^{2}$ values of $0.79(-)$ are found for the $\tau$ - $\omega$ model retrievals in comparison to a $\mathrm{R}^{2}$ of $0.76(-)$ achieved with the TVDEM A/P setup. The $\mathrm{R}^{2}$ (see. Eq.4.10) is, however, a normalization of the squared differences between linearly regressed estimates and measurements with respect to the variance embedded in measurements. In this sense, the $\mathrm{R}^{2}$ is not a pure measure of error as it compares the same quantities, viz. soil moisture versus soil moisture, as the linear regression model will account for biases in the mean and range of the retrievals and measurements.

In conclusion, the TV-DEM A/P soil moisture retrievals are less biased than the retrieval obtained with the other approaches and lead to significantly lower MAD, RMSD and ubRMSD. This positive result warrants further investigation to discover whether a truly synergistic active/passive approach would also yield less biased soil moisture estimates for other climatic regions across the globe. In addition, the above results demonstrate that a complex physically based radiative transfer model, such as TV-DEM, can be used to estimate soil moisture with accuracies, which are, at the very least, comparable to the $\tau$ - $\omega$ model algorithms. Global application of these physically based models requires, however, additional research regarding the definition of vegetation morphology and associated parameter sets for land cover units worldwide. Kim et al. (2014) already reported on investigation in the context of the development of the experimental SMAP radar-only soil moisture products. On the other hand, physically based models may also prove useful in combination with the $\tau$ - $\omega$ model algorithms by providing parameterizations for ecosystems where detailed microwave data sets are scarce, which Rahmoune et al. (2013) already demonstrated for SMOS soil moisture retrieval over forests. 
Chapter 4

Table 4.5. Error metrics of soil moisture estimates obtained using algorithms based on the TV-DEM and the $\tau$ $\omega$ radiative transfer model along with the parameters (e.g. slope and intercept) of the linear equation $\widehat{\mathrm{SM}}_{\mathrm{e}}=a \times \mathrm{SM}_{\mathrm{o}}+b$ fitted through the data pairs.

\begin{tabular}{|c|c|c|c|c|c|c|c|c|}
\hline \multirow{2}{*}{ Model } & \multirow{2}{*}{ Algorithm } & $a$ & $b$ & $\mathrm{R}^{2}$ & MAD & RMSD & MD & ubRMSD \\
\hline & & $(-)$ & $\left(\mathrm{m}^{3} \mathrm{~m}^{-3}\right)$ & $(-)$ & \multicolumn{4}{|c|}{$\left(\mathrm{m}^{3} \mathrm{~m}^{-3}\right)$} \\
\hline \multirow{3}{*}{$\begin{array}{c}\text { TV- } \\
\text { DEM }\end{array}$} & SCA & 0.963 & 0.028 & 0.77 & 0.022 & 0.029 & 0.017 & 0.023 \\
\hline & DCA & 0.842 & 0.034 & 0.76 & 0.020 & 0.024 & -0.011 & 0.022 \\
\hline & $\mathrm{A} / \mathrm{P}$ & 0.771 & 0.057 & 0.76 & 0.018 & 0.023 & -0.008 & 0.021 \\
\hline \multirow{3}{*}{$\tau-\omega$} & Aquarius & 0.947 & 0.027 & 0.35 & 0.016 & 0.058 & 0.012 & 0.057 \\
\hline & SCA & 1.135 & -0.017 & 0.79 & 0.029 & 0.034 & 0.022 & 0.026 \\
\hline & DCA & 1.085 & -0.006 & 0.78 & 0.026 & 0.032 & 0.019 & 0.025 \\
\hline
\end{tabular}
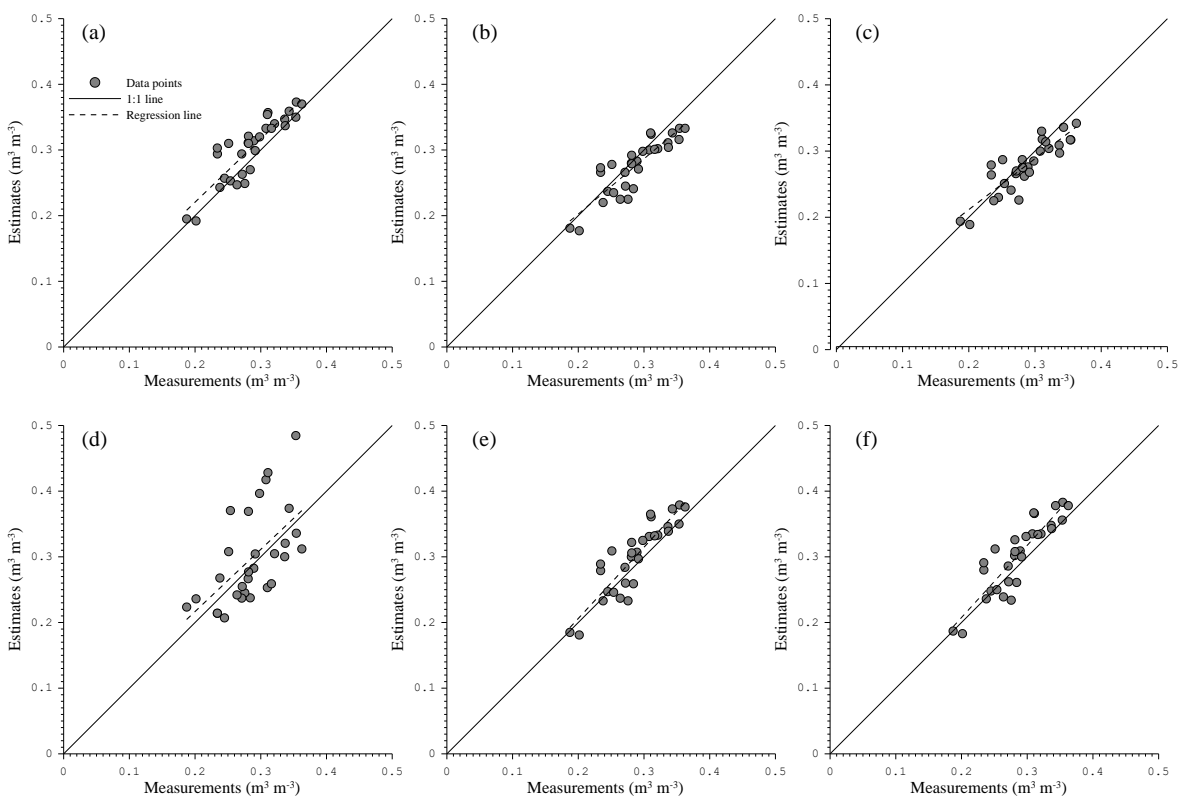

Fig.4.8. Scatter plots of soil moisture retrievals against in-situ measurements for the 2014 and 2015 warm seasons; subplots (a)-(c) show the results obtained using simulations with the calibrated TV-DEM in the SCA, DCA and A/P retrieval setups, respectively, and subplots (d)-(f) show results obtained using $\tau$ - $\omega$ model based algorithms with the official Aquarius product given in (d) and the SCA and DCA $\tau$ - $\omega$ retrievals given in (e) and (f), respectively. 
Use of a discrete electromagnetic model for simulating Aquarius $L$ band active/passive observations and soil moisture retrieval

\subsection{Discussion}

\subsubsection{Assumptions for surface roughness}

Fig.4.9 (a) shows the ratio of $e$ and $\sigma^{0}$ TV-DEM simulations with autocorrelation lengths $(l)$ varying from 6.5 to $16 \mathrm{~cm}$ with respect to simulations with a $l$ of $9 \mathrm{~cm}$ to quantify the impact of this assumption on the presented results. The plot shows that the $e$ ratio for both $\mathrm{H}$ and $\mathrm{V}$ polarization decreases, namely from 1.04 to 0.94 (-) and from1.03 to 0.97 (-), respectively, for an increasing $l$ from 6.5 to $16 \mathrm{~cm}$. However, the $\sigma^{0}$ ratio for $\mathrm{HH}$ and VV polarization shows an increasing trend as function of the $l$ up to a critical value (12.5 $\mathrm{cm}$ for $\mathrm{HH}$ polarization and $9.5 \mathrm{~cm}$ for $\mathrm{VV}$ polarization) followed by a moderate decrease in the $\sigma^{0}$ ratio.

We further investigate the sensitivity of the TV-DEM A/P retrievals for the uncertainty induced by the assumed $l$ of $9 \mathrm{~cm}$. Fig. 4.9 (b) shows the RMSDs obtained for TV-DEM A/P soil moisture retrievals from the 2014 and 2015 warm seasons with the $l$ varying from 6.5 to $16 \mathrm{~cm}$. The plot illustrates that over the $l$ range of 7 to $11 \mathrm{~cm}$ the RMSD obtained remains below the $0.04 \mathrm{~m}^{3} \mathrm{~m}^{-3}$. In combination with the relatively small changes in the $e$ and $\sigma^{0}$ ratio, it may be concluded that the assumption of a fixed $9 \mathrm{~cm} l$ is justified. Especially since the effect of selecting correlation length can be compensated by parameterization of $s$ as is described in van der Velde (2010). 
Chapter 4
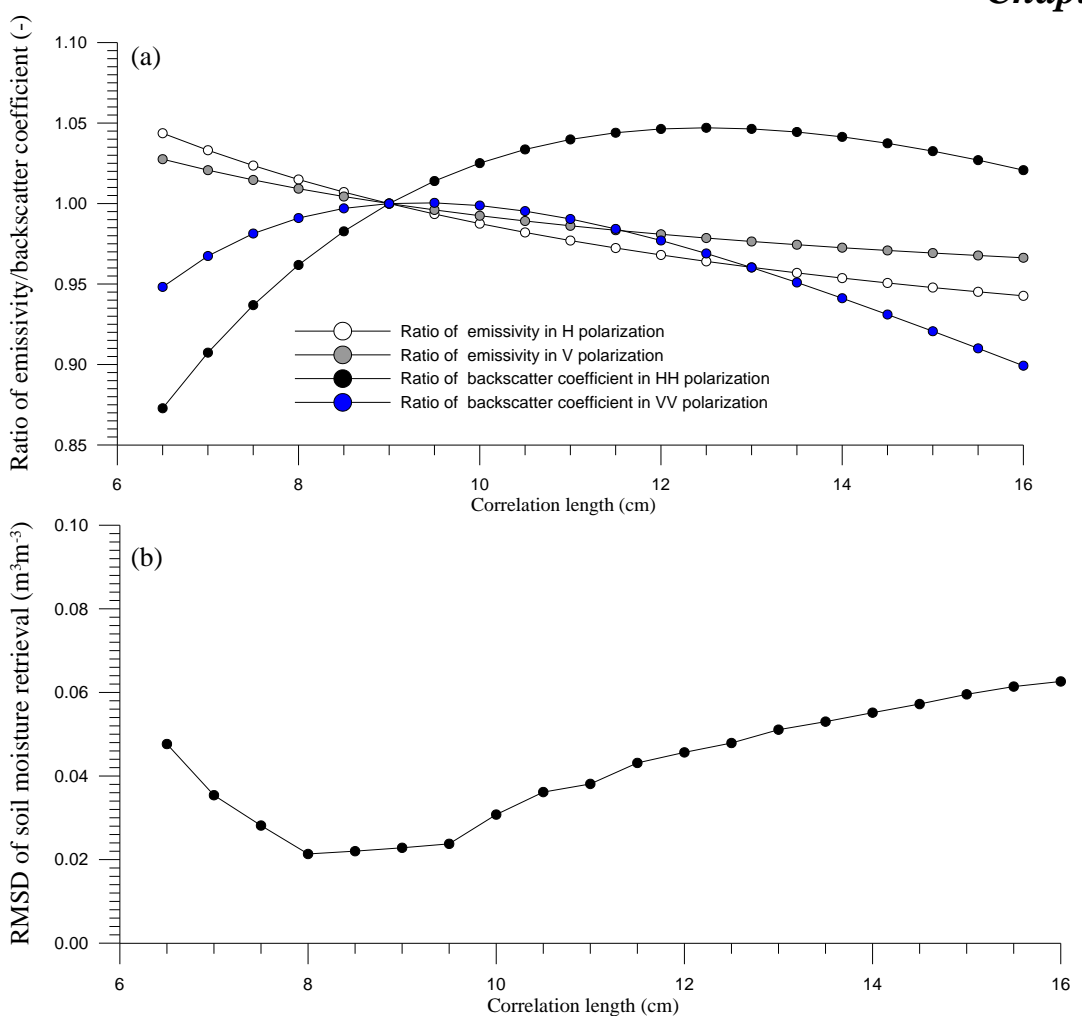

Fig. 4.9. The ratio of emissivity/backscattering coefficient in different polarizations (a) and the RMSD of soil moisture retrieval with respect to the reference value (b) by using different correlation lengths

\subsubsection{Effective soil temperature}

Estimates of $T_{\text {eff }}$ are critical for soil moisture retrieval from passive microwave observations to derive the $e$ from the observed $T_{b}$. Here, we investigate the impact of the choice for a specific $T_{\text {eff }}$ scheme by considering the approaches developed by Choudhury et al. (1982, CH82), Wigneron et al. (2008, W08), Lv et al. (2014, Lv14) and the in-situ measured soil temperature at $5 \mathrm{~cm}$ depth. Fig.4.10 shows time series of the $\mathrm{H}$ and $\mathrm{V}$ polarized $T_{b}$ for the 2012 and 2013 warm seasons derived from simulation with the calibrated TV-DEM using the W08 and Lv14 $T_{\text {eff }}$ methods along with the Aquarius $T_{b}$. The results based on the CH82 method and the $5 \mathrm{~cm}$ in-situ measurements are not included in the plots as they are similar to those using LV14 and W08, respectively. The plots in Fig.4.10 show that the $T_{b}$ derived using $\mathrm{L}_{\mathrm{V}} 14$ and W08 are comparable to each other; hardly any differences are noted. 
Use of a discrete electromagnetic model for simulating Aquarius $L$ band active/passive observations and soil moisture retrieval
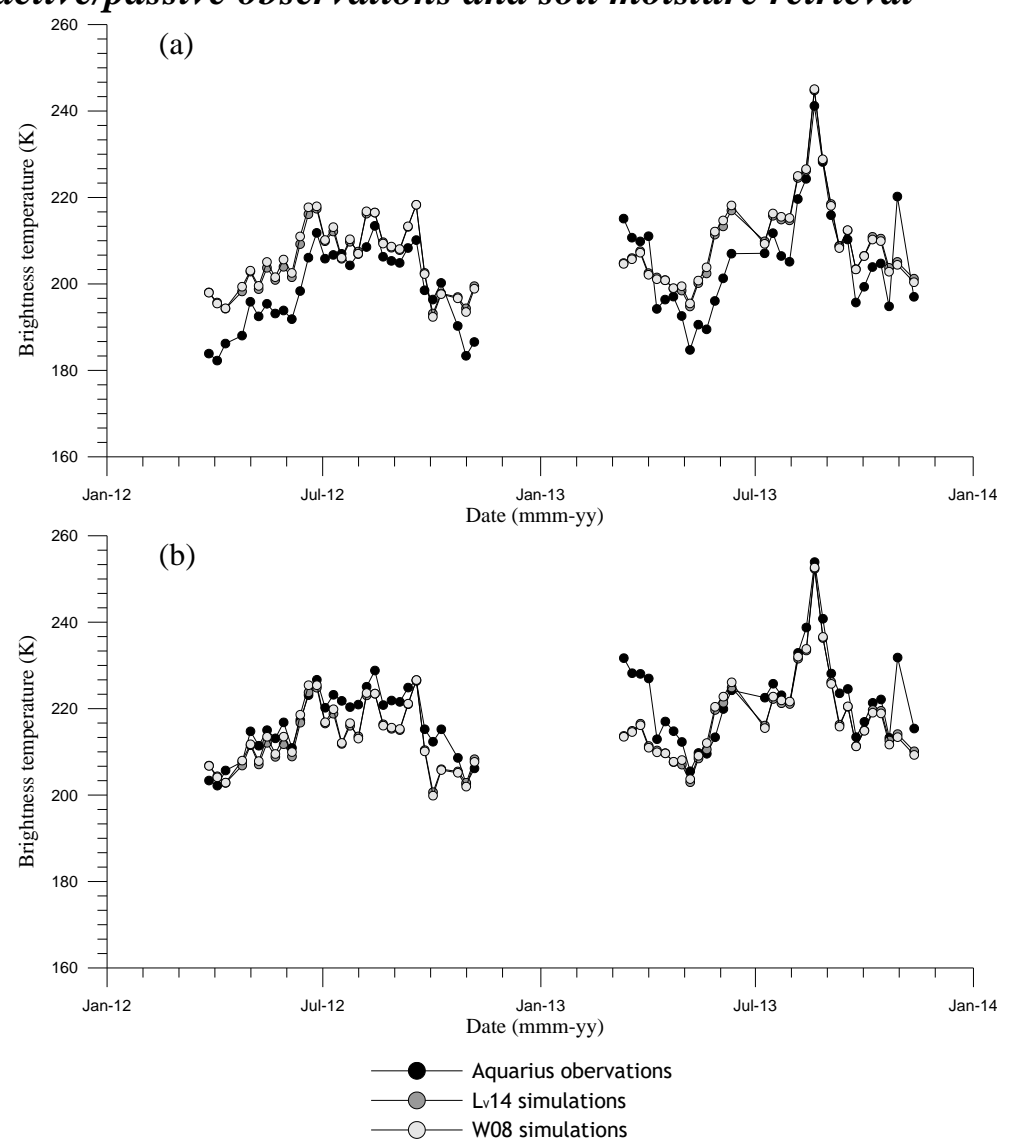

Fig.4.10. Brightness temperature time series for the Maqu study area, consisting of observations made by Aquarius as well as DEM-A/P simulations in $\mathrm{H}$ (a) and V (b) polarization, and based on effective temperature methods derived from Lv14 and W08

Table 4.6 shows the error metrics (Eq. 4.6-4.10) computed between the Aquarius $T_{b}$ and the TV-DEM $T_{b}$ 's derived through application of the CH82, W08, Lv14 and in-situ measured $T_{\text {eff }}$. It can be deduced that the Lv14 and CH82 scheme lead to comparable metrics, which are slightly better than the ones obtained with W08 and the $T_{\text {eff }}$ derived from in-situ measurements. From this analysis, we may conclude that the choice of the method adopted for computation of $T_{\text {eff }}$ has a limited impact on $T_{b}$ derived from TV-DEM simulations. 
Chapter 4

Table 4.6 Statistics of brightness temperature (in $\mathrm{H}$ and $\mathrm{V}$ polarizations) of TV-DEM based DEM-A/P simulations relative to observations made by Aquarius, using different methods of calculating effective temperature

\begin{tabular}{|c|c|c|c|c|c|}
\hline & & MAD (K) & RMSD (K) & MD (K) & $\mathbf{R}^{2}(-)$ \\
\hline \multirow{4}{*}{$T_{b}^{H}$} & $\mathrm{~L}_{\mathrm{V}} 14$ & 6.72 & 5.20 & 7.73 & 0.75 \\
\hline & CH82 & 6.70 & 5.19 & 7.71 & 0.75 \\
\hline & W08 & 7.02 & 5.41 & 8.11 & 0.71 \\
\hline & In-situ & 7.00 & 5.39 & 8.09 & 0.72 \\
\hline \multirow{4}{*}{$T_{b}^{V}$} & $\mathrm{~L}_{\mathrm{V}} 14$ & 4.57 & -4.00 & 6.10 & 0.77 \\
\hline & CH82 & 4.57 & -4.00 & 6.10 & 0.77 \\
\hline & W08 & 4.58 & -3.77 & 6.19 & 0.74 \\
\hline & In-situ & 4.59 & -3.79 & 6.19 & 0.74 \\
\hline
\end{tabular}

\subsubsection{Effect of depolarization on calibration results}

A clear discrepancy exists between simulated and observed $\sigma_{\mathrm{hh}}^{0}$ in Fig.4.4 (c). Such a discrepancy is not seen for $\sigma_{\mathrm{vv}}^{0}$. This depolarization phenomenon found for Aquarius is likely attributable to the topographic effect as suggested by Utku and Le Vine (2014). We investigate the impact of this depolarization by analyzing the results of four additional calibrations of the TV-DEM carried out with PEST for six Aquarius acquisitions from June 2012 and 2013 to minimize the effects of soil freeze/thaw and inundation. The four calibrations are based on objective functions (see Eq. 4.3) built up out of the Aquarius derived/observed,

1) $\mathrm{H}$ polarized $e$ (computed using Eq. 4.4), hereafter H-pol,

2) V polarized $e$, hereafter V-pol,

3) Sums of $\mathrm{H}$ and $\mathrm{V}$ polarized $e$, and $\mathrm{HH}$ and $\mathrm{VV}$ polarized $\sigma^{0}$, hereafter $\mathrm{A} / \mathrm{P}$,

4) Individual $\mathrm{H}$ and $\mathrm{V}$ polarized $e$, and $\mathrm{HH}$ and $\mathrm{VV}$ polarized $\sigma^{0}$, hereafter $\mathrm{A} / \mathrm{P}$ dual-pol. 
Use of a discrete electromagnetic model for simulating Aquarius Lband active/passive observations and soil moisture retrieval

The parameters used for the four calibrations are listed in Table 4.7. Clear distinctions can be noted concerning the obtained parameter sets with the largest differences between the H-pol and V-pol, whereas much smaller deviations are found between the A/P and A/P dual-pol set. Furthermore, it should be noted that the A/P dual-pol set is quite close to calibrated parameters listed in Table 4.3 .

Table 4.7 Four TV-DEM parameter sets calibrated using Aquarius observations collected over the Maqu study area June 2012 and 2013.

\begin{tabular}{|c|c|c|c|c|}
\hline & \multicolumn{3}{|c|}{ Calibration setup } \\
\hline Parameter name & H-pol & V-pol & A/P dual-pol \\
\hline $\begin{array}{c}\text { Standard deviation of } \\
\text { height variation, } s(\mathrm{~cm})\end{array}$ & 3.50 & 2.41 & 2.99 & 2.75 \\
\hline Litter moisture factor (-) & 0.80 & 1.03 & 0.80 & 1.05 \\
\hline $\begin{array}{c}\text { Litter biomass }\left(\mathrm{g} \mathrm{cm}{ }^{-2}\right) \\
\text { Plant moisture content }(\mathrm{kg}\end{array}$ & 0.01 & 0.04 & 0.01 & 0.02 \\
\hline $\left.\mathrm{kg}^{-1}\right)$ & 0.40 & 0.52 & 0.40 & 0.40 \\
\hline
\end{tabular}

Table 4.8 lists the error metrics (e.g. MAD, RMSD, MD, ubRMSD and $\mathrm{R}^{2}$ ) computed from the matchup of the Aquarius observations and the TV-DEM simulations. Generally, the metrics presented in the table illustrate that the different calibration setups lead to some changes in the biases, but do not lead to very large alterations in the overall performance of the TV-DEM. Notably, the $\mathrm{R}^{2}$ obtained for $T_{b}$ varies from 0.72 to 0.77 (-) and for $\sigma^{0}$ from 0.30 to 0.34 (-). Therefore, we expect that the polarization dependent bias between the Aquarius observations and TV-DEM simulations will not have significant consequences for the conclusion of this investigation. 
Chapter 4

Table 4.8 Error metrics computed for matchups of DEM-A/P simulations and Aquarius observations of $\sigma^{\circ}$ and $\mathrm{Tb}$ for the calibration period by using four schemes for calibration

\begin{tabular}{|c|c|c|c|c|c|c|}
\hline & & MAD & RMSD & MD & ubRMSD & $\mathbf{R}^{2}$ \\
\hline & & & & & & $(-)$ \\
\hline & $T_{b}^{H}$ & 8.67 & 9.97 & 8.14 & 5.76 & 0.76 \\
\hline & $T_{b}^{V}$ & 5.07 & 6.28 & -4.34 & 4.54 & 0.78 \\
\hline & $\sigma_{H H}^{0}$ & 1.34 & 1.44 & -1.34 & 0.53 & 0.37 \\
\hline & $\sigma_{V V}^{0}$ & 1.19 & 1.33 & 1.18 & 0.62 & 0.31 \\
\hline & $T_{b}^{H}$ & 5.17 & 6.43 & 2.47 & 5.94 & 0.73 \\
\hline & $T_{b}^{V}$ & 5.50 & 6.95 & -5.02 & 4.81 & 0.75 \\
\hline & $\sigma_{H H}^{0}$ & 2.27 & 2.34 & -2.27 & 0.57 & 0.42 \\
\hline & $\sigma_{V V}^{0}$ & 0.49 & 0.62 & 0.31 & 0.54 & 0.36 \\
\hline & $T_{b}^{H}$ & 5.03 & 5.97 & 1.19 & 5.85 & 0.74 \\
\hline & $T_{b}^{V}$ & 9.33 & 10.56 & -9.31 & 4.98 & 0.76 \\
\hline & $\sigma_{H H}^{0}$ & 1.32 & 1.42 & -1.32 & 0.52 & 0.37 \\
\hline & $\sigma_{V V}^{0}$ & 1.28 & 1.42 & 1.28 & 0.62 & 0.31 \\
\hline & $T_{b}^{H}$ & 5.28 & 6.27 & 0.82 & 6.22 & 0.71 \\
\hline $\mathrm{A} / \mathrm{P}$ & $T_{b}^{V}$ & 8.45 & 9.66 & -8.29 & 4.96 & 0.73 \\
\hline dual-pol & $\sigma_{H H}^{0}$ & 1.60 & 1.68 & -1.60 & 0.51 & 0.33 \\
\hline & $\sigma_{V V}^{0}$ & 1.00 & 1.15 & 0.99 & 0.59 & 0.27 \\
\hline
\end{tabular}


Use of a discrete electromagnetic model for simulating Aquarius Lband active/passive observations and soil moisture retrieval

\subsection{Conclusion}

This chapter reports on the simulation of L-band Aquarius emission and scattering by the TV-DEM (Discrete Electromagnetic Model developed at the Tor Vergata University in Rome) for the Maqu study area, which is a region situated in the north-eastern part of the Tibetan plateau. The TV-DEM parameters (standard deviation of surface height variations, litter moisture factor, litter biomass and plant moisture content), found to have the largest impact on simulations, have been calibrated using Aquarius observed brightness temperature $\left(T_{b}\right.$ 's) and backscattering coefficients $\left(\sigma^{0}\right)$ for the 2012 and 2013 warm seasons. For these forward TV-DEM simulations, the Moderate resolution imaging Spectroradiometer (MODIS) Leaf Area Index (LAI) product MCD15A2), the in-situ measured soil moisture and profile soil temperature were employed as inputs.

Fairly good agreement, with an average $\mathrm{R}^{2}$ of 0.80 for $T_{b}$ and 0.53 (-) for $\sigma^{0}$, is achieved between the Aquarius observations and the calibrated TV-DEM simulations for the calibration period as well as the independent validation composed of the Aquarius acquisitions collected during the warm season of 2014 and 2015. The simulations, however, systematically overestimate Aquarius observations made in the $\mathrm{H}$ polarization, and underestimate the observations made in the $\mathrm{V}$ polarization. Further, the largest variations in differences between the Aquarius observation and TV-DEM are found for the months around the season transitions (e.g. March, April and October) from freezing to thawing. Analysis of the individual scattering and emission components produced by the TV-DEM suggests that the L-band land surface emissivity is highly dependent on the surface component composed of soil and litter contributions, whereas the vegetation component is relatively small. For the active case, the TV-DEM $\sigma^{0}$ simulations are utterly dominated by the surface components, and the vegetation and vegetation-surface scattering components are essentially negligible.

The calibrated TV-DEM is also employed to retrieve soil moisture from three combinations of Aquarius data from the 2014 and 2015 warm seasons, namely: i) $\mathrm{H}$ polarized $T_{b}$ (hereafter SCA), ii) $\mathrm{H}$ and $\mathrm{V}$ polarized $T_{b}$ (hereafter DCA) and iii) $\mathrm{H}$ and $\mathrm{V}$ polarized $T_{b}$, and $\mathrm{HH}$ and $\mathrm{VV}$ polarized $\sigma^{0}$ (hereafter $\mathrm{A} / \mathrm{P}$ ). The performance of TV-DEM soil moisture retrievals is assessed using in-situ measurements and also compared to the performance of the official Aquarius 


\section{Chapter 4}

soil moisture products, which is based upon a global application of the $\tau$ (optical depth)- $\omega$ (single scattering albedo) radiative transfer model similar to the SCA defined here. Since the TV-DEM has been calibrated using local data, soil moisture retrieval has also been performed with a calibrated $\tau-\omega$ model. The error metrics computed from the matchup of the retrievals with the measurements suggest that the calibrated TV-DEM yields the least biased results with a MD (mean difference) of $-0.008 \mathrm{~m}^{3} \mathrm{~m}^{-3}$ and a ubRMSD (unbiased root mean squared difference) of $0.021 \mathrm{~m}^{3} \mathrm{~m}^{-3}$ found for the A/P setup. On the other hand, the largest coefficients of determination $\left(\mathrm{R}^{2}\right)$ are obtained for the retrievals with the calibrated $\tau$ - $\omega$ model, on average 0.785 versus 0.765 (-) for TV-DEM.

In conclusion, the investigation shows that a single model, TV-DEM, can simulate both brightness temperatures and backscattering coefficients that are to some extent in agreement with L-band observations made from the Aquarius space platform. The surface contribution dominates the scattering and emission from the Maqu study area, where vegetation (particularly in the active case) has an almost negligible contribution. Soil moisture retrieval is successfully conducted using a calibrated TV-DEM, whereby synergistic use of active and passive Aquarius observations leads to the least biased estimates.

These positive results encourage further investigation of the synergistic use of active and passive microwave observations for soil moisture retrieval as well as the usage of complex physically radiative transfer model as part of existing global soil moisture retrieval processors. However, the results presented here only demonstrate the possibility to reproduce coincident active and passive microwave signals for one site. Additional research will need to be undertaken to develop definitions of vegetation morphology and associated parameter sets for land cover units worldwide. Kim et al. (2014) already reported on research in the context of the experimental SMAP L2 radar only soil moisture product and Rahmoune et al. (2013) adopted a similar approach to aid the $\tau$ - $\omega$ model SMOS soil moisture retrieval over forests worldwide. 
Use of a discrete electromagnetic model for simulating Aquarius $\mathbf{L}$ band active/passive observations and soil moisture retrieval 


\section{Chapter 5 Soil moisture estimation from L-band active and passive microwave observations acquired by Aquarius over the Tibetan Plateau*}

\subsection{Introduction}

Soil moisture is the key state controlling the exchange of momentum, heat and mass at the land-atmosphere interface. The availability of soil moisture information may lead to a better understanding of biology, hydrology, meteorology and climatology. Numerous algorithms have been developed during the last two decades based on aircraft and satellite observations (Jackson, 1993; Wagner et al., 1999; Owe et al., 2008). Jackson (1993) showed the relationship between emissivity and soil moisture by aircraft observations and presented a Single Channel Algorithm (SCA) for soil moisture retrieval. Owe et al. (2008) and Wagner et al. (1999) proposed the Land Parameter Retrieval Model (LPRM) and a change detection algorithm to retrieve soil moisture from passive multiple frequency Scanning Multichannel Microwave Radiometer (SMMR) and active C-band European Space Agency's (ESA) Earth Remote Sensing (ERS) scatterometer, respectively. As L-band proved to be the preferred frequency for soil moisture retrieval (Schmugge and Jackson,1994; Wagner 2007) at global scale, two dedicated missions for soil moisture mapping were launched in 2009 and 2015, namely Soil Moisture and Ocean Salinity (SMOS) and Soil Moisture Active Passive (SMAP), respectively. Aquarius carrying both a radiometer and a scatterometer for measuring sea surface salinity operated from 10 June 2011 to 8 June, 2015.

Since both active and passive microwave observations contain soil moisture information, various investigators have carried out research to combine the backscatter and emission signals measured by active and passive microwave sensors. For instance, Das et al. $(2012,2014)$ and van der Velde et al. (2015) studied statistical methods for downscaling coarse passive microwave products

\footnotetext{
* This chapter is based on Wang, Q., van der Velde.,R., Ferrazzoli, P., Bai, X., and Su, Z. (2018) Mapping soil moisture across the Tibetan Plateau using Aquarius active and passive L-band microwave observations. (In review)
} 


\section{Soil moisture estimation from $L$-band active and passive microwave observations acquired by Aquarius over the Tibetan Plateau}

using the higher resolution active microwave observations towards an intermediate resolution soil moisture product. Liu et al (2012) generated a global soil moisture map by cumulative distribution function (CDF) matching soil moisture products from active and passive observations. Physical interpretation of simultaneous active and passive microwave signals has been pursued by investigators (e.g. Chauhan et al, 1994; Ferrazzoli et al, 1989; Guerriero et al., 2016; Dente et al., 2014; Wang et al., 2018]) as well. Chauhan et al. (1994) demonstrated that a discrete scatter approach can be used to predict both L-band radar and radiometer observations. Dente et al. (2014) investigated a discrete electromagnetic model for simulating C-band Advanced Microwave Scanning Radiometer for EOS (AMSR-E) brightness temperature $\left(T_{b}\right)$ and ASCAT backscattering coefficient $\left(\sigma^{0}\right)$ in the Maqu area and proved its applicability to satellite observations. Guerriero et al. (2016) applied a discrete electromagnetic model to reproduce the active and passive observations simultaneously collected in airborne field campaigns at $\mathrm{L}$ band.

With the launch of Aquarius, the first L-band active and passive microwave observations were recorded simultaneously from space. Wang et al. (2016) investigated the Aquarius observation against the in-situ measurement of Maqu network and showed that both brightness temperature $\left(T_{b}\right)$ and backscattering coefficient $\left(\sigma^{0}\right)$ hold sensitivity to soil moisture. Furthermore, a single discrete electromagnetic model was used to simulate Aquarius emission and scattering in Wang et al. (2018) with Maqu as the study area. Moreover, Wang et al. (2018) also concluded the vegetation is insignificant in scattering and emission compared to soil-litter layer and reliable soil moisture estimates are obtained by the synergistic use of Aquarius data. In this chapter, an algorithm for soil moisture retrieval in a large spatial domain is described. Look UP Tables (LUTs) are generated on basis of simulations performed with Tor VergataDiscrete electromagnetic model (TV-DEM), and it is used as a tool for soil moisture retrieval in this algorithm. The in-situ measurement of three regionalscale monitoring networks covering different climate regions in Tibetan Plateau (Su et al., 2011) served as the ground truth. The forthcoming soil moisture estimates and three other public available soil moisture products (L3 gridded $1^{\circ}$ grid Aquarius/SAC-D, ASCAT level 2, ERA-Interim) are validated in a point scale against the mean soil moisture of in-situ measurements of three networks. Moreover, the spatial distribution of the retrieved soil moisture product as well as three other soil moisture products are verified using antecedent rainfall fields available via the Climate Hazards Group Infrared Precipitation with Station data 
Chapter 5

(CHIRPS, Funk et al., 2015) and thermal remote sensing retrieved evapotranspiration products (Chen et al., 2014).

\subsection{Materials and methods}

\subsubsection{Look up table (LUT) establishment}

The TV-DEM can perform simulations of the horizontal (H) and vertical (V) polarized emissivity, and the horizontally and vertically co-polarized ( $\mathrm{HH}$ and $\mathrm{VV}$, respectively) backscattering coefficients as a function of input parameters of the soil-vegetation system. Table 4.2 (section 4.2.2) lists the set of parameters needed to run TV-DEM along with the values that were used previously to reproduce satellite observations over Maqu (e.g. Dente et al., 2014; Wang et al., 2018). In section 4.3.1 it is shown that apart from the soil moisture, the standard deviation of surface height variations $(s)$, litter moisture and litter biomass are the most sensitive parameters as well as the plant water content. Based on these findings, the LUTs are composed of forward TV-DEM simulations by varying the soil moisture from 0.03 to $0.50 \mathrm{~m}^{3} \mathrm{~m}^{-3}$ with an interval of $0.001 \mathrm{~m}^{3} \mathrm{~m}^{-3}$ and the LAI, varying from 0.1 to $5.0 \mathrm{~m}^{2} \mathrm{~m}^{-2}$ with an interval of $0.1 \mathrm{~m}^{2} \mathrm{~m}^{-2}$, while $s$, litter moisture and litter biomass, plant water content calibrated in Maqu site in section 4.3.2 is used in LUTs creation as well.

The vast Tibetan Plateau holds a variety of land covers that require different morphological descriptions of the soil-vegetation system. Here, we distinguish the two main categories:

(1) Vegetation surface in Tibetan Plateau Plains mainly located in the eastern and southern part of Tibetan Plateau according to Fig.2.1 (section 2.1). Foliage is represented as a collection of discs and the soil litter module is invoked.

(2) Bare soil surfaces indicated in Fig.2.1, which are located in the western and northern part of Tibetan Plateau. Neither vegetation nor litter is included, and IEM is used to simulate the backscattering coefficient. 
Soil moisture estimation from $L$-band active and passive microwave observations acquired by Aquarius over the Tibetan Plateau

\subsubsection{Object function definition and soil moisture retrieval}

\section{scheme}

As both active and passive observations are used simultaneously for soil moisture estimation, a reliable object function should be proposed. Moreover, regularization or normalization should be further considered to make the weight of the active and passive observation comparable in the object function. Akbar and Moghaddam (2015) proposed a detailed algorithm to assign weights by considering the noise level of SMAP observations. Dente et al. (2014) and Wang et al. (2018) used the standard deviation to normalize the passive and active observations in an object function for $\mathrm{C}$ - and L-band observations in Maqu. Following the method of Wang et al. (2018), a joint active-passive object function is defined as follows for soil moisture estimation from Aquarius observations.

$$
\phi=\sum_{P=V . H}\left[\frac{e_{P}(s i m)-e_{P}(o b s)}{\delta_{e P}(o b s)}\right]^{2}+\left[\frac{\sigma_{P P}^{0}(\operatorname{sim})-\sigma_{P P}^{0}(o b s)}{\delta_{\sigma_{P P}^{0}}(o b s)}\right]^{2}
$$

where $\phi$ is the object function, $P$ indicates $\mathrm{H}$ or $\mathrm{V}, e_{P}$ indicate the emissivity and $\sigma_{P P}^{0}$ are backscattering coefficient (in power units), respectively, sim denotes the simulation of the LUT and obs indicates the Aquarius observation, $\delta$ indicates the standard deviation.

The LUT is generated based on TV-DEM simulations and then an algorithm for retrieving soil moisture for Tibetan Plateau is proposed as follows.

(a): The brightness temperature $\left(T_{b}\right)$ measured by Aquarius is converted to emissivity based on Eq 4.4 indicated in section 4.2.3.

where $p$ denotes the polarization being either $\mathrm{H}$ or $\mathrm{V}, T_{\text {eff }}$ is the effective temperature of the emitting layer $(\mathrm{K})$ for which we use surface temperature obtained from NCEP GFS GDAS product which provided in the Aquarius/SAC-D level-2 processed dataset with version 4.0.

(b): By searching the minimum of Eq. 5.1 in the LUT, the soil moisture value of the Aquarius footprint is retrieved from the LUT and called the TV-DEM retrieved soil moisture. The flow chart for soil moisture retrieval of TV-DEM is shown in Fig.5.1. 
Chapter 5

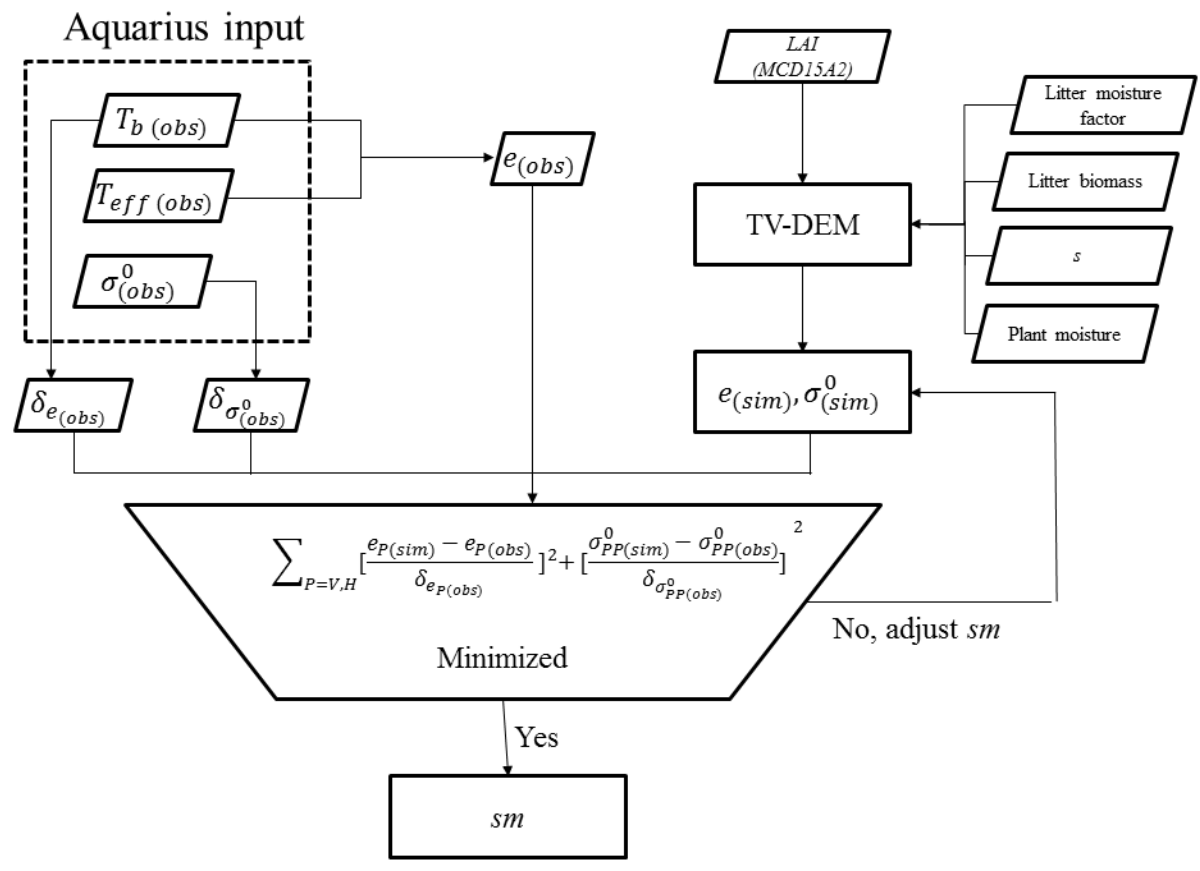

Fig. 5.1. Flow chart for soil moisture retrieval scheme ( $\mathrm{sm}$ represents soil moisture)

\subsubsection{Matchup and error metrics}

As in-situ soil moisture and ASCAT dataset are in point scale and $12.5 \mathrm{~km}$ resolution, while official Aquarius and ERA-Interim soil moisture product are of a resolution of $1^{\circ}$, upscaling the high resolution soil moisture product to a coarse resolution is required. As many investigators (Dente et al., 2014; Jackson et al., 2000; Jackson et al., 2012; Leroux et al., 2014; Su et al., 2012; Dente et al., 2012) already used spatial average for upscaling and proved its feasibility, it is adopted here as well. Soil moisture measurements of Tibet-Obs as well as ASCAT soil moisture nested (Maqu, Naqu and Ngari ) in $1^{\circ} \times 1^{\circ}$ grid are spatially averaged to represent the ground truth of the $1^{\circ} \times 1^{\circ}$ grid based on the topography and soil texture (Dente et al., 2012) in the same resolution for the same grid.

The error metrics are used to evaluate the TV-DEM Aquarius as well as the official Aquarius, ASCAT and ERA-Interim soil moisture with respect to the in-situ measurements collected by the Tibetan Plateau Observatory. The adopted error scores are the bias, root mean squared difference (RMSD), 


\section{Soil moisture estimation from L-band active and passive microwave}

observations acquired by Aquarius over the Tibetan Plateau unbiased root mean squared difference (ubRMSD) and coefficient of determination $\left(\mathrm{R}^{2}\right)$, detailed calculation of these error scores are described in Eq. 4.6 - 4.10 in section 4.3.2.

\subsection{Validation}

\subsubsection{Footprint-scale assessment}

The TV-DEM Aquarius is generated based on the algorithm discussed in previous section for the whole Aquarius acquisition period (August 2011 to June 2015) by using the parameters obtained for two years observations over single site (Maqu) from Wang et al. (2018). The TV-DEM Aquarius, official Aquarius, ASCAT and ERA-Interim soil moisture products in 2012 are plotted in Fig. 5.2 as time series along with the mean of in-situ measurements for the available sites from the three regional scale networks included in the Tibet-Obs (Ngari for Fig. 5.2 (a), Naqu for Fig. 5.2 (b) and Maqu for Fig.5.2 (c)). Soil moisture over the Ngari network is retrieved with the LUT with bare soil surface. Soil moisture estimates over Naqu and Maqu networks are obtained by using the LUT with vegetated surfaces. The in-situ measurements of Tibet-Obs are taken as the reference for comparison with the TV-DEM Aquarius, official Aquarius, ASCAT and ERA-Interim soil moisture products. The soil moisture information from two grid cells $\left(31^{\circ} \mathrm{N}, 92^{\circ} \mathrm{E}\right)$ and $\left(33^{\circ} \mathrm{N}, 102^{\circ} \mathrm{E}\right)$ were used for Naqu and Maqu, respectively. Soil moisture retrieval of TV-DEM Aquarius is not available for Ngari in-situ grid cell $\left(32^{\circ} \mathrm{N}, 80^{\circ} \mathrm{E}\right)$ since Aquarius doesn't pass the grid with beam 1, hereby, the soil moisture of nearest grid cell $\left(32^{\circ} \mathrm{N}\right.$, $81^{\circ} \mathrm{E}$ ) for TV-DEM Aquarius, official Aquarius, ASCAT and ERA-Interim are used for comparison with respect to the Ngari in-situ measurement. 


\section{Chapter 5}
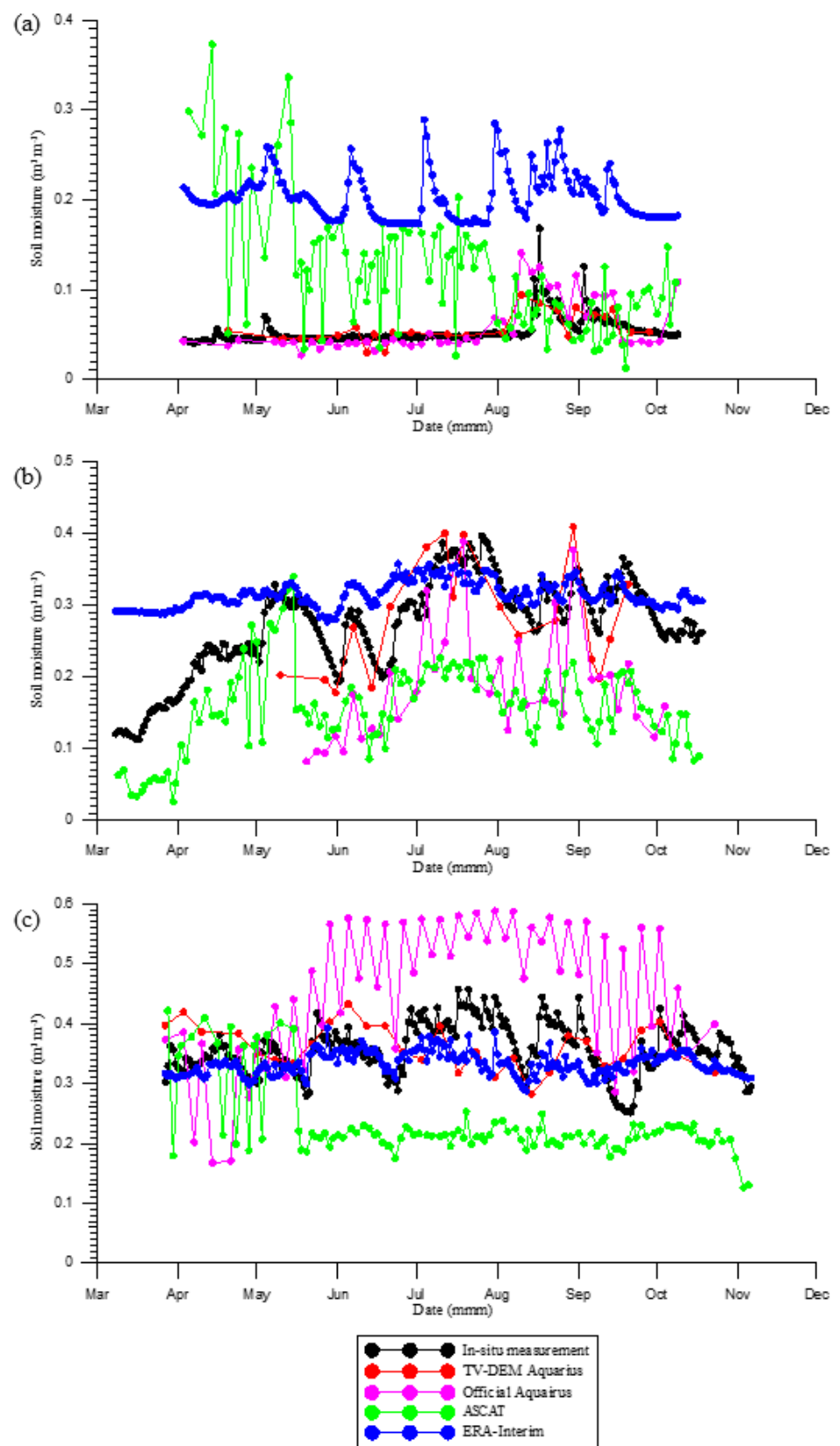

Fig.5.2. Time series of different soil moisture products as well as in-situ soil moisture over Ngari (a), Naqu (b) and Maqu (c) for year 2012 


\section{Soil moisture estimation from $L$-band active and passive microwave observations acquired by Aquarius over the Tibetan Plateau}

Fig. 5.2 (a)-(c) show that the seasonal soil moisture variations measured at the three networks are captured by TV-DEM Aquarius product. Similarly, official Aquarius soil moisture product also show the seasonal change of soil moisture, however, a clear dry bias is shown for Naqu network while a wet bias is seen for Maqu network. ASCAT soil moisture product also captures the variation of soil moisture across the warm season, but it is more scattered in comparison to the in-situ measurements over Ngari site. Moreover, ASCAT indicates a large dry bias for Maqu and Naqu network while a slight wet bias is seen for Ngari network in May and June. ERA-Interim captures the seasonal variation well, but with a limited soil moisture ranging from 0.15 to $0.35 \mathrm{~m}^{3} \mathrm{~m}^{-3}$, this produces a more than $0.10 \mathrm{~m}^{3} \mathrm{~m}^{-3}$ wet bias over Ngari site, which is in agreement with observations of Leroux et al. (2014) who found a wet bias of $0.1-0.2 \mathrm{~m}^{3} \mathrm{~m}^{-3}$ over four Watersheds in U.S. Detailed error metrics calculated by $95 \%$ confidence interval for the three networks in the Aquarius acquisition period are listed in Table 5.1. 


\section{Chapter 5}

Table 5.1. Error metrics of different soil moisture products with respect to in-situ measurement for Aquarius acquisition period (August 2011 to June 2015)

\begin{tabular}{|c|c|c|c|c|c|c|c|}
\hline & & $\begin{array}{l}\text { Number } \\
\text { of } \\
\text { original } \\
\text { retrievals }\end{array}$ & $\begin{array}{l}\text { Number } \\
\text { of match- } \\
\text { up }\end{array}$ & $\begin{array}{c}\text { Bias } \\
\left(\mathrm{m}^{3} \mathrm{~m}^{-3}\right)\end{array}$ & $\begin{array}{l}\text { RMSD } \\
\left(\mathrm{m}^{3} \mathrm{~m}^{-3}\right)\end{array}$ & $\begin{array}{c}\text { ubRMS } \\
\text { D } \\
\left(\mathrm{m}^{3} \mathrm{~m}^{-3}\right)\end{array}$ & $R^{2}(-)$ \\
\hline \multirow{4}{*}{ Ngari } & $\begin{array}{l}\text { TV-DEM } \\
\text { Aquarius }\end{array}$ & 132 & \multirow{4}{*}{33} & -0.007 & 0.017 & 0.016 & 0.499 \\
\hline & $\begin{array}{l}\text { Official } \\
\text { Aquarius }\end{array}$ & 163 & & 0.002 & 0.027 & 0.027 & 0.498 \\
\hline & ASCAT & 336 & & 0.032 & 0.064 & 0.055 & 0.005 \\
\hline & ERA-Interim & 651 & & 0.143 & 0.146 & 0.026 & 0.427 \\
\hline \multirow{4}{*}{ Naqu } & $\begin{array}{l}\text { TV-DEM } \\
\text { Aquarius }\end{array}$ & 78 & \multirow{4}{*}{22} & -0.056 & 0.075 & 0.050 & 0.274 \\
\hline & $\begin{array}{l}\text { Official } \\
\text { Aquarius }\end{array}$ & 92 & & -0.062 & 0.088 & 0.062 & 0.393 \\
\hline & ASCAT & 374 & & -0.106 & 0.127 & 0.070 & 0.294 \\
\hline & ERA-Interim & 735 & & 0.025 & 0.051 & 0.044 & 0.248 \\
\hline \multirow{4}{*}{ Maqu } & $\begin{array}{l}\text { TV-DEM } \\
\text { Aquarius }\end{array}$ & 129 & \multirow{4}{*}{37} & -0.046 & 0.066 & 0.048 & 0.384 \\
\hline & $\begin{array}{l}\text { Official } \\
\text { Aquarius }\end{array}$ & 205 & & 0.121 & 0.149 & 0.087 & 0.352 \\
\hline & ASCAT & 427 & & -0.100 & 0.122 & 0.070 & 0.094 \\
\hline & ERA-Interim & 875 & & 0.007 & 0.049 & 0.049 & 0.387 \\
\hline
\end{tabular}

Table 5.1 illustrates that TV-DEM Aquarius soil moisture always performs with the ubRMSD is better than $0.050 \mathrm{~m}^{3} \mathrm{~m}^{-3}$ and the $\mathrm{R}^{2}$ is larger than $0.274(-)$ over Tibet-Obs. The official Aquarius product is also in line with the in-situ measurements except dry and wet biases are found for Naqu and Maqu respectively. A slightly lower $\mathrm{R}^{2}$ is obtained for the Naqu area compared to the Ngari and Maqu area for ERA-Interim, which is caused by an overestimation of soil moisture by ERA-Interim over the early months before June in 2012 and 2014. This agrees with the findings of Su et al. (2013), who found that ERAInterim in Naqu is overestimated while a comparable value of ERA-Interim is found for Maqu. The significant overestimation of soil moisture over the 


\section{Soil moisture estimation from L-band active and passive microwave observations acquired by Aquarius over the Tibetan Plateau}

western Plateau from ERA-Interim indicates an overestimation of dielectric constant for the surface, which corresponds to a decreasing transmissivity for the surface. Hereby, a lower surface temperature is expected, which is consistent with the cold bias in its skin temperature reported by Chen et al. (2017) caused by its land surface temperature modeling. For ASCAT, low correlation is obtained for Ngari area, this may come from part of it (before June 2012) is scattered over the in-situ measurements with around $0.1 \mathrm{~m}^{3} \mathrm{~m}^{-3}$ overestimation (see Fig.5.2 (a)). For ASCAT, it is quite noisy with low $\mathrm{R}^{2} \mathrm{~s}$ (less than 0.1) are found for Ngari and Maqu network, which in accordance with previous findings (Leroux et al., 2014; Albergel et al., 2012b). Moreover, a slightly wet bias is found for Ngari area while clear dry bias is found for Naqu and Ngari area. Overall, it can be concluded that TV-DEM Aquarius performs best with less bias compared to the other three soil moisture products. Detailed scatter plots of the four soil moisture products against in-situ measurement are shown in Appendix A (Fig.A1-A3).

\subsubsection{Plateau-scale assessment}

The resampled $1^{\circ} \times 1^{\circ}$ grid TV-DEM Aquarius and official Aquarius are averaged per month. Similarly, the ASCAT and ERA-Interim products are also averaged per month for comparison purposes. To demonstrate the spatial soil moisture distribution, the monthly averaged Plateau-scale soil moisture products over Tibetan Plateau from May to October 2012 are shown the first four columns of Fig.5.3. The monthly accumulated precipitation from CHIRPS and monthly evapotranspiration (ET) generated from a revised SEBS model (Chen et al., 2013) are shown in the last two columns.

Fig.5.3 indicates that TV-DEM Aquarius, official Aquarius and ASCAT soil moisture products show the seasonal soil moisture dynamics with increasing values from May to July/August and then decreasing afterwards. This can be attributed to the influence of East Asia monsoon over Tibetan Plateau. The monsoon dominates weather over the Tibetan Plateau and leads to frequent and large amount of precipitation occurring in July and August, resulting in a high soil moisture level during these months.

Moreover, TV-DEM Aquarius, official Aquarius and ASCAT soil moisture products also show clear decreasing gradient in the east-west direction for most of the months in Fig.5.3, this confirms the monsoon movement from south-east to north-west. This pattern is well represented by the evapotranspiration 


\section{Chapter 5}

obtained from SEBS in Fig.5.3, which implies that the TV-DEM Aquarius, official Aquarius and ASCAT can capture the spatial soil moisture variability over the Tibetan Plateau. The dry-wet from northwest to southeast is also exposed by spatial pattern of evapotranspiration (Chen et al., 2014). Similarly, the spatial pattern of TV-DEM Aquarius also can be found in most months of monthly accumulated precipitation from CHIPRS in Fig.5.3. The monsoon effect is not obvious in the ERA-interim product, which has a small magnitude of soil moisture variations, in line with the findings of Su et al. (2013). ASCAT has a lower dynamic range of soil moisture variation during May to October 2012 compared with TV-DEM Aquarius and official Aquarius. ERA-Interim contains low spatial variability of soil moisture over Tibetan Plateau and no soil moisture gradient can be found in west-east direction. 
Soil moisture estimation from L-band active and passive microwave observations acquired by Aquarius over the Tibetan Plateau

TV-DEM Aquarius

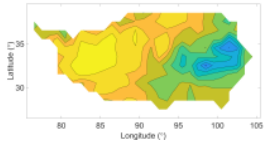

June

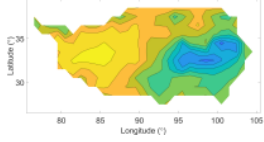

July

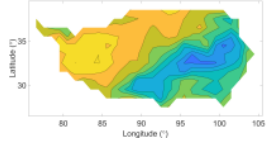

August

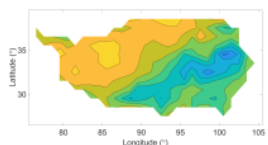

Septembe$$
\mathrm{r}
$$

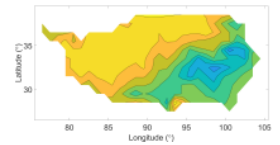

Official Aquarius
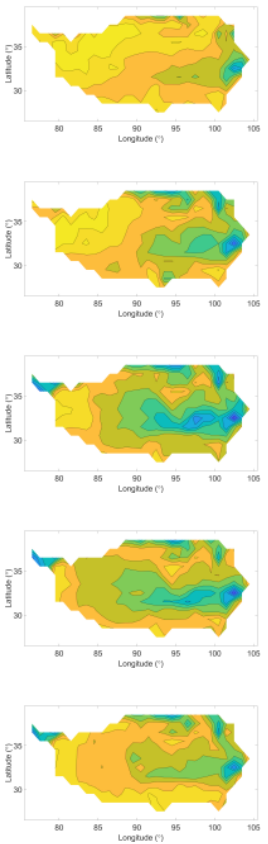

ASCAT
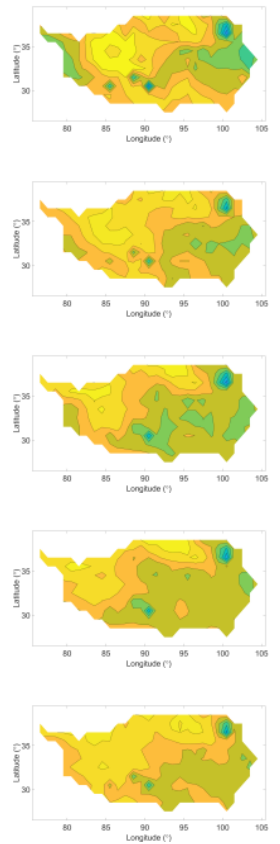

ERA-Interim
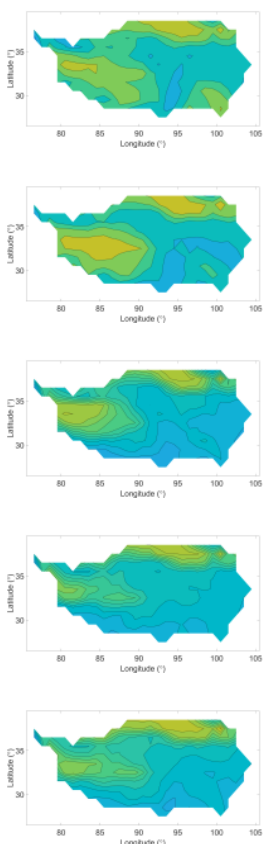

CHIRPS
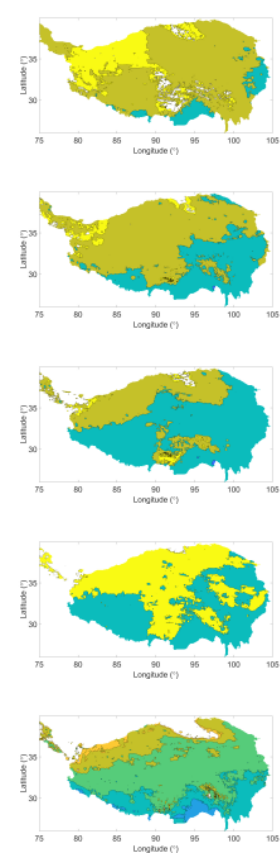

SEBS-ET
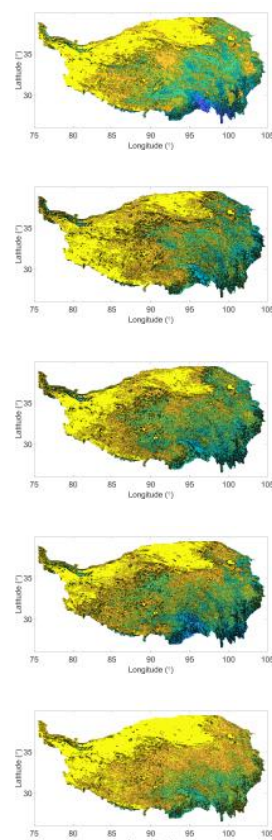
October

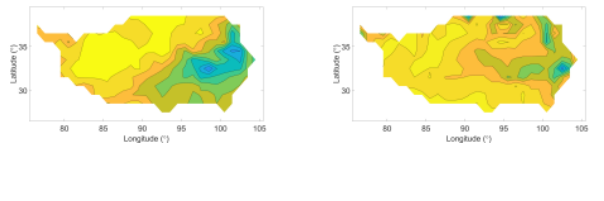

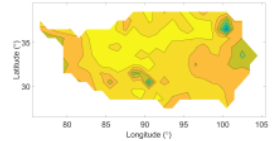

0.3

0.4

0.1

0.2
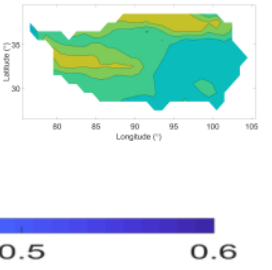

Soil moisture $\left(\mathrm{m}^{3} \mathrm{~m}^{-3}\right)$

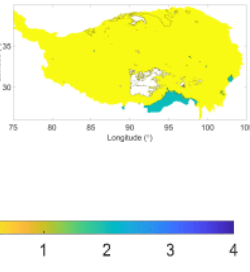

Precipitation (mm/month)

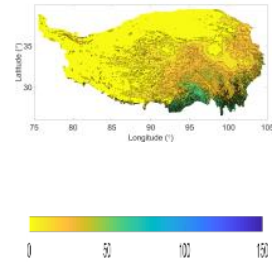

$\mathrm{ET}(\mathrm{mm} / \mathrm{month})$

Fig.5.3. Plateau-scale interpolated monthly soil moisture of TV-DEM-Aquarius, official Aquarius, ASCAT and ERA-Interim from May to October, 2012 as well as the monthly accumulated precipitation from CHIRPS (log10 scale) and evapotranspiration from SEBS 


\section{Soil moisture estimation from $L$-band active and passive microwave observations acquired by Aquarius over the Tibetan Plateau 5.4 Discussion}

\subsubsection{Effect of roughness change}

As single model TV-DEM can simulate emissivity and backscattering coefficient simultaneously with the same set of input parameters, it can be seen that there are three scenarios can be used to retrieve soil moisture, namely TVDEM algorithm using both active and passive observation (TV-DEM-A/P), only the passive observation (TV-DEM-P) and only the active observation (TVDEM-A). However, if the TV-DEM-A/P is needed or TV-DEM-P and TVDEM-A can have a good estimation of soil moisture already is under question. Hereby, we investigated. the added value for using both active and passive Aquarius observation to retrieve soil moisture. To this end, the soil moisture retrieval of TV-DEM-A/P, TV-DEM-P and TV-DEM-A for vegetated surface and bare surface are compared. The effect of $s$ change on object functions for TV-DEM-A/P, TV-DEM-P, TV-DEM-A over vegetated surface and bare soil surface are analyzed and shown in Figs. 5.4 (a) and (b) respectively by carrying out numerical simulation for 100 uniform distributed soil moisture (hereby, we name this set of data as test dataset) in the range of $0.03-0.50 \mathrm{~m}^{3} \mathrm{~m}^{-3}$.

Fig. 5.4(a) and 5.4(b) indicate that object function of TV-DEM-A shows largest sensitivity on $s$ for both vegetated area and bare soil surface, followed by TVDEM-A/P and TV-DEM-P. More specifically, a 50\% underestimation of $s$ will result in a change of $1.024(-), 0.714$ (-) and 0.270 (-) for object function of TVDEM-A, TV-DEM-A/P and TV-DEM-P, respectively for vegetated cover surface and it will lead to a change of $1.502(-), 1.031$ (-) and 0.273 (-) for TVDEM-A, TV-DEM-A/P and TV-DEM-P for bare surface correspondingly. Compared Fig. 5.4(b) with Fig. 5.4(a), it can be concluded that with the same change of $s$, the change of object function for bare soil is larger than vegetated area, which can be explained by the fact that vegetation reduces transmitting signal from the atmosphere to the surface. Moreover, it can be seen that an underestimation of the $s$ results in larger increment in the object function than an overestimation of the roughness, this can be explained by the scattering increases with the increment of $s$, however, when $s$ is at a high level, the increase in scattering is less based on the IEM simulation (Fig.1 (b) of Altese et al. (1996)). 


\section{Chapter 5}
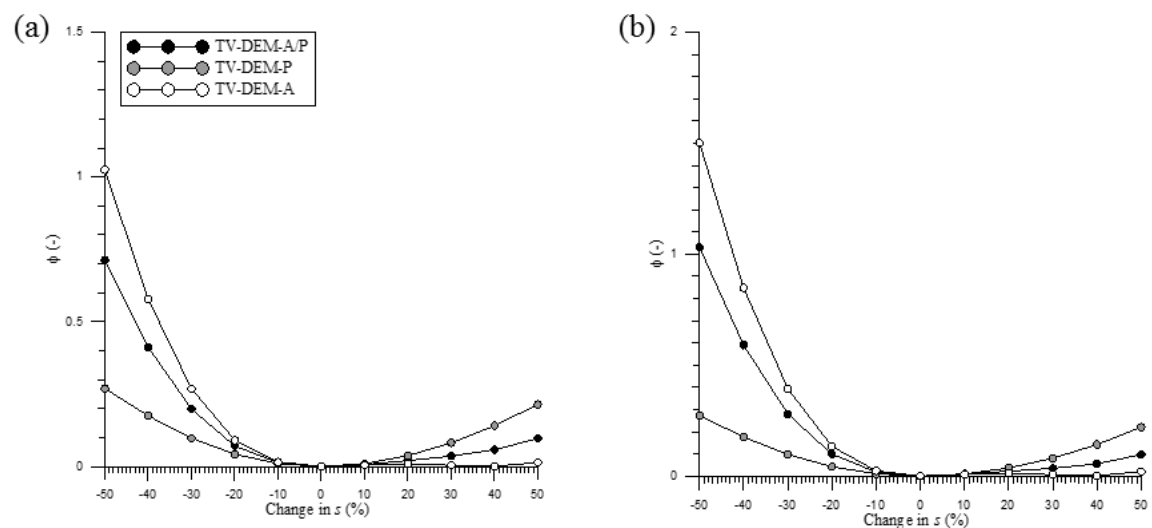

Fig. 5.4. Values of object function of TV-DEM simulation results obtained with a perturbed $s$ over the simulation results achieved with the reference parameter set as functions of the parameter change for a) vegetated $b$ ) bare surface.

Moreover, the effect of $s$ change (within IEM validity domain) on soil moisture retrievals (TV-DEM-A/P, TV-DEM-P, TV-DEM-A) for vegetated areas and bare surfaces have been simulated using the test dataset. For example, the corresponding result for soil moisture of $0.19 \mathrm{~m}^{3} \mathrm{~m}^{-3}$ is shown in Fig. 5.5 (a) and 5.5 (b) for vegetated surface and bare surface, respectively. In Fig. 5.5 (a) and 5.5 (b), a dashed horizontal line represents the soil moisture of $0.19 \mathrm{~m}^{3} \mathrm{~m}^{-3}$ and the reference roughness is $2.67 \mathrm{~cm}$. The displacement with respect to the horizontal line represents the retrieval error due to a possible change of surface roughness. Similar results are observed for vegetated and bare surfaces. As expected, the trend of retrieved soil moisture of TV-DEM-P is inverse with respect to the one of TV-DEM-A. A decrease of " $s$ " has the same effect of soil moistening with passive systems, and soil drying for active systems. The algorithm compensates this by retrieving a lower soil moisture in the first case and a higher soil moisture in the second case. The consequent error is particularly high with smooth soils and active systems. In case of an increase of " $s$ " all effects are reversed. The cost function of the TV-DEM-AP produces a balance between errors of active and passive systems, which reduces the impact of both positive and negative " $s$ " variations, substantially reducing the error on retrieved soil moisture. 


\section{Soil moisture estimation from L-band active and passive microwave observations acquired by Aquarius over the Tibetan Plateau}

(a)

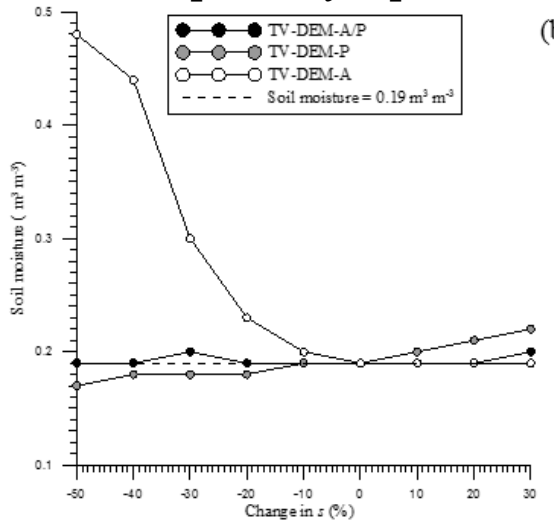

(b)

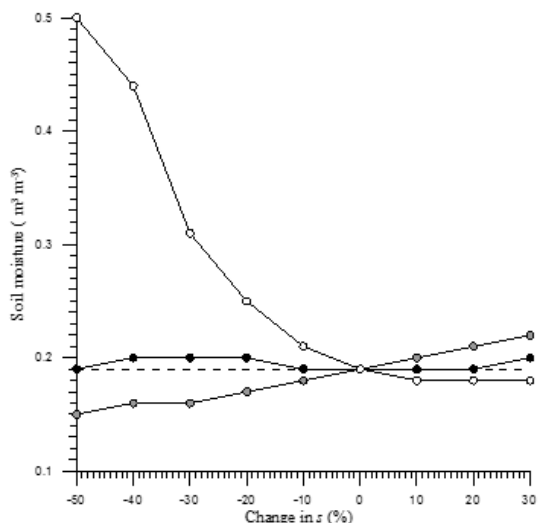

Fig. 5.5. The soil moisture retrievals obtained with a measured soil moisture of $0.19 \mathrm{~m} 3 / \mathrm{m} 3$ and a perturbed $s$ for a) vegetated b) bare surface.

\subsubsection{Spatially variable roughness}

As the $s$ is sensitive to IEM surface scattering (Altese et al., 1996), the validity of the assumption for taking a constant $s$ of $2.67 \mathrm{~cm}$ for the entire Tibetan Plateau for estimating soil moisture with algorithm based on TV-DEM simulations is investigated. Van der Velde et al. (2012a) proposed a roughness estimation algorithm based on minimizing the absolute difference between and model simulated of satellite observed $\sigma^{0}$ collected from three view angles over frozen soil. Different from van der Velde et al. (2012a), we use single angle satellite observations with two polarizations ( $\mathrm{HH}$ and $\mathrm{VV}$ ) for retrieving roughness here, which is shown as follows.

$$
\phi_{s}=\sum_{p=H, V}\left|\sigma_{p p}^{0}(\operatorname{sim})-\sigma_{p p}^{0}(o b s)\right|
$$

where $\phi_{s}(-)$ represents the object function used for the surface roughness estimation, the observation of each grid used here is the solo acquisition with minimal backscattering coefficient in both $\mathrm{HH}$ and $\mathrm{VV}$ polarization. We assume the aforementioned observation corresponds to the frozen soil with a water content level of $0.05 \mathrm{~m}^{3} \mathrm{~m}^{-3}$ (Wegmüller, 1990). Hereby, the IEM simulations are performed by changing $s$ from 0.10 to 3.50 with $0.01 \mathrm{~cm}$ interval with a fixed $l$ of $9 \mathrm{~cm}$ and an exponential ACF is considered as well as the Mironov model (Mironov et al., 2009) is used for calculating the soil dielectric constant for a soil moisture of $0.05 \mathrm{~m}^{3} \mathrm{~m}^{-3}$. By searching the minimum of Eq. 5.2 with $s$ 
Chapter 5

varies in the range of 0.10 to $3.50 \mathrm{~cm}$, the corresponding $s$ for each grid is computed. The retrieved $s$ over the Tibetan Plateau and its histogram are shown in Fig. 5.6.
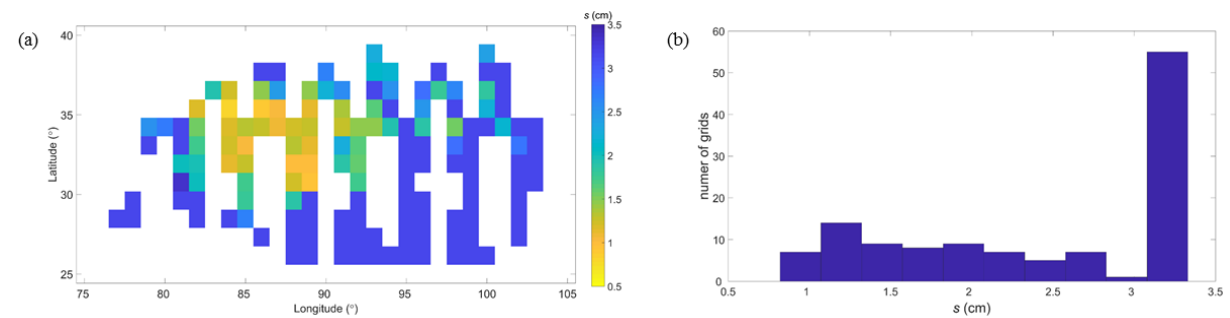

Figure. 5.6 Retrieved s (a) and its histogram (b) over Tibetan Plateau by using approach of van der Velde (2012a)

Fig. 5.6 (a)-(b) indicate that the retrieved $s$ for the Tibetan Plateau changes from 0.82 to $3.16(\mathrm{~cm})$. Among them, 55 out of $122(45.1 \%)$ retrieved $s$ value is 3.16 $(\mathrm{cm})$, which are mostly located in the eastern vegetated areas of the Tibetan Plateau. This $s(3.16 \mathrm{~cm})$ is in the range of $(+10 \%,+20 \%)$ with respect to the reference roughness and will cause a less than 0.20 (-) change of object function value (Fig.5.5 (a)), resulting in an ubRMSD of less than $0.015 \mathrm{~m}^{3} \mathrm{~m}^{-3}$ for TVDEM-A/P by computing Fig.5.5 for the whole test dataset. Other retrieved $s$ in vegetated areas are in the range of $(1.40,3.16) \mathrm{cm}$, which corresponds to $(-50 \%$, $+20 \%$ ) range with respect to the referenced roughness $(2.67 \mathrm{~cm})$, and this will result an ubRMSD of less than $0.024 \mathrm{~m}^{3} \mathrm{~m}^{-3}$ by calculating TV-DEM-A/P retrievals in Fig.5.5 for the whole test dataset.

Fig. 5.6 (a) also show that the retrieved $s$ of serval grids are even lower than $50 \%$ of the reference roughness, for example, a minimal $s$ of $0.82 \mathrm{~cm} \mathrm{(-69 \%} \mathrm{of}$ the referenced roughness) is retrieved for the grid $(35,84)$. These grids with a low $s$ are located in the eastern part of Tibetan Plateau and fall in the land cover of bare soil, with the corresponding ubRMSD will be less than $0.011 \mathrm{~m}^{3} \mathrm{~m}^{-3}$ with the retrieved $s$ falls in $(-50 \%,+20 \%)$ with respect to the reference roughness. By expanding the low boundary of $s$ change in Fig.5.5 to $-70 \%$ with respect to the referenced roughness $(0.80 \mathrm{~cm})$, the corresponding ubRMSD of retrieved soil moisture of TV-DEM-A/P for the whole test dataset with the $s$ will be $0.024 \mathrm{~m}^{3} \mathrm{~m}^{-3}$. Hereby, we conclude that by using a constant $s$ across Tibetan Plateau (bare soil and vegetated area are included), the ubRMSD of $0.024 \mathrm{~m}^{3} \mathrm{~m}^{-3}$ will be obtained by using TV-DEM-A/P, which is acceptable based on SMOS and SMAP mission requirement. However, more accurate soil 


\section{Soil moisture estimation from L-band active and passive microwave observations acquired by Aquarius over the Tibetan Plateau}

moisture map should be generated by using various roughness for each grid.

Furthermore, it should be noted that the roughness estimated by using algorithm provided in Van der Velde et al. (2012a) is $2.77 \mathrm{~cm}$ for Maqu site (Fig.5.6 (a)), which is very close to $2.67 \mathrm{~cm}$ used in our TV-DEM algorithm, this implies the roughness estimation by using derivative method of Van der Velde et al. (2012a) will be a reasonable option.

\subsection{Conclusion}

An algorithm is developed for retrieving soil moisture at plateau scale by combined usage of Aquarius active and passive L-band observations. For this algorithm, Look-up tables (LUT) are generated by using optimized parameters (standard deviation of surface height $(s)$, plant moisture, litter moisture, litter biomass) of Tor Vergata-Discrete Electromagnetic Model (TV-DEM) obtained from single site (Maqu) in Tibetan Plateau. For vegetated areas, the LUT is created with soil moisture and leaf area index (LAI) as variables, while soil moisture is the sole variable for the bare surface LUT. By using these LUTs, soil moisture is retrieved from Aquarius brightness temperature $\left(T_{b}\right)$ and backscattering coefficient $\left(\sigma^{0}\right)$ observed over Tibetan Plateau from August 2011 to June 2015. The retrievals (indicated as TV-DEM Aquarius) are validated with the ground measurements in three networks located respectively in the western, central and eastern Tibetan Plateau. TV-DEM retrieved soil moisture captures the seasonal dynamics well and agrees with in-situ soil moisture with the $\mathrm{R}^{2}$ are $0.499,0.274$ and 0.384 (-) together with ubRMSDs of $0.016,0.050$ and $0.048 \mathrm{~m}^{3} \mathrm{~m}^{-3}$ for the Ngari, Naqu and Maqu networks, respectively. TVDEM Aquarius is further compared with official Aquarius, ASCAT and ERAInterim surface soil moisture products over the three networks and we find that the performance of TV-DEM Aquarius is in line with other three soil moisture products over these networks by considering the ubRMSD and $\mathrm{R}^{2}$ values.

The four soil moisture products are also compared at a Plateau-scale with respect to the precipitation dataset from CHIRPS and evapotranspiration (ET) from thermal remote sensing method during May to October 2012. In terms of temporal change, TV-DEM Aquarius, official Aquarius and ASCAT soil moisture products show clear seasonal dynamics over these months due to the influence of East Asian monsoon. The ERA-Interim soil moisture product shows little variation in the same period. In terms of spatial variability, TVDEM Aquarius, official Aquarius and ASCAT soil moisture products also show 


\section{Chapter 5}

decreasing soil moisture gradient in the northwest to southeast direction for most of the months, which dry-wet spatial pattern has been clearly shown by the spatial variability of ET and precipitation. With these findings, we conclude the TV-DEM based algorithm can be used to retrieve reliably soil moisture in a Plateau scale.

By combined usage of Aquarius active and passive observations, the uncertainty of roughness on soil moisture retrieval is reduced and a more reliable soil moisture estimation is obtained compared with the soil moisture retrievals with only active or passive observation is used. Furthermore, the accuracy of our TVDEM soil moisture retrieval is comparable with other state of art products, which is encouraging to investigate further the usage discrete electromagnetic models as part of retrieval algorithms. As this TV-DEM based algorithm can be modified based on land cover, global soil moisture estimation can be considered later on by including accurate global vegetation parameters, for example, morphologic parameters for trees in forested area. 
Soil moisture estimation from L-band active and passive microwave observations acquired by Aquarius over the Tibetan Plateau 


\section{Chapter 6 Conclusions and recommendations}

\subsection{Introduction}

Soil moisture is one of the key components in the water cycle and plays an important role in land and atmosphere interaction with respect to energy, water and gasses. Accurate soil moisture estimation will benefit hydrology, agriculture, meteorology, and climate change research. Both active and passive microwave observations show sensitivity to soil moisture and can be used to retrieve soil moisture. Soil moisture estimation by combined usage of active and passive microwave observations may solve some of the ambiguity involved in soil moisture retrieval due to the inherent problems in remote sensing retrievals, but a fundamental investigation has not received much traction into uncovering the critical factors in synergistic use of active and passive microwave observation. This thesis contributes to a better estimation of soil moisture across the Tibetan Plateau by combining the usage of single L-band active and passive observations from the satellite Aquarius. Three research objectives have been formulated (section 1.3) and the conclusions reached as a result of the research outlined in the previous chapters follow below in section 6.2. Recommendations for the further research are listed in section 6.3.

\subsection{Conclusions}

\subsubsection{Sensitivity of Aquarius observations over soil moisture in}

\section{Maqu network}

The time series of Aquarius scatterometer and radiometer observations indicate clear seasonal dynamics. In the winter season when the soil is dry, the backscattering coefficient $\left(\sigma^{0}\right)$ is at a relatively low level while the brightness temperature $\left(T_{b}\right)$ is high; in the summer season, on the other hand, a low $T_{b}$ and a high $\sigma^{0}$ are observed, corresponding to a wetter soil. The passive microwave measurements converted to emissivity $(e)$ by dividing the $T_{b}$ with temperature measured at 5-cm soil depth show a clear sensitivity to mean soil moisture at 5$\mathrm{cm}$ depth for the Maqu area. Similarly, the $\sigma^{0}$ increases with rising soil moisture, 


\section{Conclusions and recommendations}

but saturates at a level of $0.30 \mathrm{~m}^{3} \mathrm{~m}^{-3}$. These findings prove that Aquarius active and passive observations can be synergistically used for further soil moisture estimation.

The vegetation effects on $\sigma^{0}$ are quantified through the radar vegetation index (RVI) and results show that the RVI indeed shows promise regarding quantifying the vegetation biomass. However, the RVI in the Maqu area is barely greater than 0.4 (-), indicating that in the Maqu area vegetation has a limited effect. Furthermore, the Microwave Polarization Difference Index (MPDI) derived from Aquarius $T_{b}$ is used to reproduce the optical depth $(\tau)$ and results show that the dynamics of $\tau$ are in agreement with vegetation change in the Maqu area.

\subsubsection{Use of a discrete electromagnetic model for simulating}

\section{Aquarius L-band active/passive observations and soil moisture retrieval}

A theoretical model, TV-DEM (Discrete Electromagnetic Model developed at the Tor Vergata University in Rome) is selected to simulate Aquarius active and passive observations and is applied together with the in-situ measurements at the Maqu study area. The sensitivity of the model output to input parameters is first analyzed to simplify the model, and it is concluded that the most sensitive input parameters in the TV-DEM are standard deviation of surface height, litter moisture, litter biomass and plant moisture. With the four most sensitive input parameters in TV-DEM selected, the calibrated values of these parameters are attained, based on the minimization of the difference between the Aquarius observations and the TV-DEM output in a least-squares sense, by considering the dataset for years 2012 and 2013. These calibrated values are $2.67 \mathrm{~cm}$ for standard deviation of surface height, 1.06 (-) for litter moisture, $0.03\left(\mathrm{~g} \mathrm{~cm}^{-2}\right)$ for litter biomass and $0.59\left(\mathrm{~kg} \mathrm{~kg}^{-1}\right)$ for plant moisture. Forward simulations by the TV-DEM using the calibrated parameters are compared with the Aquarius observations for the years 2014 and 2015 to further validate the choice of calibrated parameters. An average $\mathrm{R}^{2}$ of 0.80 for $T_{b}$ and of 0.53 for $\sigma^{0}$ is achieved between the Aquarius observations and the calibrated TV-DEM simulations for the calibration period as well as the validation period.

Moreover, soil moisture retrieval based on the TV-DEM is proposed and these retrievals are compared with the widely used $\tau$ - $\omega$ model. With the error metrics 


\section{Chapter 6}

computed, we concluded that TV-DEM retrievals have the least biased difference of $0.008 \mathrm{~m}^{3} \mathrm{~m}^{-3}$ with respect to the in-situ measurements as well as an unbiased Root Mean Square Difference (ubRMSD) of $0.021 \mathrm{~m}^{3} \mathrm{~m}^{-3}$, which is comparable with the performance of the retrievals of the $\tau$ - $\omega$ model. This proves that a single model, the TV-DEM, can simulate both brightness temperatures and backscattering coefficients that are to some extent in agreement with Lband observations made from the Aquarius space platform. It also ascertains that the soil moisture retrieval by the TV-DEM from Aquarius active and passive observations is of great potential.

\subsubsection{Soil moisture estimation over the Tibetan Plateau}

A soil moisture retrieval algorithm at plateau scale is developed by combining the usage of Aquarius active and passive observations. The algorithm starts with Look-up tables (LUTs) generated by using optimized parameters (standard deviation of surface height $(s)$, plant moisture, litter moisture, litter biomass) from the Maqu area and varied soil moisture levels $\left(0.03\right.$ to $0.50 \mathrm{~m}^{3} \mathrm{~m}^{-3}$ with an interval of $0.001 \mathrm{~m}^{3} \mathrm{~m}^{-3}$ ) together with the TV-DEM. The leaf area index (LAI, 0.1 to $5.0 \mathrm{~m}^{2} \mathrm{~m}^{-2}$ with an interval of $0.1 \mathrm{~m}^{2} \mathrm{~m}^{-2}$ ) is considered for vegetated areas, but set to zero for bare soil surface, for the establishment of the LUTs.

Soil moisture is retrieved from Aquarius brightness temperature $\left(T_{b}\right)$ and backscattering coefficient $\left(\sigma^{0}\right)$ observations over the Tibetan Plateau in the Aquarius acquisition period and interpolated into a $1^{\circ} \times 1^{\circ}$ grid. The retrievals (denoted as TV-DEM Aquarius) are validated in the three networks located in the western (Ngari), central (Naqu) and eastern (Maqu) Tibetan Plateau with the corresponding ground measurements. Results show that an $\mathrm{R}^{2}$ of $0.499,0.274$ and $0.384(-)$, and an ubRMSD of $0.016,0.050$ and $0.048 \mathrm{~m}^{3} \mathrm{~m}^{-3}$ are achieved, respectively, for the Ngari, Naqu and Maqu network. Furthermore, TV-DEM Aquarius retrievals show less bias than the other three soil moisture products (official Aquarius, ASCAT and ERA-Interim) with respect to the in-situ measurements across the three networks. All four soil moisture products are compared with the precipitation dataset from CHIRPS as well as evapotranspiration (ET) from May to October 2012 at plateau scale in terms of spatial-temporal distributions. Results show that the TV-DEM Aquarius soil moisture product can capture clear seasonal dynamics, as is also seen in the official Aquarius and ASCAT soil moisture products. Furthermore, TV-DEM Aquarius indicates a clear dry-wet spatial pattern in the northwest to southeast direction for most of the months, which agrees with the spatial variability of ET 


\section{Conclusions and recommendations}

and precipitation, and is less clearly observed in official Aquarius and ASCAT soil moisture products. This leads to the conclusion that the TV-DEM based algorithm may be used to reliably retrieve soil moisture at Plateau scale.

\subsection{Recommendations}

This research showed the successful soil moisture retrieval over the Tibetan Plateau by using Aquarius active and passive observations on the basis of the TV-DEM. Moreover, it gives an insight into the influence the Asian monsoon has over the Tibetan Plateau in terms of response by spatial-temporal soil moisture to precipitation and evapotranspiration.

Firstly, as indicated in Chapter 3, Aquarius observations are sensitive to frozen soil, which implies that soil moisture estimation may be further studied during periods of frost as well. As frozen soil is a mixture of liquid water, ice and soil particles, specific equations to represent the frozen soil dielectric constant should be further developed. Moreover, to what extent the TV-DEM may be used to retrieve data on liquid water in frozen soil would also make an interesting study topic.

Secondly, soil moisture estimation for other land covers should be further investigated, such as for forest or shrub. As the TV-DEM shows many variants depending on the vegetation type that is represented by the morphological parameters, the most sensitive parameters for each land cover should be investigated. Furthermore, soil moisture estimation can be conducted for various land cover types.

Thirdly, TV-DEM soil moisture retrieval through the combination of active and passive observations with different resolutions should be further analyzed. The soil moisture active passive (SMAP) satellite provided 1-3 km resolution radar observations and $36 \mathrm{~km}$ resolution radiometer observations for the first half year of the mission until the radar failed. Hence, how to produce an intermediate resolution soil moisture map based on the TV-DEM with fine resolution radar observations and coarse resolution radiometer observations should be further investigated. 


\section{Appendix A}

(a)

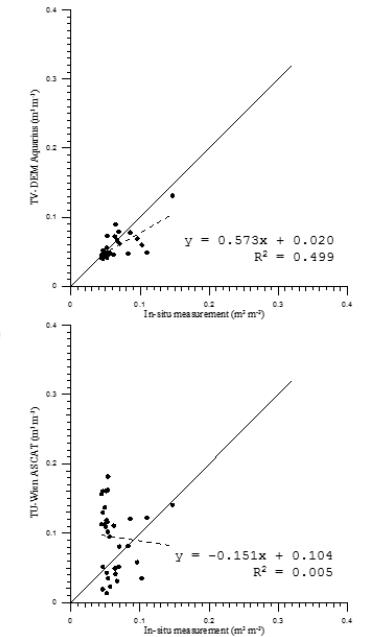

(b)

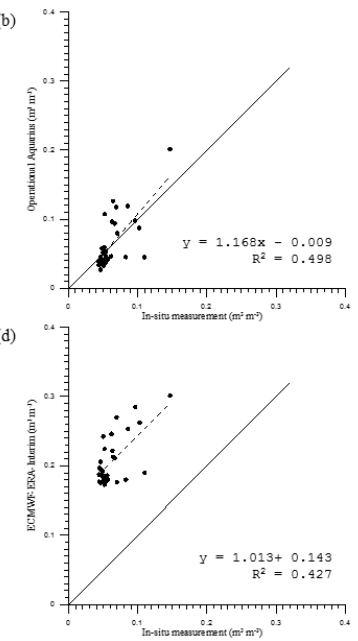

Figure A1. Scatter plot of soil moisture products (a) TV-DEM Aquarius (b) Official Aquarius (c) ASCAT (d) ERA-Interim against in-situ soil moisture over Ngari with 1:1 line (solid line) and regression line (dashed line) are indicated

(a)
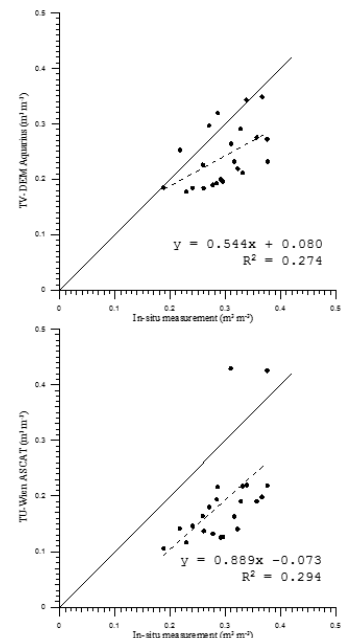

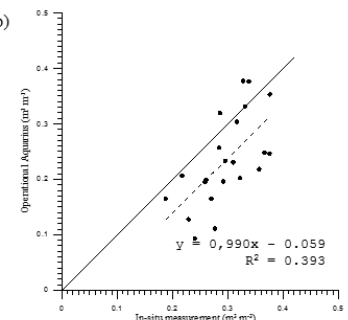

(d)

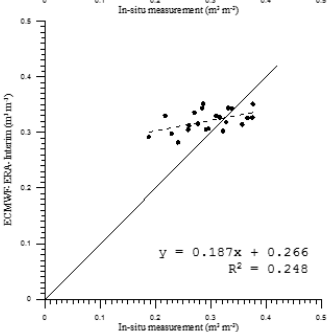

Figure A2. Scatter plot of soil moisture products (a) TV-DEM Aquarius (b) Official Aquarius (c) ASCAT (d)

ERA-Interim against in-situ soil moisture over Naqu with 1:1 line (solid line) and regression line (dashed line) are indicated 


\section{Appendix A}
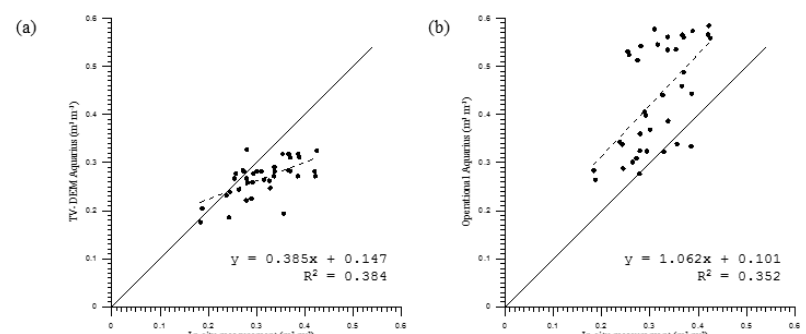

(c)

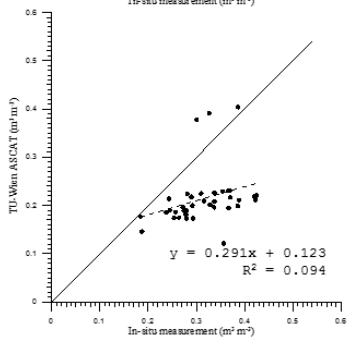

(d)

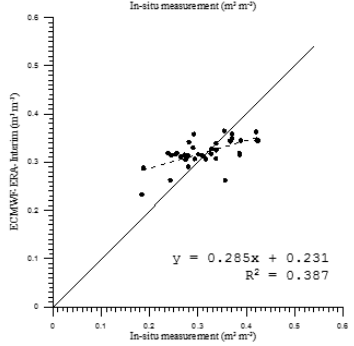

Figure A3. Scatter plot of soil moisture products (a) TV-DEM Aquarius (b) Official Aquarius (c) ASCAT (d) ERA-Interim against in-situ soil moisture over Maqu with 1:1 line (solid line) and regression line (dashed line) are indicated 


\section{Bibliography}

Abdel-Messeh M. and Quegan, S. (2001). Relating ERS scatterometer data to global vegetation models. In ERS-ENVISAT Symposium'Looking down to Earth in the New Millennium. Available at https://pdfs.semanticscholar.org/6811/92f5aed5724a494a9bcdb73a76787670e56a.pdf

Arfken, G. B.; Weber, H.; and Harris, F. E. Mathematical Methods for Physicists, 7th ed.: A Comprehensive Guide. Orlando, FL: Academic Press, 2012.

Akbar, R. and Moghaddam, M. (2015). A combined active-passive soil moisture estimation algorithm with adaptive regularization in support of SMAP. IEEE Transactions on Geoscience and Remote Sensing, 53(6), 3312-3324. DOI: 10.1109/TGRS.2014.2373972

Albergel, C., De Rosnay, P., Balsamo, G., et al. (2012a). Soil moisture analyses at ECMWF: Evaluation using global groundbased in situ observations. Journal of Hydrometeorology, 13(5), 1442-1460. DOI: 10.1175/JHM-D-11-0107.1

Albergel, C., De Rosnay, P., Gruhier, C., et al. (2012b). Evaluation of remotely sensed and modelled soil moisture products using global ground-based in situ observations. Remote Sensing of Environment, 118, 215-226. DOI: 10.1016/j.rse.2011.11.017 Algorithm Theoretical Baseline Document (ATBD) Surface Soil Moisture ASCAT NRT Orbit. [online]. Available: http://hsaf.meteoam.it/documents/ATDD/ssm_ascat_nrt_o_atbd.pdf

Altese, E., Bolognani, O., Mancini, M., et al. (1996). Retrieving soil moisture over bare soil from ERS 1 synthetic aperture radar data: Sensitivity analysis based on a theoretical surface scattering model and field data. Water Resources Research, 32(3), 653661. DOI:10.1029/95WR03638

Al-Yaari, A., Wigneron, J. P., Ducharne, A., et al. (2014). Global-scale comparison of passive (SMOS) and active (ASCAT) satellite based microwave soil moisture retrievals with soil moisture simulations (MERRA-Land). Remote Sensing of Environment, 152, 614-626. DOI: 10.1016/j.rse.2014.07.013

Aquarius level-2 data product (version 3.0). (2015). [online]. Available: ftp://podaac-

ftp.jpl.nasa.gov/allData/aquarius/docs/v4/AQ-014-PS-0018_AquariusLevel2specification_DatasetVersion4.0.pdf

Attema, E. P. W. and Ulaby, F. T. (1978). Vegetation modeled as a water cloud. Radio science, 13(2), 357-364. DOI:

10.1029/RS013i002p00357

Bindlish, R., T.J. Jackson, E.F. Wood, et al. (2003). Soil moisture estimates from TRMM Microwave Imager Observations over the Southern United States, IEEE Transactions on. Geoscience and. Remote. Sensing., 85(4), 507-515. DOI:10.1016/S00344257(03)00052-X

Bindlish, R., Jackson, T., Cosh, M., et al. (2015). Global soil moisture from the Aquarius/SAC-D satellite: description and initial assessment. IEEE Geoscience and Remote Sensing Letters, 12(5), 923-927. DOI: 10.1109/LGRS.2014.2364151. 


\section{Bibliography}

Bindlish, R. and T. Jackson. (2015). Aquarius L3 Gridded 1-Degree Daily Soil Moisture, Version 4. [Indicate subset used]. Boulder, Colorado USA. NASA National Snow and Ice Data Center Distributed Active Archive Center. DOI: http://dx.doi.org/10.5067/Aquarius/AQ3_DYSM.004

Bracaglia, M., Ferrazzoli, P., and Guerriero, L. (1995). A fully polarimetric multiple scattering model for crops. Remote Sensing of Environment, 54, 170-179. DOI: 10.1016/0034-4257(95)00151-4

Brocca, L., Melone, F., Moramarco, T., et al. (2010). ASCAT soil wetness index validation through in situ and modeled soil moisture data in central Italy. Remote Sensing of Environment, 114(11), 2745-2755. DOI: 10.1016/j.rse.2010.06.009

Brocca, L., Crow, W. T., Ciabatta, L., et al. (2017). A review of the applications of ASCAT soil moisture products. IEEE Journal of Selected Topics in Applied Earth Observations and Remote Sensing, 10(5), 2285-2306. DOI: 10.1109/JSTARS.2017.2651140

Bruscantini, C. A., Crow W.T., G rings, F., et al. (2014). An Observing System Simulation Experiment (OSSE) for the Aquarius/SAC-D soil moisture product. IEE Transactions on Geoscience and Remote Sensing, 52 (10),1-9. DOI:

10.1109/TGRS.2013.2294915

Chan, S., Bindlish, R., Hunt, R., et al. (2013). Ancillary Data Report: Vegetation Water Content. Jet Propulsion Laboratory, California Institute of Technology. https://smap.jpl.nasa.gov/documents/

Chauhan, N. S., Le Vine, D. M., and Lang, R. H. (1994). Discrete scatter model for microwave radar and radiometer response to corn: comparison of theory and data. IEEE Transactions on Geoscience and Remote Sensing, 32(2), 416-426. DOI:

$10.1109 / 36.295056$

Chen, X., Su, Z., Ma, Y., et al. (2013). An improvement of roughness height parameterization of the Surface Energy Balance System (SEBS) over the Tibetan Plateau. Journal of Applied Meteorology and Climatology, 52(3), 607-622. DOI:

10.1175/JAMC-D-12-056.1

Chen, X., Su, Z., Ma, Y., et al. (2014). Development of a 10-year (2001-2010) 0.1 ${ }^{\circ}$ data set of land-surface energy balance for mainland China. Atmospheric chemistry and physics,14,13097-13117. DOI: 10.5194/acp-14-13097-2014

Chen, X., Su, Z., Ma, Y., et al. (2017). An accurate estimate of monthly mean land surface temperatures from MODIS clear-sky retrievals. Journal of Hydrometeorology, 18,2827-2847. DOI: 10.1175/jhm-d-17-0009.1

Choudhury, B. J., Schmugge, T. J., Chang, A., et al. (1979). Effect of surface roughness on the microwave emission from soils. Journal of Geophysical Research: Oceans (1978-2012),84(C9), 5699-5706. DOI: 10.1029/JC084iC09p05699

Choudhury, B. J., Tucker, C. J., Golus, R. E., et al. (1987). Monitoring vegetation using Nimbus-7 scanning multichannel microwave radiometer's data. International Journal of Remote Sensing, 8(3), 533-538. DOI:10.1080/01431168708948660

Colliander, A. and Xu, X. (2013). Normalized Residual Scattering Index Applied to Aquarius L-Band Measurements. IEEE Geoscience and Remote Sensing Letters, 10(4), 890-894. DOI: 10.1109/LGRS.2012.2226559

Colliander, A., Jackson, T. J., Bindlish, R., et al. (2017). Validation of SMAP surface soil moisture products with core validation sites. Remote Sensing of Environment, 191, 215-231. DOI: 10.1016/j.rse.2017.01.021

Cosh, M. H., S. Moran, and Bindlish.R (2008). Temporal persistence and stability of surface soil moisture in a semi-arid watershed, Remote Sensing of Environment., 112, 304-313, DOI:10.1016/j.rse. 2007.07.001 


\section{Bibliography}

Das, N. N., Entekhabi, D., and Njoku, E. G. (2011). An algorithm for merging SMAP radiometer and radar data for highresolution soil-moisture retrieval. IEEE Transactions on Geoscience and Remote Sensing, 49(5), 1504-1512. DOI:

10.1109/TGRS.2010.2089526

Das, N. N., Entekhabi, D., Njoku, E. G., et al. (2014). Tests of the SMAP combined radar and radiometer algorithm using airborne field campaign observations and simulated data. IEEE Transactions on Geoscience and Remote Sensing, 52(4), 20182028. DOI: 10.1109/TGRS.2013.2257605

Dee, D. P., Uppala, S. M., Simmons, A. J., et al. (2011). The ERA-Interim reanalysis: Configuration and performance of the data assimilation system. Quarterly Journal of the royal meteorological society, 137(656), 553-597. DOI: 10.1002/qj.828

Della Vecchia, A., Ferrazzoli, P., Guerriero, L., et al. (2006). Influence of geometrical factors on crop backscattering at C-band. IEEE transactions on geoscience and remote sensing, 44(4), 778-790. DOI: 10.1109/TGRS.2005.860489

Della Vecchia, A., Ferrazzoli, P., Wigneron, J. P., et al. (2007). Modeling forest emissivity at L-band and a comparison with multitemporal measurements. IEEE Geoscience and Remote Sensing Letters, 4(4), 508-512. DOI: 10.1109/LGRS.2007.900687

Della Vecchia, A., Ferrazzoli, P., Guerriero, L., et al. (2010). Modeling the multifrequency emission of broadleaf forests and their components. IEEE Transactions on Geoscience and Remote Sensing, 48(1), 260-272. DOI: 10.1109/TGRS.2009.2029343

Dente, L., Su, Z., and Wen, J. (2012). Validation of SMOS soil moisture products over the Maqu and Twente regions. Sensors, 12(8), 9965-9986. DOI: 10.3390/s120809965

Dente, L., Vekerdy, Z., Wen, J., et al. (2012). Maqu network for validation of satellite-derived soil moisture products. International Journal of Applied Earth Observation and Geoinformation,17, 55-65. DOI:10.1016/j.jag.2011.11.004

Dente, L., Ferrazzoli, P., Su, Z., et al. (2014). Combined use of active and passive microwave satellite data to constrain a discrete scattering model. Remote Sensing of Environment, 155, 222-238. DOI: 10.1016/j.rse.2014.08.031

Doherty, J. (2004). PEST: Model Independent Parameter Estimation User Manual, 5th ed. Watermark Numerical Computing, Brisbane, Australia.

Dorigo, W., Chung, D., Parinussa, R.M.,et al. (2014).[Global Climate] Soil Moisture [in: "State of the Climate in 2013”].

Bulletin of the American Meteorological Society 95 (7), S25-S26.

Entekhabi, D., Njoku, E. G., O'Neill, et al.,2010. The soil moisture active passive (SMAP) mission. Proceedings of the IEEE, 98(5), 704-716. DOI:10.1109/JPROC.2010.2043918

Dubois, P. C., Van Zyl J., and Engman, T. (1995). Measuring soil moisture with imaging radars. IEEE Transactions on Geoscience and Remote Sensing, ,33(4), 915-926. DOI:10.1109/36.406677

Entekhabi, D., Njoku, E., Houser, P., et al. (2004). The Hydrosphere State (HYDROS) mission concept: An Earth system pathfinder for global mapping of soil moisture and land freeze/thaw. IEEE Transactions on Geoscience and Remote Sensing, 42(10), 2184-219. DOI: 10.1109/TGRS.2004.834631

Entekhabi, D., Njoku, E. G., O'Neill, P. E., et al. (2010). The soil moisture active passive (SMAP) mission. Proceedings of the IEEE, 98(5), 704-716. DOI: 10.1109/JPROC.2010.2043918 


\section{Bibliography}

Eom, H. J., Fung, A. K. (1984). A scatter model for vegetation up to Ku-band. Remote Sensing of Environment, 15(3), 185-200. DOI: 10.1016/0034-4257(84)90030-0.

Escorihuela, M. J., Chanzy, A., Wigneron, J. P., et al. (2010). Effective soil moisture sampling depth of L-band radiometry: A case study. Remote Sensing of Environment, 114(5), 995-1001. DOI: 10.1016/j.rse.2009.12.011

Fabre, S., Briottet, X., and Lesaignoux, A. (2015). Estimation of soil moisture content from the spectral reflectance of bare soils in the 0.4-2.5 $\mu$ m domain. Sensors, 15(2), 3262-3281. DOI: $10.3390 / \mathrm{s} 150203262$

Fan, J. and I. Gijbels. 1996. Local Polynomial Modelling and its Applications, Chapman and Hall, 1996.

Fascetti, F., Pierdicca, N., Pulvirenti, L., ET AL. (2016). A comparison of ASCAT and SMOS soil moisture retrievals over Europe and Northern Africa from 2010 to 2013. International journal of applied earth observation and geoinformation, 45, 135142. DOI: $10.1016 /$ j.jag.2015.09.008

Ferrazzoli, P., Luzi, G., Paloscia, S., et al. (1989). Comparison between the microwave emissivity and backscatter coefficient of crops. IEEE Transactions on Geoscience and Remote Sensing, 27(6), 772-778. DOI: 10.1109/TGRS.1989.1398244

Ferrazzoli P. and Guerriero L. (1996). Passive microwave remote sensing of forests: A model investigation, IEEE Transactions on Geoscience and Remote Sensing, 34(2), 433-443, DOI: 10.1109/36.485121

Fock, V.A. J. Phys. (Moscow) 10, 130 (1946); 10, 399 (1946)

Fung, A. K., Li, Z. and Chen, K. S. (1992). Backscattering from a randomly rough dielectric surface. IEEE Transactions on Geoscience and Remote Sensing,30(2), 356-369. DOI:10.1109/36.134085

Gallagher, M., and Doherty, J. (2007). Parameter estimation and uncertainty analysis for a watershed model. Environmental Modelling \& Software, 22(7), 1000-1020. DOI: 10.1016/j.envsoft.2006.06.007

Goegebeur, M. and V. R. N. Pauwels (2007), Improvement of the PEST parameter estimation algorithm through Extended Kalman Filtering, Journal of Hydrology, 337(3-4), 436-451. DOI: 10.1016/j.jhydrol.2007.02.006

Göhler, M., Mai, J., and Cuntz, M., (2013). Use of eigendecomposition in a parameter sensitivity analysis of the Community Land Model, Journal of Geophysical Research, 118, 904-921. DOI: 10.1002/jgrg.20072.

Grant, J. P.,Wigneron, J. P., Van de Griend, A. A., et al. (2007). A field experiment on microwave forest radiometry: L-band signal behaviour for varying conditions of surface wetness. Remote Sensing of Environment, 109, 10-19. DOI:

10.1016/j.rse.2006.12.001

Guerriero, L., Ferrazzoli, P., and Rahmoune, R. (2012). A synergyc view of L-band active and passive remote sensing of vegetated soil. In Microwave Radiometry and Remote Sensing of the Environment (MicroRad), 2012 12th Specialist Meeting on (pp. 1-3). IEEE. DOI: 10.1109/MicroRad.2012.6185238

Guerriero, L., Ferrazzoli, P., Vittucci, C., et al. (2016). L-Band Passive and Active Signatures of Vegetated Soil: Simulations With a Unified Model, IEEE Journal of Selected Topics in Applied Earth Observations and Remote Sensing 9 (6), 2520 - 2531. DOI: $10.1109 /$ JSTARS.2016.2570424

Immerzeel, W.W. and Droogers, P. (2008). Calibration of a distributed hydrological model based on satellite evapotranspiration. Journal of Hydrology. 349 (3-4), 411-424. DOI: 10.1016/j.jhydrol.2007.11.017 


\section{Bibliography}

Jackson, T. J. and O'Neill, P. E. (1990). Attenuation of soil microwave emission by corn and soybeans at 1.4 and 5 GHz. IEEE

Transactions on Geoscience and Remote Sensing, 28(5), 978-980. DOI:10.1109/36.58989

Jackson, T. J. (1993). III. Measuring surface soil moisture using passive microwave remote sensing. Hydrological processes 7(2),139-152. DOI:10.1002/hyp.3360070205

Jackson, T. J., Le Vine, D. M., Hsu, A. Y, et al. (1999). Soil moisture mapping at regional scales using microwave radiometry: the Southern Great Plains hydrology experiment. IEEE Transactions of Geoscience and Remote Sensing. 37, 2136-2151. DOI: $10.1109 / 36.789610$

Jackson, T. J., Bindlish, R., Cosh, M. H., et al. (2012). Validation of Soil Moisture and Ocean Salinity (SMOS) soil moisture over watershed networks in the US. IEEE Transactions on Geoscience and Remote Sensing, 50(5), 1530-1543. DOI:

10.1109/TGRS.2011.2168533

Joseph, A. T., van der Velde, R., O'Neill, et al. (2010). Effects of corn on C-and L-band radar backscatter: A correction method for soil moisture retrieval. Remote Sensing of Environment,114(11), 2417-2430. DOI:10.1016/j.rse.2010.05.017

Kaleita, A. L., Tian, L. F., and Hirschi, M. C. (2005). Relationship between soil moisture content and soil surface reflectance. Transactions of the American Society of Agricultural Engineers, 48(5), 1979-1986. DOI: 10.13031/2013.19990

Kaojarern, S., Toan, T. L. andDavidson, M. W. J. (2004). Monitoring Surface Soil Moisture in Post-Harvest Rice Areas Using C-band Radar Imagery in Northeast Thailand. Geocarto international, 19(3), 61-71. DOI:10.1080/10106040408542319

Karam, M. A., Fung, A. K. and Antar, Y. M. (1988). Electromagnetic wave scattering from some vegetation samples. IEEE Transactions on Geoscience and Remote Sensing, 26(6), 799-808. DOI: 10.1109/36.7711

Katsanos, D., Retalis, A., \& Michaelides, S. (2016). Validation of a high-resolution precipitation database (CHIRPS) over Cyprus for a 30-year period. Atmospheric Research, 169, 459-464. DOI: 10.1016/j.atmosres.2015.05.015

Keller, J. B. (1962). Geometrical theory of diffraction. Journal of the Optical Society of America, 52(2), 116-130. DOI: 10.1364/JOSA.52.000116

Kerr, Y. H., Waldteufel, P., Wigneron, J. P., et al. (2001). Soil moisture retrieval from space: The Soil Moisture and Ocean Salinity (SMOS) mission. IEEE Transactions on Geoscience and Remote Sensing 39(8), 1729-1735. DOI:10.1109/36.942551

Kim, S. B., Moghaddam, M., Tsang, L., et al. (2014). Models of L-band radar backscattering coefficients over global terrain for soil moisture retrieval. IEEE Transactions on Geoscience and Remote Sensing, 52(2), 1381-1396. DOI:

10.1109/TGRS.2013.2250980

Kim, Y., Jackson, T., Bindlish, R., et al. (2012). Radar vegetation index for estimating the vegetation water content of rice and soybean. IEEE Geoscience and Remote Sensing Letters, 9(4), 564-568. DOI: 10.1109/LGRS.2011.2174772.

Kim, Y., Jackson, T., Bindlish, R., et al. (2014). Retrieval of Wheat Growth Parameters With Radar Vegetation Indices.. IEEE Geoscience and Remote Sensing, 11(4), 808-812. DOI: 10.1109/LGRS.2013.2279255.

Kim, Y. and Van Zyl, J (2001). Comparison of forest parameter estimation techniques using SAR data. In Geoscience and Remote Sensing Symposium. IGARSS'01 (3),.1395-1397. DOI:10.1109/IGARSS.2001.976856 


\section{Bibliography}

Kim, Y. and Van Zyl, J (2004). Vegetation effects on soil moisture estimation. In Geoscience and Remote Sensing Symposium, IGARSS'04. (2), 800-802. DOI:10.1109/IGARSS.2004.1368525

Kim, Y. and van Zyl, J. J. (2009). A time-series approach to estimate soil moisture using polarimetric radar data. Geoscience and Remote Sensing, IEEE Transactions on, 47(8), 2519-2527. DOI: 10.1109/TGRS.2009.2014944

Kornelsen, K. C., and Coulibaly, P. (2013). Advances in soil moisture retrieval from synthetic aperture radar and hydrological applications. Journal of Hydrology, 476, 460-489. DOI:10.1016/j.jhydrol.2012.10.044

Lang, R. H. and Sighu, J. S. (1983). Electromagnetic backscattering from a layer of vegetation: A discrete approach. IEEE Transactions on Geoscience and Remote Sensing, (1), 62-71. DOI: 10.1109/TGRS.1983.350531

Lawrence, H., Wigneron, J. P., Richaume, P et al. (2014). Comparison between SMOS Vegetation Optical Depth products and MODIS vegetation indices over crop zones of the USA. Remote Sensing of Environment,140, 396-406.

DOI:10.1016/j.rse.2013.07.021

Lesaignoux, A., Fabre, S., and Briottet, X. (2013). Influence of soil moisture content on spectral reflectance of bare soils in the 0.4-14 $\mu \mathrm{m}$ domain. International journal of remote sensing, 34(7), 2268-2285. DOI : 10.1080/01431161.2012.743693

Lilly, Jonathan and Gary Lagerloef. 2008. Aquarius Level 3 Processing Algorithm Theoretical Basis Document. ftp://podaacftp.jpl.nasa.gov/allData/aquarius/docs/v2/AquariusLevel3_GriddingSmoothingPaper_Lilly\&Lagerloef2008.pdf

Leroux, D. J., Kerr, Y. H., Al Bitar, A., et al. (2014). Comparison between SMOS, VUA, ASCAT, and ECMWF soil moisture products over four watersheds in US. IEEE Transactions on Geoscience and Remote Sensing, 52(3), 1562-1571. DOI:

10.1109/TGRS.2013.2252468

Le Vine, D. M., Meneghini, R., Lang, R. H., et al. (1983). Scattering from arbitrarily oriented dielectric disks in the physical optics regime. JOSA, 73(10), 1255-1262. DOI:10.1007/s11430-012-4410-7

Lievens, H., Verhoest, N. E., Keyser, E. D., et al. (2011). Effective roughness modelling as a tool for soil moisture retrieval from C-and L-band SAR. Hydrology and Earth System Sciences, 15(1), 151-162. DOI:10.5194/hess-15-151-2011

Liu,Y., Parinussa, R.M., Dorigo,W.A., et al. (2011). Developing an improved soil moisture dataset by blending passive and active microwave satellite-based retrievals. Hydrology and Earth System Sciences, 15(2):425-436, 2011. DOI: 10.5194/hess-15425-2011

Lu, H., Koike, T., Fujii, H., et al. (2009). Development of a physically-based soil moisture retrieval algorithm for spaceborne passive microwave radiometers and its application to AMSR-E. Journal of The Remote Sensing Society of Japan, 29(1), 253-262. DOI: $10.11440 / \mathrm{rssj} .29 .253$

Luo,Y,.Feng,x,.Houser.P, et al.. (2013). Potential soil moisture products from the aquarius radiometer and scatterometer using an observing system simulation experiment. Geoscientific Instrumentation, Methods and Data Systems, 2(1, 113-120.

DOI:10.5194/gi-2-113-2013

Lv, S., Wen, J., Zeng, Y., et al. (2014). An improved two-layer algorithm for estimating effective soil temperature in microwave radiometry using in situ temperature and soil moisture measurements. Remote Sensing of Environment, 152, 356-363. DOI: 10.1016/j.rse.2014.07.007 


\section{Bibliography}

Ma, W., Ma, Y., and Ishikawa, H. (2014). Evaluation of the SEBS for upscaling the evapotranspiration based on in-situ observations over the Tibetan Plateau. Atmospheric research, 138, 91-97. DOI: 10.1016/j.atmosres.2013.10.020

Mancini, M., Hoeben, R., Troch, P. A. (1999). Multifrequency radar observations of bare surface soil moisture content: A laboratory experiment. Water Resources Research,35(6), 1827-1838. DOI:10.1029/1999WR900033

Matgen, P., Heitz, S., Hasenauer, S., et al. (2012). On the potential of MetOp ASCAT-derived soil wetness indices as a new aperture for hydrological monitoring and prediction: a field evaluation over Luxembourg. Hydrological Processes, 26(15), 23462359. DOI: $10.1002 /$ hyp.8316

Matzler, C. (1994). Microwave (1-100 GHZ) dielectric model of leaves. IEEE Transactions on Geoscience and Remote Sensing, 32, 947-949. DOI: $10.1109 / 36.298024$

McColl, K. A., Entekhabi, D. and Piles, M. (2014). Uncertainty Analysis of Soil Moisture and Vegetation Indices Using Aquarius Scatterometer Observations. IEEE Transactions on Geoscience and Remote Sensing,52(7),4259-4272. DOI: 10.1109/TGRS.2013.2280701

Mironov, V. L., Dobson, M. C., Kaupp, et al. (2004). Generalized refractive mixing dielectric model for moist soils. IEEE Transactions on Geoscience and Remote Sensing, 42(4), 773-785. DOI: 10.1109/TGRS.2003.823288

Mironov, V. L., Kosolapova, L. G., and Fomin, S. V. (2009). Physically and mineralogically based spectroscopic dielectric model for moist soils. IEEE Transactions on Geoscience and Remote Sensing, 47(7), 2059-2070. DOI:

10.1109/TGRS.2008.2011631

Misra, S. and Ruf, C. S. (2008). Detection of radio-frequency interference for the Aquarius radiometer. IEEE Transactions on Geoscience and Remote Sensing,46(10), 3123-3128. DOI:10.1109/TGRS.2008.920371

Montzka, C., Bogena, H. R., Weihermuller, L., et al. (2013). Brightness temperature and soil moisture validation at different scales during the SMOS validation campaign in the Rur and Erft catchments, Germany. IEEE Transactions on Geoscience and Remote Sensing, 51(3), 1728-1743. DOI: 10.1109/TGRS.2012.2206031

Mo, T., Choudhury, B. J., Schmugge, T. J., et al. (1982). A model for microwave emission from vegetation-covered fields. Journal of Geophysical Research: Oceans (1978-2012), 87(C13), 11229-11237. DOI:10.1029/JC087iC13p11229

Matsushima, D., Kimura, R., and Shinoda, M. (2012). Soil moisture estimation using thermal inertia: potential and sensitivity to data conditions. Journal of Hydrometeorology, 13(2), 638-648. DOI: 10.1175/JHM-D-10-05024.1

Narayan, U., Lakshmi, V., and Jackson, T. J. (2006). High-resolution change estimation of soil moisture using L-band radiometer and radar observations made during the SMEX02 experiments. IEEE Transactions on Geoscience and Remote Sensing, 44(6), 1545-1554. DOI: 10.1109/TGRS.2006.871199

Naeimi, V., Bartalis, Z., and Wagner, W. (2009). ASCAT soil moisture: An assessment of the data quality and consistency with the ERS scatterometer heritage. Journal of Hydrometeorology, 10(2), 555-563. DOI: 10.1175/2008JHM1051.1

Njoku, E. G., and Entekhabi, D.,1996. Passive microwave remote sensing of soil moisture. Journal of hydrology 184(1), 101-129. DOI:10.1016/0022-1694(95)02970-2 


\section{Bibliography}

Njoku, E. G., Wilson, W. J., Yueh, S. H., et al. (2002). Observations of soil moisture using a passive and active low-frequency microwave airborne sensor during SGP99. IEEE Transactions on Geoscience and Remote Sensing, 40(12), 2659-2673. DOI: 10.1109/TGRS.2002.807008

Njoku, E. G., Jackson, T. J., Lakshmi, V., et al. (2003). Soil moisture retrieval from AMSR-E. IEEE transactions on Geoscience and remote sensing, 41(2), 215-229. DOI: 10.1109/TGRS.2002.808243

Njoku, E. G., and Chan, S. K. (2006). Vegetation and surface roughness effects on AMSR-E land observations. Remote Sensing of environment, 100(2), 190-199. DOI: 10.1016/j.rse.2005.10.017

Oh, Y., Sarabandi, K., and Ulaby, F. T. (1992). An empirical model and an inversion technique for radar scattering from bare soil surfaces. IEEE transactions on Geoscience and Remote Sensing, 30(2), 370-381. DOI: 10.1109/36.134086

Oh, Y., Sarabandi, K., and Ulaby, F. T. (2002). Semi-empirical model of the ensemble-averaged differential Mueller matrix for microwave backscattering from bare soil surfaces. IEEE Transactions on Geoscience and Remote Sensing, 40(6), 1348-1355.DOI: 10.1109/TGRS.2002.800232

O’NEILL, B.C., Chauhan, N.C, and Jackson, T.J. (1995) Use of active and passive microwave remote sensing for soil moisture estimation through corn. International Journal of Remote Sensing, 17(10):1851-1865, 1996. DOI: 10.1080/01431169608948743

O’Neill, B.C., Carter, T.R., Ebi, K.L, et al. (2012). Meeting Report of the Workshop on The Nature and Use of New Socioeconomic Pathways for Climate Change Research, Boulder, CO, November 2-4, 2011. Available at: http://www.isp.ucar.edu/socioeconomic-pathway

Osborn, J. A. (1945). Demagnetizing factors of the general ellipsoid. Physical review, 67(11-12), 351. DOI: $10.1080 / 14786430600617161$

Owe, M., de Jeu, R. and Walker, J. (2001). A methodology for surface soil moisture and vegetation optical depth retrieval using the microwave polarization difference index.IEEE Transactions on Geoscience and Remote Sensing, 39(8), 1643-1654.

DOI:10.1109/36.942542

Owe, M., De Jeu, R. A. M. and Holmes, T. R. H. (2008) Multi-sensor historical climatology of satellite-derived global land surface moisture. Journal of Geophysical Research, 113(F01002). DOI: 1029/2007JF000769.

Paloscia, S., Macelloni, G., Santi, E., et al. (2001). A multifrequency algorithm for the retrieval of soil moisture on a large scale using microwave data from SMMR and SSM/I satellites. IEEE Transactions on Geoscience and Remote Sensing, ,39(8), 16551661. DOI: $10.1109 / 36.942543$

Paloscia, S. and Pampaloni, P. (1988). Microwave polarization index for monitoring vegetation growth.IEEE Transactions on Geoscience and Remote Sensing,, 26(5), 617-621. DOI:10.1109/36.7687

Pardé. P, Wigneron, J.P, Waldteufel.P, et al. (2004) N-parameter retrievals from L-band microwave observations acquired over a variety of cropfields IEEE Transactions on Geoscience and Remote Sensing, 42 (6) , 1168-1178. DOI:

10.1109/TGRS.2004.826820

Paredes-Trejo, F. J., Barbosa, H. A., \& Kumar, T. L. (2017). Validating CHIRPS-based satellite precipitation estimates in Northeast Brazil. Journal of arid environments, 139, 26-40. DOI: 10.1016/j.jaridenv.2016.12.009 


\section{Bibliography}

Peake, W. (1959). Interaction of electromagnetic waves with some natural surfaces, IRE Trans. Antennas Propag., 325-329. DOI: 10.1109/TAP.1959.1144736

Peel, M. C., Finlayson, B. L., and McMahon, T. A. (2007). Updated world map of the Köppen-Geiger climate classification. Hydrology and earth system sciences, 11, 1633-1644. DOI:10.5194/hess-11-1633-2007

Pellarin, T., Wigneron, J. P., Calvet, J. C. and Waldteufel, P. (2003). Global soil moisture retrieval from a synthetic L-band brightness temperature data set. Journal of Geophysical Research: Atmospheres, 108(D12). DOI:10.1029/2002JD003086

Piepmeier, J., Bindlish, R., Brown, S., et al. (2013). Aquarius radiometer post-launch calibration for product version 2, AQ-014PS-0015, Tech. Rep. AQ-014-PS-0015, NASA and CONAE, Pasadena, CA, USA.

Pierdicca, N., Pulvirenti, L., and Marzano, F. S. (2010). Simulating topographic effects on spaceborne radiometric observations between L and X frequency bands. IEEE Transactions on Geoscience and Remote Sensing, 48(1), 273-282. DOI:

10.1109/TGRS.2009.2028881

Piles, M., Entekhabi, D., and Camps, A. (2009). A change detection algorithm for retrieving high-resolution soil moisture from SMAP radar and radiometer observations. IEEE Transactions on Geoscience and Remote Sensing, 47(12), 4125-4131. DOI: 10.1109/TGRS.2009.2022088

Pratt, D. A., and Ellyett, C. D. (1979). The thermal inertia approach to mapping of soil moisture and geology. Remote sensing of environment, 8(2), 151-168. DOI: 10.1016/0034-4257(79)90014-2

Pulvirenti, L., Pierdicca, N., and Marzano, F. S. (2011). Prediction of the error induced by topography in satellite microwave radiometric observations. IEEE Transactions on Geoscience and Remote Sensing, 49(9), 3180-3188. DOI:

10.1109/TGRS.2010.2096514

Rahmoune, R, Ferrazzoli, P., Kerr, Y.H., et al. (2013). SMOS level 2 retrieval algorithm over forests: Description and generation of global maps, IEEE Journal of Selected Topics in Applied Earth Observations and Remote Sensing, 6(3): 1430-1439. DOI: 10.1109/JSTARS.2013.2256339

Robinson, D.A., Campbell C.S., Hopmans, J.W, et al. (2008). Soil moisture measurement for ecological and hydrological watershed-scale observatories: a review. Vadose Zone Journal 7(1): 358-389. DOI:10.2136/vzj2007.0143

Ryu, D. and Famiglietti, J.S. (2005). Characterization of footprint-scale surface soil moisture variability using Gaussian and beta distribution functions during the Southern Great Plains 1997 (SGP97) hydrology experiment. Water Resources Research 41:DOI: 10.1029/2004WR003835. issn: 0043-1397.

Saatchi, S. S., Le Vine, D. M., and Lang, R. H. (1994). Microwave backscattering and emission model for grass canopies. IEEE Transactions on Geoscience and Remote Sensing, 32(1), 177-186. DOI: 10.1109/36.285200

Saatchi, S. S., Zyl, J. J., and Asrar, G. (1995). Estimation of canopy water content in Konza Prairie grasslands using synthetic aperture radar measurements during FIFE. Journal of Geophysical Research: Atmospheres (1984-2012), 100(D12), 25481-25496. DOI: 10.1109/JSTARS.2015.2422998

Sahebi, M.R., Bonn, F., and Gwyn, Q. H. J. (2003). Estimation of the moisture content of bare soil from RADARSAT-1SAR using simple empirical models. International journal of remote sensing, 2003, 24(12), 2575-2582. DOI:

10.1080/0143116031000072948 


\section{Bibliography}

Saleh, K., Wigneron, J. P., De Rosnay, P., et al. (2006). Impact of rain interception by vegetation and mulch on the L-band emission of natural grass. Remote Sensing of Environment,101(1), 127-139. DOI:10.1016/j.rse.2005.12.004

Schmugge, T., Gloersen, P., Wilheit, T., et al. (1974). Remote sensing of soil moisture with microwave radiometers. Journal of Geophysical Research, 79(2), 317-323. DOI: 10.1029/JB079i002p00317

Skahill, B. E. and Doherty, J. (2006). Efficient accommodation of local minima in watershed model calibration. Journal of Hydrology, 329(1), 122-139. DOI: 10.1016/j.jhydrol.2006.02.005

Su, Z., Troch, P. A., and De Troch, F. P. (1997). Remote sensing of bare surface soil moisture using EMAC/ESAR data. International Journal of Remote Sensing, 18(10), 2105-2124. DOI: 10.1080/014311697217783

Su, Z. (2002). The Surface Energy Balance System(SEBS) for estimation of turbulent heat fluxes. Hydrology and Earth System Sciences 6(1): 85-99. DOI:10.5194/hess-6-85-2002

Su, Z., Wen, J., Dente, L., et al. (2011). The Tibetan Plateau observatory of plateau scale soil moisture and soil temperature (Tibet-Obs) for quantifying uncertainties in coarse resolution satellite and model products. Hydrology and Earth System Sciences, 15(7), 2303-2316. DOI: 10.5194/hess-15-2303-2011

Su, Z., Rosnay, P., Wen, J., et al. (2013). Evaluation of ECMWF's soil moisture analyses using observations on the Tibetan Plateau. Journal of Geophysical Research: Atmospheres, 118(11), 5304-5318. DOI: 10.1002/jgrd.50468

The EUMETSAT Network on Satellite Application Facilities, Support to Operational Hydrology and Water Management (HSAF), Algorithm Theoretical Basis Document (ATBD) for Product H25/SMOBS-4: METOP ASCAT Soil Moisture Time Series. [Online]. Available: http://hsaf.meteoam.it/documents/ATDD/SAF_HSAF_CDOP_ATBD- 25_0_4.pdf

Ulaby, F. (1974). Radar measurement of soil moisture content. IEEE Transactions on Antennas and propagation, 22(2), $257-265$. DOI: $10.1109 /$ TAP.1974.1140761

Ulaby, F. T., Dubois, P. C.and Van Zyl, J. (1996). Radar mapping of surface soil moisture. Journal of Hydrology, 184(1), $57-84$. DOI:10.1016/0022-1694(95)02968-0

Ulaby, F. T., and El-Rayes, M. A. (1987). Microwave dielectric spectrum of vegetation-Part II: Dual-dispersion model. IEEE Transactions on Geoscience and Remote Sensing, (5), 550-557. DOI: 10.1109/TGRS.1987.289833

Ulaby, F. T., Moore, R. K. and Fung, A. K. (1982). Microwave Remote Sensing Active and Passive-Volume II: Radar Remote Sensing and Surface Scattering and Emission Theory. Reading, Massachusetts: Addison-Wesley.

Ulaby, F. T., Moore, R. K. and Fung, A. K. (1986). Microwave Remote Sensing Active and Passive-Volume III: From Theory to Applications. Reading, Massachusetts: Addison-Wesley.

Utku, C., and Le Vine, D. M. (2014). Topographic signatures in Aquarius radiometer and scatterometer response. IEEE Transactions on Geoscience and Remote Sensing, 52(7), 4141-4154. DOI: 10.1109/TGRS.2013.2280015

van de Griend, A. A., Owe, M., de Ruiter, et al. (1996). Measurement and behavior of dual-polarization vegetation optical depth and single scattering albedo at 1.4-and 5-GHz microwave frequencies. Geoscience and Remote Sensing, IEEE Transactions on,34(4), 957-965. DOI: 10.1109/36.508412 


\section{Bibliography}

van der Kwast, J., Timmermans, W., Gieske, A., et al. (2009). Evaluation of the Surface Energy Balance System (SEBS) applied to ASTER imagery with flux-measurements at the SPARC 2004 site (Barrax, Spain). Hydrology and Earth System Sciences Discussions, 6(1), 1165-1196. DOI: 10.5194/hess-13-1337-2009

van der Velde, R. and Su, Z. (2009). Dynamics in land-surface conditions on the Tibetan Plateau observed by Advanced Synthetic Aperture Radar (ASAR). Hydrological sciences journal,54(6), 1079-1093. DOI:10.1623/hysj.54.6.1079

van der Velde, R., Su, Z., Ek, M., Rodell, M., et al. (2009). Influence of thermodynamic soil and vegetation parameterizations on the simulation of soil temperature states and surface fluxes by the Noah LSM over a Tibetan plateau site. Hydrology and earth system sciences (HESS) , 2009 (13), 759-777. DOI: 10.5194/hess-13-759-2009

van der Velde (2010). Soil moisture remote sensing using active microwaves and land surface modelling. (Doctoral thesis, University of Twente, Enschede, The Netherlands). https://www.itc.nl/library/papers_2010/phd/vd_velde.pdf

van der Velde, R., Su, Z., van Oevelen, P., et al. (2012a). Soil moisture mapping over the central part of the Tibetan Plateau using a series of ASAR WS images. Remote Sensing of Environment, 120, 175-187. DOI: 10.1016/j.rse.2011.05.029

van der Velde, R., Salama, M. S., van Helvoirt, M. D., et al. (2012b). Decomposition of uncertainties between coarse MM5Noah-simulated and fine ASAR-retrieved soil moisture over central Tibet. Journal of Hydrometeorology, 13(6), 1925-1938. DOI: 10.1175/JHM-D-11-0133.1

van der Velde, R., Salama, M. S., Pellarin, T., et al. (2014). Long term soil moisture mapping over the Tibetan Plateau using Special Sensor Microwave/Imager.Hydrology and Earth System Sciences,18(4), 1323-1337. DOI:10.5194/hess-18-1323-2014

van der Velde, R., Salama, M. S., Eweys, et al. (2015). Soil moisture mapping using combined active/passive microwave observations over the east of the Netherlands. IEEE Journal of Selected Topics in Applied Earth Observations and Remote Sensing, 8(9), 4355-4372. DOI: 10.1109/JSTARS.2014.2353692

Vachaud, G., Passerat De Silans, A., Balabanis, P., et al. (1985). Temporal Stability of Spatially Measured Soil Water Probability Density Function. Soil Science Society of America Journal49(4), 822-828. DOI: 10.2136/sssaj1985.03615995004900040006x

Verhoef, W., Menenti, M., and Azzali, S. (1996). Cover A colour composite of NOAA-AVHRR-NDVI based on time series analysis (1981-1992). International Journal of Remote Sensing, 17(2), 231-235. DOI: 10.1080/01431169608949001

Verhoest, N. E., Lievens, H., Wagner, W., et al. (2008). On the soil roughness parameterization problem in soil moisture retrieval of bare surfaces from synthetic aperture radar. Sensors, 8(7), 4213-4248. DOI: 10.3390/s8074213

Verstraeten, W. W., Veroustraete, F., van der Sande, C. Jet al. (2006). Soil moisture retrieval using thermal inertia, determined with visible and thermal spaceborne data, validated for European forests. Remote Sensing of Environment, 101(3), 299-314. DOI: 10.1016/j.rse.2005.12.016

Wagner, W., Lemoine, G. and Rott, H. (1999). A method for estimating soil moisture from ERS scatterometer and soil data. Remote sensing of environment, 70(2), 191-207. DOI: 10.1016/S0034-4257(99)00036-X

Wagner, W., Blöschl, G., Pampaloni, P., et al. (2007). Operational readiness of microwave remote sensing of soil moisture for hydrologic applications. Hydrology Research, 38(1), 1-20. DOI: 10.2166/nh.2007.029 


\section{Bibliography}

Wagner, W., Hahn, S., Kidd, R., et al. (2013). The ASCAT soil moisture product: A review of its specifications, validation results, and emerging applications. Meteorologische Zeitschrift, 22(1), 5-33. DOI: 10.1127/0941-2948/2013/0399

Walker, J. P., Willgoose, G. R. and Kalma, J. D. (2004). In situ measurement of soil moisture: a comparison of techniques. Journal of Hydrology, 293(1), 85-99. DOI:10.1016/j.jhydrol.2004.01.008

Wang, Q., Van der Velde, R., Su, Z., et al. (2015). Aquarius L-band scatterometer and radiometer observations over a Tibetan Plateau site. International Journal of Applied Earth Observation and Geoinformation. DOI: 10.1016/j.jag.2015.06.010

Wang, Q., van der Velde, R., and Su, Z. (2018). Use of a discrete electromagnetic model for simulating Aquarius L-band active/passive observations and soil moisture retrieval. Remote Sensing of Environment, 205, 434-452.

DOI:10.1016/j.rse.2017.10.044

Wegmüller, U. (1990). The effect of a frozen soil layer on the microwave signature of bare soil, Remote Sens. Environ.,33, 123135,DOI:: 10.1016/0034-4257(90)90038-N

Weiss, M., Baret, F., Garrigues, S., et al. (2007). LAI and fAPAR CYCLOPES global products derived from VEGETATION. Part 2: validation and comparison with MODIS collection 4 products. Remote sensing of Environment, 110(3), 317-331. DOI: 10.1016/j.rse.2007.03. 001

Wigneron, J. P., Chanzy, A., de Rosnay, P., et al. (2008). Estimating the effective soil temperature at L-band as a function of soil properties. IEEE Transactions on Geoscience and Remote Sensing, 46, 797-807. DOI: 10.1109/TGRS.2007.914806

Wen, J., Jackson, T. J., Bindlish, R, et al. (2005). Retrieval of soil moisture and vegetation water content using SSM/I data over a corn and soybean region. Journal of Hydrometeorology,6(6), 854-863. DOI:10.1175/JHM462.1

Wen, J. and Su, Z. (2003). The estimation of soil moisture from ERS wind scatterometer data over the Tibetan plateau. Physics and Chemistry of the Earth, Parts A/B/C,28(1), 53-61. DOI: 10.1016/S1474-7065(03)00007-X

Wigneron, J. P., Kerr, Y., Waldteufel, P., et al. (2007). L-band Microwave Emission of the Biosphere (L-MEB) Model: Description and calibration against experimental data sets over crop fields. Remote Sensing of Environment,107(4), 639-655. DOI:10.1016/j.rse.2006.10.014

Wu, T. D. and Chen, K. S. (2004). A reappraisal of the validity of the IEM model for backscattering from rough surfaces. IEEE Transactions on Geoscience and Remote Sensing, 42(4), 743-753. DOI: 10.1109/TGRS.2003.815405

Yang, K., Qin, J., Zhao, L., et al. (2013). A multiscale soil moisture and freeze-thaw monitoring network on the third pole. Bulletin of the American Meteorological Society, 94(12), 1907-1916. DOI: 10.1175/BAMS-D-12-00203.1

Zambrano-Bigiarini, M., Nauditt, A., Birkel, C., Verbist, K., et al. (2017). Temporal and spatial evaluation of satellite-based rainfall estimates across the complex topographical and climatic gradients of Chile. Hydrology and Earth System Sciences, 21(2), 1295. DOI: 10.5194/hess-21-1295-2017

Zribi, M., and Dechambre, M. (2003). A new empirical model to retrieve soil moisture and roughness from C-band radar data. Remote Sensing of Environment, 84(1), 42-52. DOI: 10.1016/S0034-4257(02)00069-X

Zribi, M., Kotti,F. ,Amri, R., et al. (2014). Soil moisture mapping in a semiarid region, based on ASAR/Wide Swath satellite data. Water resources reserach,50(2), 823-835. DOI: 10.1002/2012WR013405 


\section{Bibliography}

Zheng, D., van der Velde, R., Su, Z.,et al. (2015). Under-canopy turbulence and root water uptake of a Tibetan meadow ecosystem modelled by Noah-MP. Water resources research, 51(7), 5735-5755. DOI: 10.1002/2015WR017115 
Bibliography 